Florida International University FIU Digital Commons

7-15-1997

\title{
Valued occupational roles and life satisfaction among south Florida HIV-infected and Non- infected homosexual males : an exploratory study
}

Kenneth Morton Byers

Florida International University

DOI: $10.25148 /$ etd.FI14052509

Follow this and additional works at: https://digitalcommons.fiu.edu/etd

Part of the Occupational Therapy Commons

\section{Recommended Citation}

Byers, Kenneth Morton, "Valued occupational roles and life satisfaction among south Florida HIV-infected and Non-infected homosexual males : an exploratory study" (1997). FIU Electronic Theses and Dissertations. 2003.

https://digitalcommons.fiu.edu/etd/2003 


$$
\text { Miami, Florida }
$$

Valued Occupational Roles and Life Satisfaction Among South Florida HIV-infected and Non-infected Homosexual Males: An Exploratory Study

A thesis submitted in partial satisfaction of the requirements for the degree of MASTER OF SCIENCE IN OCCUPATIONAL THERAPY

by

Kenneth Morton Byers

$$
\begin{aligned}
& R M \\
& 734.99 \\
& 1394 \\
& 1997 \\
& 1.2
\end{aligned}
$$


To: Judith A. Blucker

College of Health Sciences

This thesis, written by Kenneth Morton Byers, and entitled Valued Occupational Roles and Life Satisfaction Among South Florida HIVinfected and Non-infected Homosexual Males: An exploratory study, having been approved in respect to style and intellectual content, is referred to you for judgment.

We have read this thesis and rommond that it be approved.

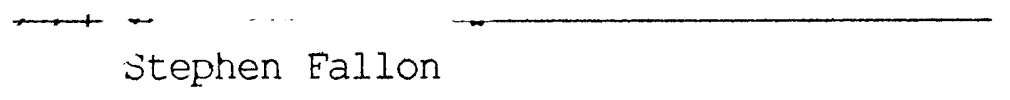

Paulette Johnson

Gail Ann Hills, Major Professor

Date of Defense: July 15, 1997

The thesis of Kenneth Morton Byers is approved.

Dean Jurith A. Blucker

Collece of Health Sciences

Dr. Richard L. Campbell

Dean of Graduate Studies

Florida International University, 1997 
CCOPYRIGHT 1997 by Kenneth Morton Byers

All rights reserved 
To Owen and Grace 


\section{ACKNOWLEDGEMENTS}

To Dr. Gail Anne Hills-for your personal mentoring and for your spirit of achievement which inspires me to soar into this great profession with high expectations for the possible...

To John Meyer-for your life and laughter that continuously inspire me to "live out loud" every day...

To Philip J. Ryan-for your countless hours of computer and moral support, for your personal sacrifice on my behalf, and for your intellectual feedback that helped fashion my thoughts...

To Michael J. Snyder-for your patient perseverance and sacrifice that have helped me get to this point in my life and for your unshakable inner strength..

To Michael Hutchison-for your gift of self over the countless coffee chats, conversations that provoked my thoughts, challenged my perceptions, and shaped my vision..

To Sue Lewis-for your faithful companionship in the academic halls of our profession and for your continued enthusiasm and interest in my life and work..

To the men who shared their lives for this study-for your sacrifice of time and privacy and for the lives you lead out in the day-in and day-out of this challenging world..

To all of these, my life companions and friends-for your investment into my life and for helping me understand the world more clearly through each of your lives...

..my deepest gratitude. 


\section{ABSTRACT OF THE THESIS}

VALUED OCCUPATIONAL ROLES AND LIFE SATISFACTION AMONG SOUTH FLORIDA HIV-INFECTED AND NON-INEECTED HOMOSEXUAL MALES: AN EXPLORATORY STUDY

by

Kenneth Morton Byers

Florida International University, 1997 Miami, Florida

\section{Professor Gail Ann Hills, Major Professor}

A study was concucted in order to describe and understand the occupational role behavior of gay men with particular interest on understanding the impact of an HIV diagnosis on their roles and life satisfaction. A 137item questionnaire was developed for this study and distributed through various gay comminity groups in south Florida. The process resulted in ranked description of 24 valued occupational roles of gay men $(n=80)$ along with a general understanding of potential shifts that may occur in those roles as a result of becoming infected with HIV. The study concludes that a diagnosis of HIV infection impacts gay men both by altering their value for particular roles and by darkening the images they hold of their future. The study also identified key factors which may contribute to the greater life satisfaction of gay men including greater confidence in personal knowledge of HIV, a more optimistic outlook on life, the use of stronger coping styles, and perceiving stronger social support and lower stress. 


\section{TABLE OF CONTENTS}

\section{CHAPTER}

PAGE

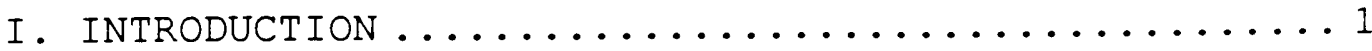

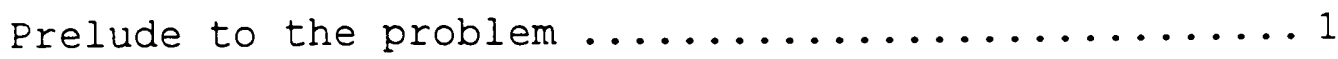

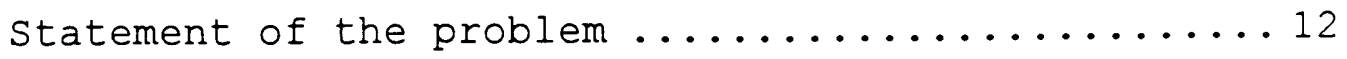

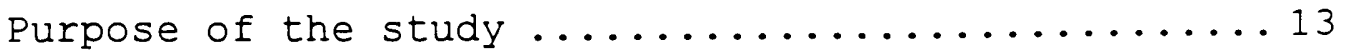

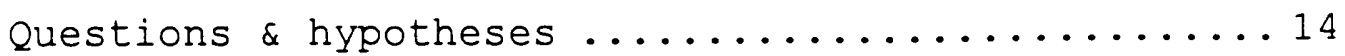

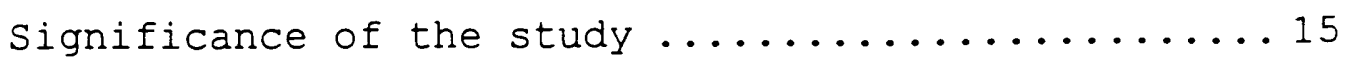

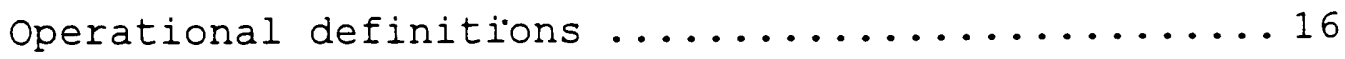

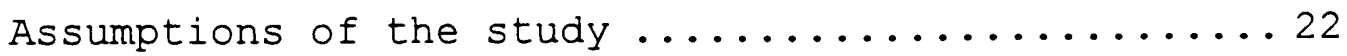

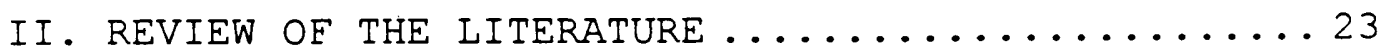

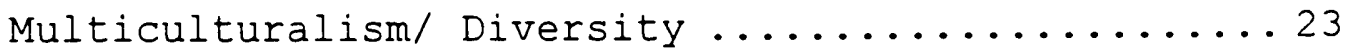

Gay Men and Healthcare in the United States .....26

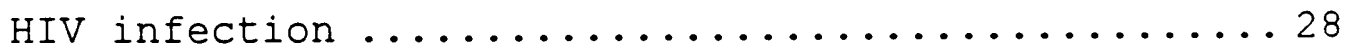

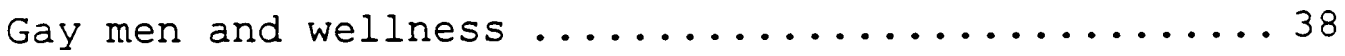

Theoretical Understanding of Gay Men ..........46

The Model of Human Occupation...............46

Occupational science concepts................51

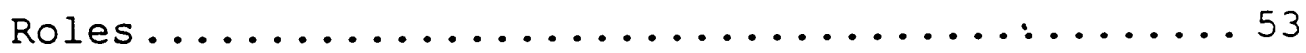

Developmental models...................60

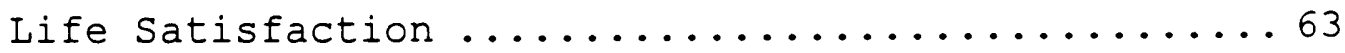

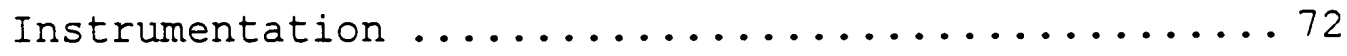

III. RESEARCH PROCEDURES \& METHODOLOGY ..........77 
Research Questions and Hypotheses .............77

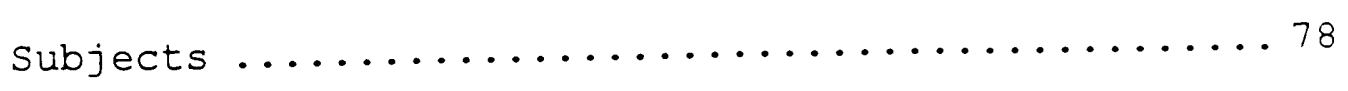

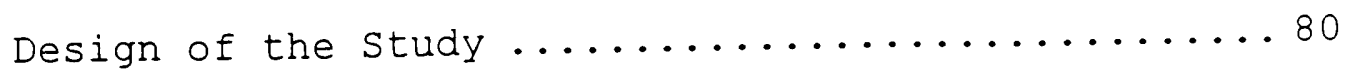

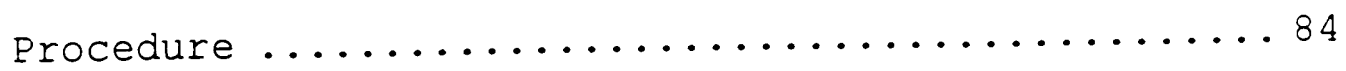

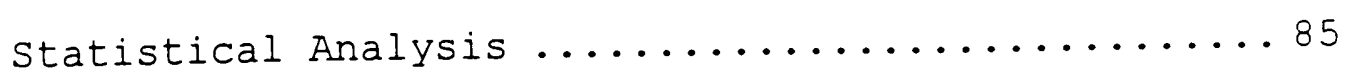

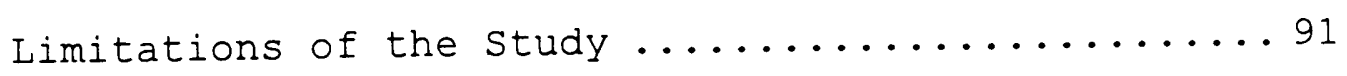

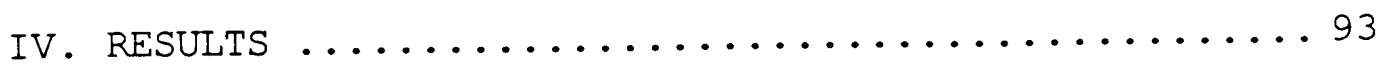

Characteristics of Respondents ...............93

Relationships between demographic variables .....996

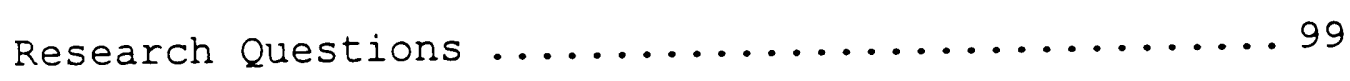

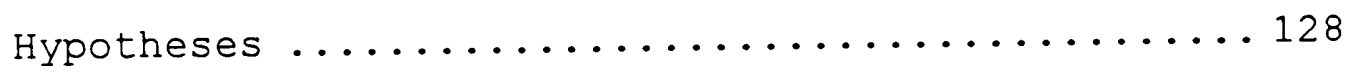

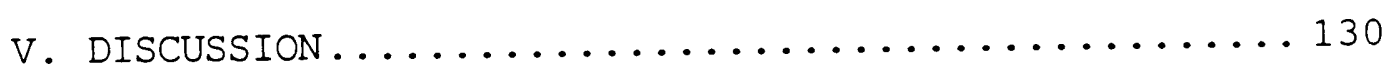

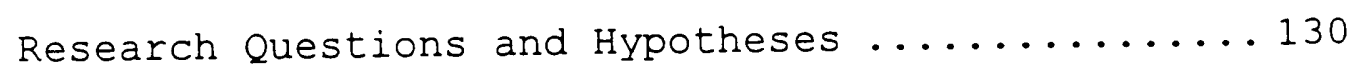

General relationships among demographic data... 130

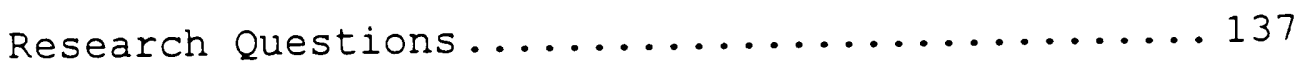

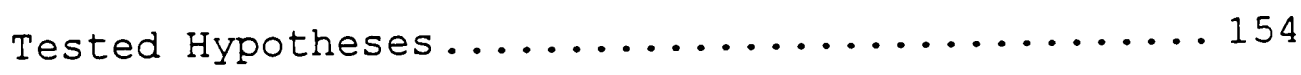

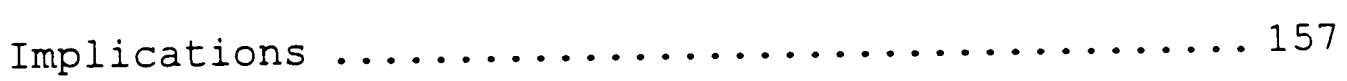

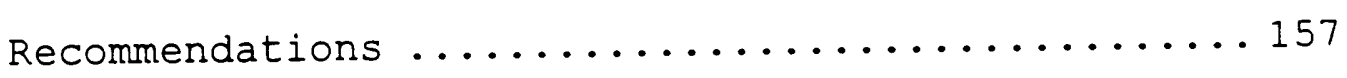

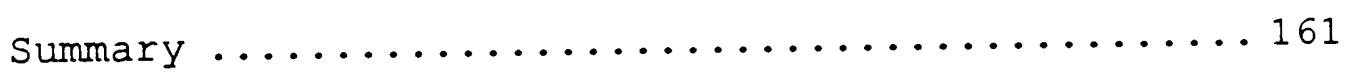

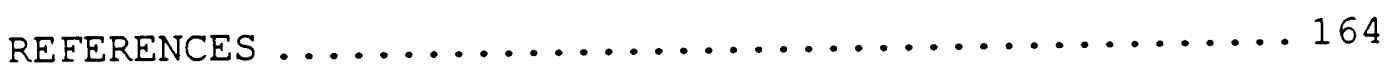

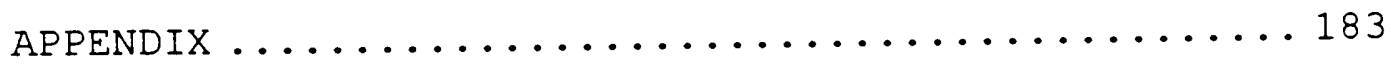




\section{LIST OF TABLES}

Table 1. Inter-relations between general attitude, coping and stress items

Table 2. Ranked current role frequency by all respondents

Table 3. Ranked current role valuation by all respondents

Table 4. Ranked current role autonomy by all respondents Table 5. Ranked role enjoyment by all respondents Table 6. Correlation of demographic variables with current roles

Table 7. Comparison of top eleven current roles by valuation and HIV status

Table 8. Significant expected role shifts by valuation of all respondents

Table 9. Comparison of top ranked expected valued role shifts by HIV groups

Table 10 Correlation of demographic items with current satisfaction scores

Table 11 Correlation of current satisfaction with roles of all respondents 


\section{CHAPTER 1: INTRODUCTION \\ Prelude to the problem \\ Ideals and Reality}

An ageless struggle in the ascent of humanity has been the difficult task of transforming the great ideals of its thinkers into reality for the people. The founding fathers of the United States crystallized their ideals for a free democratic society in documents such as the Declaration of Independence, the Constitution and the Bill of Rights. The resounding theme of these was penned by Thomas Jefferson when he declared in our Declaration of Independence that "all Men are created equal, that they are endowed by their creator with certain inalienable Rights, that among these are Life, Liberty, and the Pursuit of Happiness" (Declaration of Independence, July 4, 1776). The process, however, of making these lofty ideals work for all of this country's constituents has been a long and difficult one which continues even today.

A similar theme was captured by the leaders of the occupational therapy profession who summarized their ideals for the profession in the Occupational Therapy Code of Ethics and Revised: Standards of Practice for Occupational Therapy. Principle 1 of the Code of Ethics states that ethical practice of occupational therapy involves "providing services without 
regard to race, creed, national origin, sex, age, handicap, disease entity, social status, financial status, or religious affiliation" (AOTA Representative Assembly, 1988). This statement summarizes the fundamental ethic of beneficence. Beneficence refers to the profession's value and desire for doing good and avoiding harm to those it serves. The principle, as stated, makes it clear that this spirit of doing good is to be extended to all individuals regardless of the human characteristics that often divide our society. The task of fully implementing this ideal of the profession has also been a matter of process. This process has been the gradual development of strategies which address the specific occupational health needs of all people groups in this society. Despite occupational therapy's value and respect for human individuality and cultural differences as a profession, practical methods to actualize this in professional services, especially among gay men, have not been fully developed. This general fault, however, has been addressed more frequently in the profession in recent years as evidenced by "diversity" conference themes, the formation of minority culture caucuses, and recent trends in the research. This study is part of that trend. 


\section{Homosexuals and their culture in U.S. Society}

The homosexual population is a group that stretches across all ethnic, religious, national, and gender lines. The emergence of this group as distinct in the midst of others has been a recent phenomenon brought about by various socio-environmental factors (Barry, 1987; Herek, 1991).

Homosexuals as a group are both numerous and distinct. They are "the first, second, or third most numerous minority in the U.S.--depending on which variation of the estimate is used" (Gonsiorek \& Weinrich, 1991). The difficulties in defining "homosexual" and the reluctance of individuals to self-identify as homosexual for fear of the stigma and discrimination that often goes with being gay have made the counting of the population in the United States a difficult task (Singer \& Deschamps, 1994). Even so, their numbers are significant enough to be considered in marketing, political races, and public health planning, especially in large urban areas.

In the United States homosexuals have often been targets of institutional and private hostility rising from religious convictions (i.e. that homosexuality is against nature and, therefore, immoral) or social norms (i.e. that homosexuality is unusual and non-conforming to gender norms and, therefore, 
deviant) (Herek, 1991). Despite recent strides in securing equal protection under the law for homosexuals across the United States, stigma, oppression, and discrimination based on samesex-orientation continue and are a part of this group's daily reality. This state of affairs has been noted even among health care professionals (Herek, 1991; Herek \& Berrill, 1992; The Gallup Poll, 1993; Stevens \& Hall, 1988).

A human being, regardless of all labels and groupings, is unique. Homosexuals are a particularly diverse group somewhat loosely bound. A T-shirt slogan reminds any population researcher: "For the last time...it's not a lifestyle; it's a LIFE!" Even so, population characteristics are often useful to consider from the perspective of conducting public health-needs assessments. Culture is a social construct used to describe the sum of beliefs, practices, habits, likes, norms, customs, and rituals-in essence, a person's "way-of-life"-that is learned by the process of socialization (Spector, 1991). Therefore, the study of homosexuals as individuals and as a group can be useful for health care professionals as a means of improving delivery of health care to this population.

The emerging gay culture is being investigated by scientists from both social and health sciences. Specifically, gay men and their lives have been closely studied due to their 
association with HIV (the human immunodeficiency virus) and AIDS (the acquired immune deficiency syndrome caused by prolonged infection with HIV). Descriptive population characteristics are being collected in the hope of minimizing the future impact of the virus on the human experience.

Particular patterns of thought, beliefs, behaviors, humor, values, activities, clothing, roles, speech, and the like are unique to homosexuals. These characteristic aspects of gay life are described in numerous books ranging from academic sociological research to market analysis research to lighthearted guides on gay culture and lifestyle (Weston, 1991; Rofes, 1987; Kleinberg, 1980; Barry, 1987; Browning, 1993; Herdt, 1992; Dilallo \& Krumholtz, 1994). Of note to health professionals and occupational therapists in particular is that gay men have patterns of activity, values, and roles that are clearly distinct from the American majority culture (Dilallo \& Krumholtz, 1994; Browning, 1993; Herdt, 1992). Majority culture refers to the way-of-life of the largest and most influential group which in most parts of the United States is Caucasian, heterosexual, and Christian. Effectiveness of treatment with homosexuals (which can arguably be considered a minority), therefore, hinges on addressing their needs within a larger understanding of their sub-culture. 


\section{HIV and the gay male community}

The impact of HIV on the human experience has been enormous. The intrusion by this virus has affected individuals in all aspects of human relationships--society, cultures, communities, families and most acutely, the individual self. The gay male community has been the group most heavily impacted by HIV and AIDS (Hirsch \& Enlow, 1984) in the United States. Recently, however, minority, adolescent, female, and heterosexual populations have shown increasing rates of infection while infection due to homosexual contact has decreased (Mann, Tarantola \& Weller, 1992). HIV transmission has never been a matter of risk groups (i.e. homosexuals, IV drug users) as it has been a matter of risk behaviors (i.e. unprotected sex, sharing needles). Nevertheless, gay males as a group still constitute the largest proportion of the U.S. population affected by HIV-infection and AIDS (Gonsiorek \& Shernoff, 1991; CDC, 1996).

With society and culture, HIV has impacted the course of federal state and county economics, social movements and political discourse and action. Early on, society associated the virus and disease with homosexuals. This, when added to the public fear of the disease, became fuel for discrimination and violence against infected individuals and against homosexuals in 
general. Homosexuals faced the double-jeopardy of being a stigmatized group infected with a stigmatized disease.

The gay community in particular experienced notable change. The loss of life and health among its group members was dramatic both in numbers of affected individuals and in the severity of the challenges the disease imposed. Leaders and groups within the gay community emerged and responded to the crisis brought on by HIV with a surge of political activism, the organization of social support systems, and the raising of public awareness and funding for the fight against HIV and AIDS. Fueled by fear of contagion and gay men's health education blitzes, dramatic shifts in sex-behaviors and in attitudes about sexuality came about.

The impact of HIV has been felt by the families that it has touched. Significant disturbances in family life involve matters of finances, grief, searching for answers, honesty, and journeys toward mutual respect across contrasting value systems. The family response to the virus often proceeds to either tightly bind family members together or to tear them apart. Love and anger, loss and grief, hopelessness and helplessness, despair and deep sorrow describe only a few of the often wrenching human emotions that these family units experience. 
HIV imposes its most devastating blow, however, on the individuals it infects. Its first strike to the infected individual is not as any symptom of disease but as an image of a changed future. With the awareness of being infected, a person often begins to play out all the potential future scenarios; these incorporate visions of life with changes in physical health, energy, appearance, future life plans, social relationships, sex life, finances, life activity patterns, and functional abilities. These scenarios often incorporate memories of how the virus devastated people's lives in the past. Up until recently, the individual's personal response to becoming infected was made even more difficult by the fact that there was no real medical time frame given in which to expect these changes. Recent research studying longevity and associated viral load figures, however, is now making predictions of longevity more possible (Torres, 1996).

The response to this crisis by society, by communities, by families and by infected individuals themselves has the potential for causing either a positive or negative trajectory of adaptation. Like many medical conditions that are perceived as being terminal, HIV imposes an existential crisis on those it infects and affects. The battle with the virus begins, therefore, in the mind long before it surfaces as a battle in 
the body. Regardless of the trajectory, never again does anyone infected or affected by HIV perceive life as status quo.

Occupational therapy and HIV infected gay males

Within an interdisciplinary approach, occupational

therapists have the potential to play an important role in

addressing this human and health crisis. The perspectives,

training and skills of an occupational therapist are vital to

future successful management of the HIV crisis in individuals, families and communities affected by it.

Theoretical framework

Theory provides therapists with a way of conceptualizing, organizing and understanding the occupational world's of infected gay men and their affected families. One helpful model is that proposed by Kielhofner \& Burke (1985), the Model of Human Occupation (Kielhofner, 1995). This model views the human being as an open system, that is, as in a perpetual state of dynamic interaction with his environment. Both an individual's internal and external worlds come to play on his occupational choices via a process loop of intake, throughput, output, and feedback. As such, an infected gay man receives continuous input from his environment, processes that input through a hierarchy of internal subsystems identified by the model as the 
volition, habituation, and performance subsystems and responds with an action which is itself human occupation.

The Model of Human Occupation develops the subsytems of throughput processes in detail in an effort to better explain the variables by which humans construct and assemble occupation. The phenomenon of occupational roles is one aspect of the subsystem of habituation which helps therapists toward this end. Roles are abstract images that a person and society hold which serve to organize a system of internal and external expectations of behavior and activity patterns. These internalized roles serve the individual by guiding him in the fundamental task of planning a given day or week's activities. These occupational roles are the focus of this study.

\section{Personal HIV infection awareness and occupation}

As might be expected, HIV infection is accompanied by a progression of problems related to human occupation. Clearly, with the onset of severe symptoms brought on by HIV infection, the individual begins to experience a succession of physical changes that provide him with feedback about his ability to live life as he did previously. The internal subsystems of volition and habituation, however, can be affected by the presence of HIV long before the virus compromises the physical functioning of the individual. 
From the initial onset of awareness of being infected by HIV, the subsystems of volition and habituation are at risk for dysfunction. The state of health of these subsystems bears heavily on the occupational output and the sense of well-being of the individual. The Model of Human Occupation provides therapists with ways to explore these occupational problems at levels beyond the scope of simple physical disabilities management with a view towards prevention and wellness. In this sense, therapists who implement the model in early stages of infection can play a role in delaying and/or minimizing future problems in the occupational functioning of their clients while empowering them to live fully in the present. This is the ultimate goal of any program that seeks to assist individuals with any chronic condition.

How personal awareness of being infected with HIV impacts a person's psyche has recently received more attention in the literature. However, the impact of HIV-infection awareness on a person's occupational behavior has not been addressed in the literature to any great length. Thus, there is little information available to guide therapists wishing to establish wellness programs designed for the HIV-infected community. Occupational therapy services for individuals infected with HIV (with or without an AIDS diagnosis) typically occurs at the 
stage of an acute disease or event (e.g. pneumonia, functional decline, wasting) related or unrelated to HIV infection. Currently, the primary arena in which occupational therapists have contact with gay men with HIV is in hospital settings. But the need for occupational therapy services may be much greater than what is currently available to the HIV-infected community. There is currently a need to determine whether this population could benefit from targeted community-based professional services-services that might address early issues associated with HIV infection and the initial adjustment to an HIV-infected life status.

\section{Statement of the problem}

The concern is this: gay men continue to be affected by HIV with rates of infection that continue to make it the most affected group in the United States. Infection with this virus, whether or not symptoms of disease are present, has a profound impact on the occupational behavior of individuals due to complex factors. Among the most significant factors in the early stage of infection is the human existential crisis that surfaces in an individual as a result of mortality awareness. Occupational therapy has a role in the management of this disturbance to the human occupational system. Occupational 
therapists have the skills necessary to help individuals attain and maintain patterns of activity and role configurations that are natural extensions of their unique value systems. They also have a theoretical framework in the Model of Human Occupation to guide them in their assessment and treatment of these individuals towards this end.

This being so, the problem is this: little information is available to guide professionals who wish to work with this target population. Therefore, more information about gay male occupational behavior is necessary.

\section{Purpose of the study}

The purpose of this study, therefore, was to begin to compile information regarding the occupational behavior of HIVinfected gay men as they are impacted by HIV for use in problem analysis and program development. The primary aim of the study was to determine whether or not there is evidence of need for services in this population. Towards this end, the study sought to identify specific occupational roles that are most valued by homosexual men as a group, to describe their life satisfaction in relationship to these valued occupational roles and to explore how a diagnosis of HIV-infection is perceived to alter life activities and satisfaction among gay males. The study 
hopes to begin describing adaptive responses to personal HIV infection that may be useful in clinical settings.

Questions \& hypotheses

This study was carried out in order to answer six primary research questions and test two hypotheses regarding the occupational behavior of gay men:

Q1: What are the valued occupational roles of gay men?

Q2: What factors influence the occupational roles of gay men?

Q3: Do the occupational role configurations of HIV+ gay men differ from those of HIV- gay men?

Q4: What are the occupational role shifts expected by gay men in the future?

Q5: Do the expected occupational role shifts of HIV+ gay men differ from those of HIV- gay men?

Q6: What are the factors that influence life satisfaction among gay men?

Sub-Q A: What is the relationship of role frequency, role valuation, autonomy of role participation and enjoyment of role participation to overall life satisfaction in gay men?

Sub-Q B: What is the actual and perceived impact of HIV infection on the life of a gay man? 
Sub-Q C: Is there a difference between actual and perceived impact of HIV on life among HIV-infected and noninfected gay men?

Sub-Q D: What shift in life satisfaction do gay men expect in the future?

Sub-Q E: Do the expected shifts in life satisfaction differ between HIV+ and HIV- gay men?

H1: A diagnosis of HIV infection negatively impacts life satisfaction among gay men.

H2: Gay men who have been given a diagnosis of HIV infection have higher variance in life satisfaction scores than uninfected gay men.

\section{Significance of the study}

Health care administrators continue to look for ways of decreasing overall costs and increasing efficiency of services delivered. The efficient management of chronic conditions is significantly different from the management of acute illnesses; health maintenance and disease prevention among a chronic population have been shown to be valuable and effective strategies. This particular study is significant in that it investigates several areas of concern to health professionals and to society in general: 1) it seeks to provide professionals 
with useful knowledge to combat and decrease human suffering, 2) it seeks to do so within a realistic context, that is, decreasing society's overall health care costs and increasing healthcare efficiency, 3) it investigates an area of need overlooked in the profession's contract with society, 4) it opens up possibilities to the profession for a new market (i.e. individuals with chronic HIV infection) hereto not targeted, 5) it initiates the task of developing a culturally sensitive assessment in response to the increasing expectation for cultural sensitivity and effectiveness in the profession. The knowledge gained from this study will be useful to professionals in the following ways: 1) to understand the extent of the need for directed services among HIV infected gay men, 2) to uncover trends in the role behavior and life satisfaction of gay men, 3) to assist in the development of assessment tools sensitive to the problems of this population and to other similar populations, and 4) to help plan effective occupational wellness strategies for this population.

Operational definitions

In scientific research, terms require clarification and precision of measurement. Thus, the following key terms are defined conceptually and operationally: 
1. HIV-infection and AIDS diagnoses: the acquired immune deficiency syndrome (AIDS) is positively linked to infection with the human immunodeficiency virus (HIV); however, the two terms are not synonymous. An AIDS diagnosis is given when an individual who is infected with HIV has a CD4 cell count of < $200 \mathrm{cells} / \mathrm{ml}$ or if the individual exhibits one of the clinical conditions listed by the CDC as AIDS defining opportunistic infection (CDC, 1996). A person can be infected with HIV for many years before symptoms of AIDS or a diagnosis of AIDS is given. A diagnosis of HIV is given when an individual's blood tests positive to HIV antibodies. The focus of this study is on gay men infected with HIV but without any symptoms of disease (asymptomatic).

2. Role: a position in society that contains a set of expected responsibilities and privileges; the source of the expectations are both from the individual and society (Black, 1976) .

3. Occupational roles: those specific roles that provide the opportunity for performance of behaviors on a continuum from productive to leisure activities (Oakley, Kielhofner, Barris \& Reichler, 1986, p. 159). The entire instrument is found in the Appendix and provides full definitions of each occupational role. The instrument used in this study explores 
24 occupational roles grouped into four meta-role categories listed below.

Personal life management roles: include self-care manager, physical health manager, psychological health manager, personal activity manager, and personal finances manager and are those roles which include the daily activities of organizing and managing one's obligations of life.

Social roles: include family of origin member, caregiver, family of choice, primary partner, friend, and pet owner and are those roles that involve interaction with others. Some of these roles may overlap with other areas such as group activity participant (formal \& informal), sexual activity participant, and spiritual/religious activity participant.

Productivity roles: include worker outside the home, worker inside the home, student, and volunteer and are those roles in which an individual makes a contribution to his environment through work-related activities. These also may overlap with other areas such as formal group activity participant and caregiver.

Leisure roles: include relaxation participant, outdoor activity participant, individual activity participant, group 
activity participant-formal and informal, high energy activity participant, low energy participant, sexual activity participant and spiritual activity participant. They are those roles whose purpose is enjoyment and which are often less structured by nature.

4. Perceived occupational role disturbances: any changes (e.g. brought on by time, disease, or aging) in role behavior and includes the loss of roles and the gaining of new ones.

5. Valued occupational roles: those occupational roles (from the 24 listed in the instrument) that respondents scored in role valuation as being between moderately important (score of 3) to extremely important (score of 5).

6. Frequency of participation: the number of times respondents engaged in given occupational roles. The answer options ranged from "never" to "daily (or just about)".

7. Role valuation: the degree of importance respondents placed on given occupational roles (Watson \& Ager, 1991). The answer options ranged from "not at all important to me" to "extremely important to me".

8. Autonomy of role participation: the degree of autonomy or control a person has in his participating in a given role.

9. Enjoyment of role participation: the extent to which a person derives pleasure from his participating in a given role. 
10. Life satisfaction: "a sense of contentment about life domains derived from life events, sense of contribution and perceived harmony between expectations and actual outcomes" (Watson \& Ager, 1991, pp. 33-34). This concept is measured both as a global unit of satisfaction (question 67 and 107) and as individual domains of satisfaction (questions 68-81 and 108121). In each case it is measured using a 7-point Likert scale with responses ranging between "very dissatisfied" to "very satisfied".

11. Gay or homosexual males: a sexual orientation characterized by favoring persons of the same gender with respect to both sexual and emotional intimacy. For purposes of this study, the adjective "homosexual" will be used interchangeably with "gay". Though the term "gay" is gender inclusive, it is often distinguished from "lesbian" and so typically refers to males who self-identify as homosexuals. The questionnaire derives this information from answers to question 8 which provides a continuum of responses from "exclusively heterosexual" to "exclusively homosexual". The subjects selected for this study were composed of those who responded to this item with "homosexual exclusively" or "bisexual (more homosexual)". 
12.HW-positive (or $H W$-infected): Due to the self-reporting nature of the study, these terms will be used interchangeably only to refer to a subject's perception of his body being infected by the human imunodeficiency virus. This information was derived by self-report on question 36 ("Which of the following best describes your HIV status?"). However, the level of confidence a person has about his HIV status is significant. Therefore, a follow up question identified the level of confidence with choices ranging between "very confident" to "not confident at all". All subjects who answered with "very confident", "confident" or "somewhat confident" were grouped as being HIV-positive.

13.HIV-negative (or non-infected): These terms were used interchangeably only to refer to a subject's perception of his body being free from infection by the human imunodeficiency virus. All subjects who answered question 36 with "HIV-negative" and question 37 with "very confident", "confident" or "somewhat confident" were grouped as being HIV-negative.

14. Family of origin: those people who are related to the respondents by blood or adoption regardless of emotional ties. A brief check-list administered prior to completing the questions regarding roles served to ensure that this term was 
clearly established in the respondents' minds prior to answering the questions.

15. Family of choice: all those people who a person considers "family" by virtue of their being a significant part of their emotional support system. These individuals may or may not be related to the individual by blood or adoption.

\section{Assumptions of the study}

Assumptions that must be taken into consideration in evaluating this study include the following:

1. that role performance is part of occupational functioning and, therefore, in the professional domain of occupational therapists.

2. that homosexual men comprise a distinct and identifiable subculture in the United States.

3. that an adequate representation of homosexual men can be obtained through sampling and statistical control.

4. that participants will understand the questions and respond honestly to them. 
CHAPTER 2: REVIEW OF THE LITERATURE

$$
\text { Multiculturalism/ Diversity }
$$

The United States is a nation whose unique position in the world is derived from its people and the national, racial and cultural heritage they bring with them. The composition of the American population has always been evolving from its inception, but more recently, this evolution has quickened. Changes are taking place in health-care as a result of the changes that are taking place in the cultural mix of the American population (Spector, 1991). Ethnic and racial minorities have become a larger proportion of the American population, from $16.8 \%$ of the population in 1980 to $22 \%$ of the population in 1989 (Hollman, 1990). As a result, there has been increasing attention given to issues of diversity in health-care. These trends in the population have led analysts to conclude that comprehensive and effective health-care can only be achieved if providers become more sensitive to the culture of their consumers (Spector, 1991) .

Occupational therapy has recently responded to multiculturalism as well. The Revised Standards of Practice for Occupational Therapy (1992) state that occupational therapy interventions shall be implemented in a way appropriate to, among other things, the "cultural and ethnic background" of the 
client. In this spirit, the 1995 American Occupational Therapy Association's (AOTA's) annual conference had as its theme "Diversity: Our Journey Together" with a focus on multicultural issues in practice (Wells, 1995). Research and theory development in occupational therapy have also explored the concept of multiculturalism in the profession. A recent study was conducted (Pope-Davis, Prieto, Whitaker and Pope-Davis, 1993) to explore the influence of educational and demographic variables on multicultural competencies of occupational therapists. This reflects the general awakening of the profession to the concern for multicultural competency among its practitioners. This conversation regarding multicultural approaches to practice has become active most recently (Dillard, Andonian, Flores, Lai, MacRae \& Shakir, 1992; Fitzgerald, 1992; Levine, 1987; Lowery, 1990; McCormack, 1987; Sayles-Folks \& People, 1990; Swawski, 1987; Vilaubi, 1990).

In her 1994 Eleanor Clarke Slagle Lecture entitled "Building Inclusive Community: A Challenge for Occupational Therapy", Ann Grady (1995) expanded spatiotemporal adaptation theory to include themes of multiculturalism. She posed two noteworthy challenges to today's occupational therapists: 1) to understand each person's unique community, including its culture and the context in which it was formed, and 2) to foster choices 
that reflect clients' priorities for living, even if they differ from the therapist's values or perceptions of expertise (Grady, 1995). A reflection of historical occupational therapy philosophy echoes through her words (Grady, 1995):

The idea is both profound and simple. Simply, we believe that people belong together regardless of real or perceived differences. All persons have the right to choose where they wish to live, work, learn, and play, and with whom they wish to spend time. On a deeper level, we believe that people belong together because of differences. There is a richness that characterizes a community constructed with appreciation for both differences and similarities among its members (p. 301).

Key to effective treatment in occupational therapy is building a relationship with the client based on common goals, mutual respect, and cooperation. Communication and treatment which is carried out and designed to be meaningful within the cultural context of the client are cornerstones of that therapeutic relationship (Dillard et al., 1992). Neistadt's (1995) survey of occupational therapists in adult physical dysfunction, however, led her to conclude that "therapists have not yet successfully translated their values about client- 
therapist collaboration into a formal set of procedures" for assessing client priorities on admission (Neistadt, 1995, p. $428)$.

Gay Men and Healthcare in the United States

As stated previously, homosexuals as a group are "the first, second, or third most numerous minority in the U.S.-depending on which variation of the estimate is used" (Gonsiorek \& Weinrich, 1991). The studies that have sought to answer this question have resulted in conflicting numbers ranging from $2 \%$ to $11.6 \%$ of the population according to the review of the major research reported by Singer \& Deschamps (1994). Despite the inconclusive numbers, the rise of gay Americans as a group has been difficult to ignore. Throughout the United States, large metropolitan areas in particular have become places of concentration for gay men and lesbians seeking community with New York, San Francisco, Boston, Seattle, Oakland, Washington, DC, Chicago, Atlanta, Miami, Minneapolis, Los Angeles, Portland, San Diego and Pittsburgh heading up the list (McLeod, 1991). The freedom to study gay culture has only recently developed. In 1973 the American Psychiatric Association (APA) removed homosexuality from the Diagnostic and Statistical Manual-II overturning the view of homosexuality as mental 
illness held since 1942. Homosexuality, per se, is now no longer seen as pathological, but rather, it is viewed as a normal variation of human sexuality (Cabaj, 1988). The fields of Psychiatry and Psychology have, thus, shifted perspectives and treatment protocols, initiating research to better understand this population. In health-care, however, this population is often invisible and difficult to distinguish from others. As a result, little research has been conducted with respect to the way gay clients and the delivery of heath-care services interact.

A 1991 survey of four-year medical schools in the United States concluded that the mean amount of course time devoted to the topic of homosexuality was 3 hours, 26 minutes (Wallick, 1992). This type of statistic along with similar findings led Singer \& Deschamps (1994) to conclude that lack of information about homosexuality has fostered continued deep-seated homophobia within the health fields. This homophobia has in turn resulted in the needs of the gay and lesbian community being vastly undermet and undervalued. Research has, in the past, sought to understand the relationship of alcoholism and domestic violence to homosexuals (Singer \& Deschamps, 1994). The study of HIV and AIDS, however, has finally focused necessary attention on the health of gay men (Singer \& Deschamps, 1994). 
HIV infection

Etiology and course of HIV infection

The first report of what has now come to be known as AIDS surfaced in the Centers for Disease Control's Morbidity and Mortality Weekly Report in June of 1981 (Marcil \& Tigges, 1992). At that time, theories began to be explored and research was initiated toward understanding this new mysterious illness. Since then, volumes of information have been produced regarding the pathology of the disease and it continues to change or to be updated at an extremely rapid rate. The following is a simple summary of the pathology of the human immunodeficiency virus based on current knowledge.

Being infected with the human immunodeficiency virus (HIV) is the dominant factor that leads to a person having the acquired immunodeficiency syndrome (AIDS). The infection pattern in the United States is classified as a Pattern 1. This reflects the facts that 1) the major affected groups are homosexual/ bisexual men and IV drug users, 2) that the virus was introduced in the mid-1970's and 3) that transmission of the virus is predominantly homosexual (Galantino, 1992). This pattern of transmission, however, is not worldwide. 
Between 650,000 and 900,000 Americans--one of every 160 men and one of every 1,000 women--are infected with HIV ("Groups push...," 1996). The counting of HIV infection incidence is less complete than AIDS case counts due to the fact that much of the current figures are based on estimates. Currently, only 26 states report incidence of new HIV infection to the Centers for Disease Control, and this group does not include four of the five states with the highest numbers of AIDS cases (California, Florida, New York, Texas). Even with this dramatically incomplete reporting, the CDC recorded 14,467 new cases of HIV infection between July 1995 and June 1996. With these available numbers, it was determined that $30 \%$ of the total incidences were attributed to male homosexual sex activities (CDC, 1996). Even though the rate of infection in this exposure group has dropped significantly from earlier times, it still remains the leading exposure group. Comparably, other groups show increasing rates of new HIV-infection such as women whose numbers now compose $29 \%$ of total new infection reports (CDC, 1996).

$\mathrm{HIV}$ is a retrovirus which means it uses reverse transcriptase to produce viral DNA using host DNA. The virus enters a host and fuses with host cells that have CD4 receptor areas, especially the $\mathrm{T}$-cell lymphocyte. It then uses reverse transcriptase to produce viral DNA and eventually to integrate 
this viral DNA with the host chromosome in the nucleus. Here it may lay dormant for a period of time or activate the infected cell to produce the proteins necessary for reproduction of the virus. The host cell is then killed and the new HIV goes on to infect other cells (Levy, 1989).

Because of its affinity for T-cell lymphocytes, the infection manifests itself as a gradual decrease in these lymphocytes which results in the body's inability to defend itself against infection and.malignancies due to the weakened cell-mediated immune system response (Ho, Pomerantz, \& Kaplan, 1987). There is a gradual weakening of the immune system with progressive loss of available helper $\mathrm{T}$-cells resulting in increasing infections that primarily affect the skin, the lungs, the gastrointestinal system, and the neurological system.

\section{Physiological course of HIV infection}

The most commonly used system to classify the progression of clinical manifestations of HIV infection is from the Centers for Disease Control which maps out the course of the infection in four stages. The following summary of these stages is based on the descriptions of these provided by Marcil and Tigges (1992) •

Stage $I$ is the acute infection stage immediately following initial exposure to the virus up to the point of seroconversion. 
Seroconversion refers to that event in which the levels of antibodies in the infected person's blood become detectable to laboratory testing. This event is now considered to occur anywhere between three weeks to three months following the initial infection with the virus for most people. During this stage the individual tests negative for HIV yet has the potential to pass the infection on to others, and this potential continues on for the lifetime of the individual. It is sometimes accompanied by a flu-like syndrome which may include fever, rash, arthralgia, lymphadenopathy or neurological syndromes which eventually resolve themselves. This stage has a typical duration of 1 to 12 weeks.

Stage II is known as the asymptomatic phase. The individual's blood now tests positive for HIV antibodies but he has no physiologic manifestations of infection. During this time, the virus incorporates itself into the host's DNA but on surface appearances does not affect the body systems. The reality of this phase is a gradual decrease in T-cells, an increasing viral load, and the persistent mutation of the virus over time. These mutations are a result of the virus adapting quickly through random copying flaws to the body's defense mechanisms and possible medications which can result in the evolution of new strains of the virus, entirely different from 
the form of the original infecting virus. These events occur without physical manifestation though they may be observed through laboratory tests. The duration of this stage of the disease can vary based on factors such as lifestyle, medical interventions, the strain of the virus, and the overall constitution of the individual infected. This period has a duration currently in the realm of years with some individuals reporting having no symptoms for over ten years. The reported ceiling continues to increase with the advancement of medical interventions and with more accurate reporting of the times of actual infection.

Stage III is known as persistent generalized lymphadenopathy during which an infected person experiences early clinical manifestations of a compromised immune system. In the past, it was believed that $t$-cell counts below 500 were indications of the onset of this phase. However, with current advances in understanding the concept of viral load, the t-cell count is no longer as reliable an indicator of potential clinical manifestation in itself. The use of $t$-cell counts in conjunction with viral load count are now considered more reliable laboratory methods of tracking the status of the immune system and the potential for clinical manifestations of disease. 
Stage IV is the final stage known as AIDS. This point of demarcation, however, is becoming more blurred as medical advances are becoming more effective in keeping the infection at a manageable chronic level. Persistent t-cell counts below 200 along with the manifestations of certain clinical symptoms classifies the individual as having AIDS, which can be significant in terms of receiving disability benefits. Statistics suggest that $40 \%$ of those infected with HIV reach this stage within seven years of becoming infected. The clinical manifestations include chronic constitutional symptoms, neurological diseases, secondary cancers and opportunistic infections. Eventually, most infected individuals reach this stage though, again, the advancement of medical interventions is greatly increasing the hopes and reality that this fact may not be the case in the future. Currently, this stage most often ends in the death of the individual.

\section{Current strategies in HIV/AIDS care}

HIV was originally discovered in 1983 at the Pasteur Institute in Paris and since that time great strides have been made toward defending the human body against the effects of this virus. Many approaches have been used to decrease its impact on our society: education and prevention programs, research towards the discovery of a vaccine, the study of the confounding 
variables, heightened awareness for the procurement of funding for the fight, clinical studies of medications, alternative therapies, psychological studies and the like. The list goes on extensively and includes the world of rehabilitation. Following is a description of the current therapies being used today in various professions with a focus on those being used in occupational therapy.

Medicine

The American Foundation for AIDS Research (AmFAR) compiles and publishes the AIDS/HIV Treatment Directory. Current strategies listed in this directory (June 1996) include all the available antiretroviral therapies (treatments aimed at disrupting HIV in an infected person) and immune based therapies (treatment designed to bolster the immune system of the infected person). The first line of defense is usually the antivirals used in various combinations. These generally only work for a given amount of time as the virus adapts and develops resistant strains. Most practitioners, however, now recommend early intervention with these antivirals as early as possible since new lines of defense continue to emerge that extend the possibilities of drug therapies.

Aside from these ongoing treatment strategies, health-care professionals address the specific symptoms and opportunistic 
infections as they emerge in the individual: diarrhea, weight loss, fever, fatigue to name a few. Each opportunistic infection or malignancy has a standardized treatment regimen that is followed.

Psychology and Rehabilitation professionals

For a sound understanding of the roles of psychology, neuropsychology, nutrition, exercise physiology, physical and occupational therapy, respiratory therapy, social work, and home health care, Mukand (1991) and Galantino (1992) are comprehensive resources. These books provide comprehensive details of how these professions present themselves to address the needs of HIV-infected people. Many of these health professions, including occupational therapy, are offered in various community settings including county funded programs, private community programs, prevention programs, wellness centers, home health care, and through hospice care. Most care, however, is directed at treating the physical symptoms of the infection once it begins to manifest itself. Occupational therapy

Occupational therapists define health differently from traditional definitions which are based on the medical model. In occupational therapy, health is viewed phenomenologically, that is, as the human experience of it. This experience of health 
can be influenced from within an individual. This being so, the objective of occupational therapy is to facilitate internal and external adaptation to life changes (in health, in life circumstances, in the environment, in function, in well-being) as well as to diminish any dysfunction brought on by these changes.

Michael Pizzi has been a leader in the area of HIV and AIDS as have been William Marcil and Kent Tigges. The literature they have contributed to this particular area is the backbone of the current knowledge base in occupational therapy. Occupational behavior and its evolution into the Model of Human Occupation and occupational science constructs are the primary theoretical frameworks which are used in this arena. Notably, there is a lack of literature in occupational therapy addressing the specific needs of gay men and the needs of HIV-infected persons prior to the onset of AIDS.

Uninfected persons or preventing HIV infection. Occupational therapists have been part of the health promotion and disease prevention movement since 1971 when Geraldine Finn addressed the AOTA in her Eleanor Clarke Slagle Lecture entitled "The Occupational Therapist in Prevention Programs" (AOTA, 1984). The presence of occupational therapists in HIV prevention programs is, however, practically non-existent as evidenced by 
the lack of literature on this topic. Marcil and Tigges (1992) support the idea of occupational therapists playing a role in this area by serving as educators of basic AIDS information, of infection control, of community resources, of safer sex issues, and by promoting the Americans with Disabilities Act as it relates to HIV and AIDS.

Asymptomatic or early HIV infection. The impact of a recent diagnosis of HIV infection is enormous to an individual, and a model for understanding the stages of reaction to it has been proposed in psychology literature (Ross, Tebble \& Viliunas, 1989). This, however, is yet to be addressed in occupational therapy literature. Shifts in meaning, purpose and values have been noted in gay men following an HIV infection diagnosis (Schaefer \& Coleman, 1992). The changes in role performance that might occur secondary to these shifts among this population is yet to be researched and is the focus of this study. Symptomatic or mid-stage HIV infection. With the progression of the disease, the immune system weakens and the host becomes susceptible to opportunistic infections. Recurrent bouts with symptoms such as pneumonia, transient neuropathies or chronic fatigue bring this population into closer proximity to current settings in which occupational therapists operate: acute rehabilitation, home-health care, and out-patient services. Most 
of the HIV literature in occupational therapy is focused on this and the final stage of infection (Pizzi, 1993; Denton, 1987; Marcil \& Tigges, 1992; Dunn \& Giacone, 1995). These provide the ideas (i.e. theoretical concepts) and tools (assessment areas, treatment methods, evaluations) essential for therapists to address the needs of this population at these stages.

Severe symptoms or late-stage HIV infection. Addressing the needs of people in the late stages of HIV is not very different in the literature except for a shift in the focus of treatment. Palliative rehabilitation focuses on quality of life, comfort, and meaningful experiences when the expected outcome is rapid deterioration toward death. The same authors mentioned earlier address these issues of palliative care (Dunn \& Giacone, 1995; Denton, 1987; Marcil \& Tigges, 1992). Marcil \& Tigges (1992) provide a particularly thorough understanding of the experience of dying necessary for effective intervention.

Gay men and wellness

Wellness is a concept in the literature that is used in reference to quality of life (i.e. the experience of health), health promotion-disease prevention (i.e. the practice of health maintenance), and life satisfaction (i.e. the emotions associated with healthy living). In the context of this study, 
wellness refers to this holistic health experience, one which may be affected by physical, psychological, emotional, spiritual, occupational, financial, social, and vocational issues of life.

\section{Contextual components of wellness in gay men}

The physical, social, historical, and political contexts of an individual are often key contributors to human function and wellness. This concept is often labeled "environment" in theoretical frameworks such as the Model of Human Occupation (Kielhofner, 1995). The following is a brief description of some of these components of environment that have shown to have particular influence on the occupational performance of gay men as described in the literature.

Society

Society at large is one aspect of "environment" that provides feedback to an individual, powerfully shaping his perceptions of the world in which he exists. Day-to-day experiences with family, friends, strangers, media, peers, federal and local laws, traditional religious and cultural ideas and practices provide an individual with an incessant source of information about his society. Based on these, a gay man assesses whether his social environment is generally supportive or hostile toward him. The conclusions of this assessment of 
his society significantly contributes to his general psychological adjustment and, thus, to his sense of well-being Ross (1978) demonstrated that the perceived ("putative") societal reaction toward a person's homosexuality was more influential over that person than the actual reaction itself. He went on to suggest convincingly that the more anti-homosexual a gay man perceives his society to be, the more likely he is to conform to the heterosexual model (e.g. marriage to a woman). He also demonstrated that those gay men who expect strong antihomosexual reaction from their society and who over-conform to heterosexual norms experience negative consequences in the form of maladjustment. This is explained by the argument that those who internalize negative societal reactions toward homosexuality view themselves as "sick". Thus, psychological adjustment, a key factor of wellness and life satisfaction, is directly linked in gay men to non-conformity regarding heterosexual norms (Ross, 1978) .

In addition to a person's perceptions of his society, the actual availability of practical, financial, instructional and emotional support to him also plays a large role in a person's development and sense of well-being (Barris, 1982). 
Health care delivery

Health care services represent society's desire to provide for the mind, body and welfare of its citizens. Disenfranchised citizens such as gay men, however, are not often targets of health care delivery. A recent survey of medical schools in the United States concluded that the mean amount of course time devoted to the topic of homosexuality in four years of study in medical schools was 3 hours, 26 minutes (Wallick, 1992). Certain authors believe that this situation points to a deepseated homophobia within the health fields which is fostered by a continued lack of education concerning homosexuality (Singer \& Deschamps, 1994). They conclude that this institutional devaluation of homosexual men has led to frequent failure in the provision of adequate services to them. Cultural sub-groups

Three sub-groups are of particular importance to understanding HIV-infected gay men: homosexuals, the HIVinfected community, and men. The former two have been discussed in the introduction to this study. Understanding the subculture of men, however, is another important perspective on this group. The differences between men and women have been discussed candidly in "pop" culture as well as seriously in the form of scholarly studies. Among the differences noted between 
men and women are areas of communication, motivation, social behavior, and cognitive strategies (Tannen, 1990). These differences and others are believed to be a result of the influence of hormones, physiology, society-imposed gender expectations, learned social-interaction styles, and human history. A gay man's conformity or lack of conformity to societal expectations of male identity will shape society's acceptance of him. This degree of conformity which he chooses also plays an important role in his behavior, his activities of choice, his personal identity, his psychological adjustment and his well-being (Isay, 1989; Ross, 1978).

Social support

Many studies have demonstrated the significance of social support to effective coping with HIV and death anxiety (Catania, Turner, Choi \& Coates, 1992; Wolf, et al., 1991; Blaney, et al., 1991; Britton, Zarski \& Hobfoll, 1993). Not all individuals, however, have the same degree of access to traditional networks of social support. Social resources can be available through peers, family, mental health professionals and medical professionals. The relationships and support systems which are often taken for granted among heterosexual persons, such as social and interest clubs, churches, athletic leagues, neighborhoods and families, are only recently beginning to 
emerge in gay communities. The lack of availability of these relationships can result in a gay man having an impoverished support network, with few resources to provide practical, financial or emotional assistance which can be vital to wellbeing. Because many families have negative attitudes toward homosexuality and/or HIV/AIDS, homosexuals frequently experience the loss of traditional support from them (Britton et al., 1993). In contrast, research consistently has shown the significance and benefit of peers to the social networks of gay men (Britton et al. 1993).

\section{History}

An aspect of environment that provides input to the individual system and which can affect the output of the system is history (Kielhofner, 1995). This concept refers to past events that serve to shape humans at universal, national, regional, familial or individual levels. For gay men, one significant aspect of history was the world event of the emergence of AIDS/HIV in the late 1970's. This event and its ensuing repercussions dramatically altered the mentality, behaviors, and outlook of gay men (Isay, 1989).

Family history is a significant aspect of a gay man's history. Homosexuals have a wide range of experiences with their childhood nuclear families. A developmental milestone in 
the individual and family experience is personal homosexual identification commonly referred to as "coming out". This event bears deep significance to a person's individual psychological adjustment and life experience (Isay, 1989; Cain, 1991). The decision to embrace the inward pull of same-gender sexual orientation is, however, only part of the process of gay identification. The courage to bring this to light with family members and friends and the ongoing choices to stay true to this identity is vital to developing a healthy gay identity (Cain, 1991). The reactions and responses that these choices bring out in others can significantly affect an individual's view of his environment and, thus, impact his sense of well-being.

\section{Psychosocial impact of HIV on gay men}

The emergence of AIDS and HIV has brought about changes other than the disease experience within the gay community. There was an upsurge of volunteers and activism and an energy that drew the community into a focused purpose (Hirsch \& Enlow, 1984). At the same time, a collective grief over lost loved ones and over the loss of a way of life that would be no more, stood in sharp contrast to the previous free spirit that characterized the gay community (Carmack, 1992). In addition, an immense effort was initiated to alter the sexual habits of gay men who 
had become accustomed to sexual freedoms enjoyed in the early 1970's days of gay liberation (Hirsch \& Enlow, 1984).

Gay men have been studied for their psychological responses to the crisis brought on by HIV and AIDS. During the early years of AIDS, one group of authors described their general response in this way: "What the health crisis seems to be doing is bringing the existential problems of human experience into very sharp focus, which makes for a very high level of anxiety" (Morin, Charles \& Malyon, 19.84). These existential problems include fear of death and dying, fear of lifestyle exposure, fear of contagion, loss of self-esteem, fear of loss of physical attractiveness, fear of decreased social support, fear of increased isolation and stigmatization, fear of loss of occupational and financial status, concerns and confusion over options for medical treatment, and an overwhelming sense of gloom and helplessness (Morin et al, 1984; Catania, Turner, Choi, \& Coates, 1992; Miller, Green, Farmer \& Carroll, 1985; Huggins, Elman, Baker, Forrester, Lyter, 1991; Hirsch \& Enlow, 1984). Other possible effects include change in sexual contact patterns and behaviors, internalized homophobia, emotional and sexual disengagement, and the loss of perceived quality of life (Hirsch \& Enlow, 1984). 
In retrospect, the early $1980^{\prime} \mathrm{s}$ brought about a paradigm shift in the gay community that significantly changed the course of its members' development, life experience, behavior, and strategies for well-being.

Theoretical Understanding of Gay Men in Occupational Therapy

The Model of Human Occupation

The problems that people experience when initially infected by HIV are best conceptualized in occupational therapy theory using a Model of Human Occupation (Kielhofner, 1995). This model serves to guide occupational therapists in their quest to understand and explain the occupational behavior of their clientele, including gay males. Human occupation is defined as "doing culturally meaningful work, play or daily living tasks in the stream of time and in the contexts of one's physical and social world" (Kielfhofner, 1995, p 3).

Proposed by Kielhofner \& Burke (1985), the model of human occupation views the human individual as an open system, that is in perpetual interaction with his environment. As such, an individual's intrinsic characteristics, as well as his environment, and the task itself are all factors that contribute to a gay man's assembly of behaviors. This occurs within a 
process phenomena known as input, throughput, output, and feedback. From this perspective therapy is seen as a process of "enabling active, living entities to change and reorganize themselves" (Kielhofner, 1995, p 4), in contrast to traditional reductionistic models.

A person receives input from the context of his life (e.g. his life history, physical environment, social environment, internal and external feedback) and processes that information internally. This internal processing is termed throughput and is conceptualized by the model as a hierarchy of three internal subsystems related to human performance: volition (those internal factors that influence motivation), habituation (the internalized recurrent patterns of behavior), and performance (the skills and abilities to get things done). Each of these subsystems influences the resulting action taken by the individual. This action is itself human occupation.

Output (i.e. human occupation) from the system is performed and alters the general context of the system (i.e. it alters history, the physical environment, or social relations). This same output also reshapes the internal components of the systems (e.g. it can strengthen self-efficacy, spark an interest, affirm personal mastery in an area). Thus, feedback (both internal and external) to the system is a natural result of engagement in 
occupation. From this vantage point, a gay man can be conceptualized as being an open system in a perpetual, dynamic relationship with the context of his life, both influencing it and being influenced by it.

Within an individual, therefore, subsystems work together to assemble distinct human occupation including role-related activities. Roles in which a gay man participates are chiefly a product of his current habituation subsystem, that subsystem involved in organizing routine behaviors. However, other forces in determining role-related behavior must also be considered. All occupation is intimately and inseparable related to human motivation (i.e. the volition subsystem) so that any roles taken on are based on the individual's values, interests and sense of identity. Similarly, an individual takes on roles which involve activities that he believes he is able to perform (i.e. the performance subsystem). Equally significant, role behaviors are a product of social-environmental expectations of the individual (i.e. the context of his life). Thus, human role behavior must be understood to be a function of the entire dynamic system: all three human subsystems and the life context within which they exist.

The life context is of particular significance to understanding the occupational behavior of gay males. The nature 
of human occupation is innately linked to 1) culture, that group phenomenon by which humans attach meaning to their occupation and to 2) temporality, that human awareness of the passage of time giving experiences particular character (Kielhofner, 1995).

With the onset of personal HIV infection awareness, the individual experiences a succession of changes that provide him with feedback that greatly influences the subsystems. As the disease progresses this feedback eventually takes the form of physical changes (appearance, energy level, physical ailments), changes in functional abilities (to care for self, to enjoy sexuality, to interact with the community), changes in routine of activities (hospitalizations, medicine management, need for more rest, longer times spent in-doors), and changes in psyche (the reality of death approaching, the sick role, dependence on others, libido changes). However, changes in the system also take place with HIV infection prior to any sign of limiting disease. It is hypothesized in this study that personal HIVinfection awareness will impact images of future life satisfaction in asymptomatic individuals and that these images will impact current assessment of life satisfaction as well. The effect of testing positive for HIV has little or no immediate impact on the individual's performance components. However, if an asymptomatic individual is focused on these 
images of future performance, this can affect the current habituation components. There are new roles and habits to take on, and the value of some roles may shift as a result of mortality awareness. New roles may include becoming one's own physical and psychological health manager, patient, support group member, or research volunteer. There might also be a revaluation of traditional work and family roles and a shifting of scheduling priorities (e.g. self care, medicine management, rest or time with family). These issues were intimately explored in this study.

From the very onset of HIV-infection to the end stages of AIDS, the subsystem which can most significantly be affected is the volition subsystem. This subsystem is the center of identity from which a person perceives his sense of well-being which in turn is derived from interpreting all that is happening in the areas of his life. In this sense, a person diagnosed with HIV infection is at greater risk for depression (i.e. depressed volition) due to the many areas of life that are negatively impacted by the virus. This depression can only serve to compound the problems being experienced in the total system. Typically, a depressed volition subsystem results in decreased levels of activity. Decreased activity leads to decreased feedback to the system which in turn further depresses the 
volitional subsystem. In many cases there is a growing sense of loss of control so that personal causation is diminished from thoughts of loss of normal life expectancy, independence and performance. Theoretically, the degree to which an HIV-infected individual can remain engaged in valued roles and activities can greatly influence the ability of this volitional subsystem to adapt to the necessary changes brought on by the virus over time.

\section{Occupational science concepts}

Occupational Science is a social science which has grown out of the field of occupational therapy. The primary focus of occupational scientists is the study of the human being as an occupational being, that is how human beings create and experience meaning through purposeful activity.

Michael Pizzi (1993) considers the concepts of occupational science essential for understanding the role of occupational therapy in the spectrum of HIV care, specifically the concepts of symbolism, control, temporal rhythms, wellness through occupation, occupational roles, and environment. These concepts describe aspects about human occupational behavior that may help a therapist understand the valued roles and activities of HIV- 
infected gay men. The following is a brief summary of these as described by Clark \& Jackson (1990):

Symbolism refers to the phenomenon of an individual's relative value for an activity based on the subjective and internalized meaningfulness of that activity within the person's social and historic context.

Control is the perception of being master of one's destiny. Gay men in particular enjoy feeling that they are "in control" of their physiques, their careers, their preferences, their health. Being infected with a terminal disease, in contrast, often leads to feelings of helplessness and hopelessness, of being forced into a circumstance not of one's own choosing.

Temporal rhythms is a concept that describes the subjective organization of time and occupation which results in a lifestyle of prioritized activity. Individual's often base their choices of career, activity, and roles on preferred or historic temporal rhythms.

Wellness through occupation is synonymous with "activities health". It describes the fundamental principle in occupational therapy of wellness as a product of engagement in productive and meaningful occupations of one's own choosing. Thus, activities health is not a matter of being disease-free, but rather of being in harmony with one's choices for activity within the 
context of one's individual and cultural values, environment, and competencies. Dysfunction is, thus, measured against this ideal.

Occupational science also places emphasis on environment as a factor in understanding the human as an occupational being. It is also known as "context" and includes the physical, social, cultural, and historical dimensions of the individual's experience. This profound concept has been discussed previously in this chapter.

Lastly, occupational role is considered an important concept to understand human occupational behavior. This concept is based on sociology's division of human behaviors into family roles, personal-sexual roles, and occupational roles. This is further developed in the following section.

\section{$\underline{\text { Roles }}$}

\section{Role theory}

Of particular significance to this study is the human phenomenon of roles. Shaw and Costanzo (1970) explain the concept of roles as originating in theater and later being picked up by social scientists including anthropologists, sociologists, and psychologists as a way to explain and understand human behavior. Rather than being a distinct theory, they consider the concept of roles to be a trans-disciplinary 
subject matter that shows up in the literature as isolated constructs, principles, networks of hypotheses, and groups of theories.

Four key ideas common to the concept of roles are described by Biddle \& Thomas (1966): 1) that roles are a function of two persons, an actor and an "other" who may be an individual or a group, 2) that role-related behavior is a function of role expectations and norms, role performance, and role evaluation and sanctioning, 3) that an actor and his behavior are defined by both his position in the social structure and by the roles associated with that position, and 4) that full understanding of roles must integrate components of individual personal identity and reference group behavior.

Important to the understanding of role performance is the idea developed by Sarbin (1966) regarding the intensity of performance. He stated that individuals engage in role-related behavior on a continuum of levels of intensity. Low intensity performance is mechanical and the individual differentiates himself from the behavior in contrast to high intensity performance in which the individual does not differentiate himself from his performance. As such, his identity is linked to his behavior if the behavior involved is performed with high intensity. 
Role expectations and norms are the guiding force in an individual's choice of behavior. They are the "ought" or "should" that influence choice of human actions and have both overt and covert sources of origin. Society devises and imposes role demands; this is an overt source of influence. The individual, on the other hand, devises and imposes his own set of internalized norms or demands, these being the covert source of influence.

Role evaluation is defined as the expression of approval or disapproval toward the role behavior by one-self or by others. Related to this, role sanctioning is a social process by which a resulting action engaged in following role-related behavior is performed in order to maintain positively regarded behavior (i.e. rewarding) or in order to change negatively regarded behavior (i.e. punishing). Both role evaluation and role sanctioning are expressed overtly and covertly. Overtly, they are mental assessments engaged in by others to evaluate an individual's actions. Covertly, they are the individual actor's internal evaluation of himself using assessments better known as values which results in the self-regulation of personal behavior.

Significant to role evaluation and sanctioning is the reference group concept as explained by Kelley (1952). The 
reference group, defined as a group in which an individual is a member or desires membership, is a large source of an individual's value formation. The phenomenon occurs overtly as a function of normative group pressure and covertly by the individual's comparison of himself to the group. For a gay man, this reference group to some extent includes his perception of the gay community. As such, the gay community has demonstrated a normalization of response to individuals with HIV-infection over the last fifteen years beyond that seen in the general population.

Shaw \& Costanzo (1970) considered position another important concept to the understanding of roles. Position is a unit of social culture defined as "a collectively recognized category of persons for whom the basis for such differentiation is their common attribute, their common behavior, or the common reactions of others toward them" (Biddle \& Thomas, 1966, p. 29). This is significant in understanding homosexuals as a group in the U.S. The majority culture, though it refrains from considering homosexuals a minority culture, has frequently used sex orientation as an element of position in society. The concept of role, to a degree, is a function of position (i.e. position in society is associated with distinct role performance). It has, however, many different definitions in 
the literature. The most agreed upon element of role, however, as set forth by Biddle \& Thomas (1966) is that roles are "a set of prescriptions that define the desired behavior of a position occupant." Thus, according to role concepts, position in the social structure and roles associated with that position define an individual and his behavior. Role set is a concept that describes a collection of roles in which an individual participates based on his position in the social structure. Occupational Therapy Literature and Roles

The concept of roles has become a significant part of occupational therapy thinking and treatment. However, this has not always been the case. In 1969, Mary Reilly described a shift that was taking place in the profession of occupational therapy, a shift away from dependence upon the medical model and toward the behavioral science of social psychology (Reilly, 1969). Since then, schools of thought in occupational therapy have incorporated occupational choice, occupational role, and socialization as three important processes to address within the profession.

Occupational role concept is based on sociologists' division of human patterns of behavior into family roles, personal-sexual roles, and occupational roles. Occupational roles include those patterns of behavior that involve task 
performance within the context of a social position and are, thus, an area of significance to occupational therapists. Matsutsuyu (1971) incorporated Schmaltz' model of socialization which emphasized the fact that the learning of occupational roles occurs through socialization, specifically through processes of role maintenance, role learning, or role relearning if there is an interruption in function. This follows with Reilly's vision of the occupational therapy setting as a milieu in which learning relevant to life roles can effectively take place (Reilly, 1966). Among her six specifications for occupational therapy programs she states that an examination of life roles and skills is essential.

These early ideas were further developed over time. One of these developments was a working model known as "the work-play theory" (Shannon, 1972). The premise was that occupational therapy should be directed toward improving the quality of individual's daily activities which are primarily work and play, and that these are related to human adaptation. Black (1976) developed a concept of "the career of roles", careers that all individuals course uniquely from infancy to old age. She based her work on occupational behavior theory and role theory from sociology. "Occupational role acquisition" was a set of concepts developed by Heard (1977) who placed the concept of 
roles into a model based on general systems theory. Furthermore, Kielhofner \& Burke (1985) incorporated the role concepts into "a model of human occupation", which became a reorganization and solidifying of occupational behavior concepts.

With the emerging significance given to the concept of roles in occupational therapy theory, and with its evolution from an abstract conceptualization to a concrete and practical pattern of thought, occupational therapists developed tools for gathering information about their patients' roles. Over time, these have come to include the Occupational History (Moorhead, 1969), the Occupational Role History (Florey \& Michelman, 1982) and most recently, the Role Checklist (Oakley et al., 1986). The Role Checklist has been used extensively in research. It is a written assessment which systematically collects data from an individual regarding several types of occupational roles. The Role Checklist, therefore, provides information on role participation throughout the lifespan and on the degree of value placed on individual roles. The occupational roles used in the checklist are ten in total: student, worker, volunteer, caregiver, home maintainer, friend, family member, religious participant, hobbyist/amateur, and participant in organizations. The criteria used to determine inclusion of these specific roles 
was each role's implication for productive or playful use of time (Oakley et al., 1986).

\section{Developmental models}

In 1993, the New York Times (October 31, 1991) reported that AIDS had become the leading cause of death in young adult men ages 25-44. Young adulthood is typically a time when individuals have finished their training and are eager to live the lives for which they have been preparing. Pattison (1977) determined that young adults are likely to feel more intensely emotional about imminent death than people in any other period of life, being frustrated by their inability to fulfill their dreams. They feel they have worked very hard for nothing. This frustration can turn to rage. Certainly, consideration of development theories is significant to understanding the experience of gay men infected with HIV or with AIDS.

Young adulthood (age 20 to 40 ) is the most frequent age group of men infected by HIV or with AIDS (CDC, 1996). This period of life is typically a time during which decisions are made about intimate relationships and careers, an individual's sense of identity becomes clearer, and complex intellectual abilities are called on by the challenges of life. It is also a time in which physical health and strength peak (Papalia \& Wendkos-Olds, 1992). HIV/AIDS changes all these expectations 
dramatically. In general, a person with HIV infection is transported to a developmental stage of a middle to late adult with issues such as a heightened search for meaning in life, deterioration of physical health and stamina, retirement from work, multiple losses, facing impending death and a "time left to live" temporal orientation.

These men infected with HIV are required to make quick adjustments to these changes in order to function adaptively. Thus, they must shift from a pursuit of achievement to a reintegrative stage of life with selection of pursued tasks based on meaningfulness. In view of Erickson's normative-crisis stages, the shift in development brought on by HIV-infection may be from a crisis between intimacy vs. isolation to one of generativity vs. stagnation or integrity vs. despair (Papalia \& Wendkos-Olds, 1992). These potential shifts in stages of development, though difficult, are not to be considered negatively. Kubler-Ross (1975) wrote that awareness of death is key to personal growth and the development of full human potential:

It is the denial of death that is partially responsible for living empty, purposeless lives; for when you live as if you'll live forever, it becomes too easy to postpone the things you know that you must 
do. In contrast, when you fully understand that each day you awaken could be the last you have, you take the time that day to grow, to become more of who you really are, to reach out to other human beings...For only when we understand the real meaning of death to human existence will we have the courage to become what we are destined to be (pp. 164-165).

It is this awareness of death that can bring about either despair or an awakening to.meaning-filled living.

The grieving process is another developmental aspect that is important to consider with individuals coping with HIV. Kubler-Ross (1969) identified five stages in coming to terms with death: denial, anger, bargaining, depression and acceptance. A more recent model was developed as an adaptation of Kubler-Ross' model based on a case-note review of 153 patients informed of their HIV+ status (Ross, Tebble, Viliunas, 1989). They believed that HIV infection differs from other terminal illnesses in that it is not necessarily terminal, it is superimposed on a stigmatized status associated with.it, and there is considerable uncertainty as to the changes of progression to terminal illness and status of "cures". Stages of reaction that they suggested (ones assuming fluidity and nonprogression) were Shock, Denial, Anger (all together composing 
the traditional Stages $1 \& 2$ ), Withdrawal and Depression (Stage

3), Bargaining (Stage 4) which was further broken down into "coming out" to significant others (Sub-stage A), looking for other HIV+ people (Sub-stage B), Special status (Sub-stage C), Altruistic behavior (Sub-stage D), and lastly Acceptance (Stage 5).

\section{Life Satisfaction \\ Understanding life satisfaction}

Occupational therapists have a primary role in addressing their patients" "illness experience", that is, the way in which illness affects a person's life experience (Mattingly, 1994). At one level, therapists work with individuals in order to improve the functioning of their bodies, but on a higher plane, therapists seek to enhance their client's overall experience with life as it relates to human occupation.

The process of adapting patterns of behavior and thought for the purpose of improving health (physical and metaphysical) and heightening life satisfaction is known as wellness (Opatz, 1985). Life satisfaction as defined by Watson \& Ager (1991) is "a sense of contentment about life domains derived from life events, a sense of contribution and the perceived harmony between expectations and actual outcomes" (p. 34). Among the ten 
goals that Rosenfield (1993) identifies for his wellness program (Wellness and Lifestyle Renewal) are those of participating in activities one enjoys the most, managing personal health, home, and finances effectively, balancing work, leisure, chores and rest, and paying attention to your most valued goals in life. Life satisfaction is a concept described by several terms which are often used interchangeably: well-being, morale, happiness, and contentment. The common concept in all of these terms is that they describe an individual's state of mind regarding life as a whole. Watson \& Ager (1991) reviewed the literature and reported that life-satisfaction is perhaps the issue most commonly investigated among the elderly.

With respect to its measurement, some researchers consider life-satisfaction a multi-dimensional concept, requiring a series of questions about various domains of life. One of these is the Life Satisfaction Index A (LSIA) (Neugarten, Havighurst, \& Tobin, 1961). The alternative to this is to view lifesatisfaction from a global perspective allowing the subject to use those domains of life he considers most salient in his evaluation of overall life-satisfaction. An example of this type of scale is used in Watson \& Ager's (1991) study. They used a global scale in their study of the impact of role valuation and performance on life satisfaction in the elderly. 
They believe that role performance is crucially linked to life satisfaction.

Many other studies similarly link roles with lifesatisfaction (Krause, 1994; Elliot \& Barris, 1987; Gregory, 1983). Dickerson \& Oakley (1994) in their study of roles among patient populations and community individuals determined that roles appear to be affected by disability, whether physical or psycho-social in nature. They also hypothesized that disruption to role performance and life satisfaction is likely when persons acquire conditions that necessitate changes in their life-styles due, in part, to the important component roles have in selfidentity.

Branholm \& Fugl-Meyer (1992) sought to increase the understanding of the relationship between fulfillment of occupational roles and life satisfaction through a study which described the prevalence of preferences for occupational roles in an adult Swedish population. They went on to relate those preferences to levels of life satisfaction. Their hypothesis was that fulfillment of different occupational roles would be positively and characteristically associated with related domains of life satisfaction. Their conclusions supported the idea that the number of roles and the level of meaningful role involvement is related to overall happiness. 
Hettler, the founder of the National Wellness Institute recognizes six equally important components of wellness: social, occupational, spiritual, physical, intellectual, and emotional wellness (McBreen, 1994). These general categories are often further broken down in the professional literature to include factors such as individual psychology, identity, social support, worldview and experience with stress. Some of the most relevant factors to the well-being of gay men are discussed below. Identity

Fundamental to a personal sense of well-being is the individual's perception of himself/herself. For gay men, internalized homophobia can significantly depress that sense of well-being (Malyon, 1982). Internalized homophobia may also exacerbate the degree of distress experienced in becoming infected with HIV. In fact, reaction to HIV infection often echoes the reaction to self-identification as homosexual (Ross, Tebble, Viliunas, 1989). Thus, the development of a positive gay identity is important to the psychological adjustment of this population (Miranda \& Storms, 1989). Miranda \& Storms (1989) identified two coping strategies--self-labeling as gay and selfdisclosure of sexual orientation to others--to be important 
components of positive adjustment in homosexuals leading to decreased levels of reported loneliness, depression and anxiety. Coping style

Coping is a human phenomenon defined as a person's "constantly changing cognitive and behavioral efforts to manage specific external and/or internal demands that are appraised as taxing or exceeding the resources of the person" (Lazarus \& Folkman, p. 19). Wellness is affected not so much by the individual's particular stresses per se as by the way that individual perceives and manages that stressful intrusion into his experience according to a stress and coping model. One study using a 47-item coping inventory sought to understand the relationship of three defined coping styles (active-behavioral, active-cognitive, and avoidance) to affective state among HIVinfected persons (Wolf, et al., 1991). Active-behavioral coping was positively related to lower mood disturbance/ depression and increased vigor as well as increased perceived social support. Avoidance coping was negatively related to these same items, and no relationship was found for active-cognitive coping. These results suggest that persons who mobilize their energies to actively handle their illness and who turn to others for help feel better while those who use avoidance in their thinking and behaving in response to the illness do not. The authors 
speculate that active-cognitive coping perhaps leads more to obsessing rather than positive change and therefore showed no relationship. Furthermore, coping effectively with illness may influence the availability and quality of social support while those who use avoidance coping which fosters a victim-mentality are often less likely to seek, to receive, or to perceive support from others.

Social support

Human beings are social beings and can rarely survive--much less, experience a sense of well-being--without some degree of help from a network of support. As discussed earlier, social support is positively related to psychological adjustment for asymptomatic HIV-infected gay males (Blaney, et al., 1991). Several studies suggest that gays and lesbians, when compared to heterosexuals, value friends over family (of origin) as important sources of support and that their psychological wellbeing was based on perceived support from friends and sexual partners (Kurdek, 1988; Kurdek \& Schmitt, 1987). Another study, however, more precisely suggests that support from family lof origin) may become more important as one approaches death (Catania, Turner, Choi \& Coates, 1992). In effect, HIV-infected gay men may generally value support from peers and sexual partners for a sense of well-being but may experience an 
increasing desire for support from their family of origin as they face decreased function and impending death. Thus, an individual's social-support system needs may vary depending on life and health circumstances.

Worldview/ philosophy

Through the course of on-going experience with life, a person forms images in his mind's eye about the world in which he lives. One's worldview is influenced, often deeply, by the messages that an individual is taught or chooses to accept as spiritual truth. These messages are typically conveyed to the individual through church attendance, religious writings, and people of influence such as parents and teachers. Homosexuals who turn to traditional religion for a guiding spiritual orientation in the task of finding meaning in the midst of their losses often encounter rejection and hostility. Ritter \& O'Neill (1989) make the case that it is no wonder that gay men and lesbians find traditional religion less than viable since it does not provide a useful framework for deriving meaning from their life experience. They further state that the two major principles of Judeo-Christian tradition, in essence, are withheld specifically from homosexuals, those principles being "the unconditional goodness of the human being and the unfailing love of the Creator for each person" (Ritter \& O'Neill, 1989, 
p.9). Without an internalization of messages such as these, a sense of well-being is difficult to attain or sustain.

Stressful life events

Research reveals that physical and psychological health are adversely affected by various stressful life events (Dohrenwend \& Dohrenwend, 1981). In healthy individuals, the function of the immune system in particular has been linked to various types of stress such as exam stress, bereavement and others as summarized by Ceballos-Capitaine, et al. (1990). Other studies demonstrate that gay men from racial minority groups experience unique strains from their migration experience, acculturation process, and from internalized homophobia more prevalent among minority cultures (Ceballos-Capitaine, et al., 1990). These studies are only a small portion of the large volume of research that has linked life stress to health and the immune system (Baum, McKinnon \& Silva, 1987; Blaney \& Antoni, 1990; Glaser, et al., 1987; Levy, Herberman, Lippman \& d’Angelo, 1987; Locke, et al., 1984) and that seek to isolate host variables that effectively moderate the effects of life stressors (Pennebaker, KiecoltGlaser \& Glaser, 1988; Kiecolt-Glaser, Garner, Speicher, Penn \& Glaser, 1984; Broadhead, et al., 1983; Kessler \& Cleary, 1980). Variables that have been studied for their effects on moderating 
stressful events include ethnicity, social status, social support, personality traits, and coping style among others. Occupational performance

All of these components of wellness come to bear to some extent on the occupational performance of the individual. In itself, occupation (the engagement with one's environment through activity) is fundamental to a sense of well-being (McBreen, 1994). This point is an echo of Reilly's (1962) classic statement that "Man, through the use of his hands as they are energized by his mind and will, can influence the state of his own health" (p. 9). One of the major areas of occupational performance identified as being linked to life satisfaction and wellness is that of role performance. Studies in the occupational literature have consistently shown support for the premise that life satisfaction is linked to fulfillment of occupational roles (Branhom \& Fugl-Meyer, 1992; Watson \& Ager, 1991; Elliot \& Barris, 1987; Gregory, 1983). This link between life satisfaction (i.e. perceived quality of life) and an individual's performance of valued roles (i.e. occupational performance) is important for occupational therapists to consider when addressing the needs of gay men infected by HIV. 


\section{Self-reporting}

Self-report measures are subject to distortion by their potential to be incomplete, inconsistent with actual behavior or misinterpreted by the investigator (Merluzzi, Glass \& Genest, 1981). Being aware of these limitations brought on by selfreported measures is the best way of circumventing potential problems. Gavanski \& Hoffman (1987) conducted a study which led them to conclude that people.do possess some form of privileged knowledge concerning influences on their own judgments which can be accessed to increase the accuracy of their self-reporting. When they were given instructions on being attentive to their judgment process, accuracy of the self-report increased. Despite their drawbacks, self-reporting measures are often the best tools to use. When the desired information about a person is his perspective, his attitude, his interpretation of his environment or behaviors, self-report measures may be the only means to access this information, and they provide opportunity to consider the options in a thoughtful, unhurried manner (Merluzzi, Glass, \& Genest, 1981).

\section{Instruments}

The use of surveys as a means of gathering information has been extensive in history, dating back to ancient Egypt (Mann, 
1985). Mann's (1985) review of the occupational therapy research that has used survey methods reveals that the profession has frequently used surveys to answer research questions and that their use is increasing. The reason for this is that the survey has proven to be useful for a wide variety of research problems. It is particularly appropriate for studies which have as their objective the collection of descriptive knowledge about a population as is the case in this particular study.

Throughout the course of investigating the relevant literature, a list of instruments evolved with specific application to investigating wellness and life satisfaction among gay men who are infected with HIV. The following is a description of each of these instruments:

Brief Symptom Inventory: (Derogatis \& Spencer, 1982) This instrument seeks to measure discomfort related to thoughts of death/dying.

The Profile of Mood States (POMS): (McNair, Lorr, \& Droppelman, 1971) This is a self-report instrument measuring current affect derived from subscales of anxiety, anger, depression, confusion, fatigue, and vigor for a total mood disturbance score. 
Interpersonal Support Evaluation List (ISEL): (Cohen, et al., 1984) This is a 40 statement questionnaire which yields an overall measure of functional support from subscales of material aid, appraisal, self-esteem and belonging types of social support.

The Life Experiences Survey: (Sarason, Johnson, \& Siegel, 1978) This instrument measures the impact that changes in life have had on an individual in the past six months using a questionnaire providing a negative impact score.

Competency, Achievement and Quality of Life Assessment and Evaluation: (Marcil \& Tigges, 1992). This informal instrument is based on the occupational behavior model. It assesses five components of quality of life against the concepts of competency and achievement. The information is taken from concurrent assessments of occupational history, locus of control, selfesteem, physical domains, primary caregiver and from interview with the patient.

Psychological Adjustment to Illness Scale: (Morrow, Ciarello \& Derogatis, 1978). This is a scale for assessing patients' psychosocial adjustment to medical illness.

Locus of control assessment: (Reid \& Ziegler, 1981). This is a 16-item list of statements that provide responses using a Likert-scale along a continuum from strongly agree to strongly 
disagree. This tool is a way to measure the degree to which a patient feels he is in control of his life in order to obtain a motivational profile.

Occupational History assessment: (Marcil \& Tigges, 1992). This is a structured interview instrument that seeks to extract an overall view of a person's view of their past and present roles and their future expectations based on occupational behavior principles. It includes questions regarding employment, family history, temporal adaptation and an ADL performance assessment.

Pizzi Assessment of Productive Living for Adults with HIV Infection and AIDS: (Pizzi, 1993). A structured interview designed to extract relevant information for occupational therapists using concepts from the Model of Human Occupation. Domains include demographics, ADL performance, work, play/ leisure, physical function, cognition, time organization, body/ self image, social environment, physical environment, stressors, coping, and occupational questions.

Life Satisfaction Index A (LSIA): (Neugarten, Havighurst \& Tobin, 1961). This tool is designed to measure life satisfaction in light of its multi-dimensional qualities. Its items inquire into life satisfaction along various domains of life in order to measure the concept more comprehensively. 
Lifestyle Assessment Questionnaire: (developed by Bill Hettler and available through the National Wellness Institute at 1-800-243-8694). This is a 281-question survey designed to measure individual levels of wellness defined as a balance between six domains of wellness: social, occupational, spiritual, physical, intellectual and emotional wellness. The instrument is designed to be self-scored with recommendations provided to address areas of noted deficit. 
CHAPTER 3: RESEARCH PROCEDURES \& METHODOLOGY

Research Questions and Hypotheses

This study was carried out in order to answer six primary research questions and test two hypotheses regarding the occupational behavior of gay men:

Q1: What are the valued occupational roles of gay men?

Q2: What factors influence the occupational roles of gay men?

Q3: Do the occupational role configurations of HIV+ gay men differ from those of HIV- gay men?

Q4: What are the occupational role shifts expected by gay men in the future?

Q5: Do the expected occupational role shifts of HIV+ gay men differ from those of HIV- gay men?

Q6: What are the factors that influence life satisfaction among gay men?

Sub-Q A: What is the relationship of role frequency, role valuation, autonomy of role participation and enjoyment of role participation to overall life satisfaction in gay men?

Sub-Q B: What is the actual and perceived impact of HIV infection on the life of a gay man? 
Sub-Q C: Is there a difference between actual and perceived impact of HIV on life among HIV-infected and noninfected gay men?

Sub-Q D: What shift in life satisfaction do gay men expect in the future?

Sub-Q E: Do the expected shifts in life satisfaction differ between HIV+ and HIV- gay men?

H1: A diagnosis of HIV infection negatively impacts life satisfaction among gay men.

H2: Gay men who have been given a diagnosis of HIV infection have higher variance in life satisfaction scores than uninfected gay men.

\section{Subjects}

A total of 80 subjects were recruited from Dade and Broward Counties to participate. Inclusion criteria for this study were the following: subjects were males, between the ages of 18 and 55, who voluntarily self-identified as homosexual or predominantly homosexual, who were willing to answer questions regarding their personal experience with HIV (i.e. whether they believed they were HIV-positive or HIV-negative), and who either reported to be in good health or if HIV-infected reported to be asymptomatic. Individuals who volunteered but who were excluded 
from the study were those with any significant physical or mental chronic conditions which significantly limited their life activities, several female volunteers who joined as part of a group presentation, and two persons who were unable to complete the questionnaire due to language difficulties. Participation was voluntary, and questionnaires were answered anonymously. This proposal and the questionnaire were reviewed and approved by a representative of Florida International University's Human Subjects Committee.

Subjects were recruited as individuals and in group settings at contact sites in Dade and Broward counties. Sites included the following: support groups at the Metropolitan Community Church of Greater Ft. Lauderdale, Body Positive Resource Center in Miami, groups that met at the Gay, Lesbian, Bisexual Community Center in Ft. Lauderdale, support groups at Center one in Ft. Lauderdale, and other community-based social support and interest groups (e.g. Gay Men's Chorus, political action groups). In addition, several individual volunteers were recruited from personal referrals as well as from responses to a flyer handed out at previously mentioned group gatherings. 


\section{Design of the Study}

The questionnaire developed for this study was based on relevant issues identified in studies by Branholm \& Fugl-Meyer on a Swedish population (1992) and by Watson \& Ager on a geriatric population (1991). Both of these studies sought to understand the relationship of valued occupational roles and life satisfaction in these very general populations. The questionnaire used in this study contained five sections developed by the investigator: 1) a preliminary screening tool, 2) a general information section, 3) The Valued Occupational Roles Inventory, 4) The Life Satisfaction Inventory, and 5) The Attitudes About HIV-infection Survey (refer to Appendix for the complete questionnaire). Each section of the questionnaire was developed by the investigator based on a review of the current literature and in consultation from members of his thesis committee over a period of several months.

A pilot test of the initial version of the questionnaire was conducted on ten gay male volunteers in Broward County from various socio-economic backgrounds. Pilot participants were asked to fill out the questionnaire to the best of their ability and to write out any questions in the margins regarding the clarity of the wording, format or meaning of any of the items. Open-ended interviews were also conducted with participants to 
collect further feedback on the experience of filling out the questionnaire. As part of the pilot test, participants also documented the time it took to complete the questionnaire. This ranged from 25 to 40 minutes.

Instrument

A simple five-question screening instrument entitled "Can I be a part of this study?" was used to help volunteers determine whether or not they met the criteria for inclusion in the study before proceeding to fill out the questionnaire. The items in this section were not included in the database.

The general information section opened the questionnaire with a series of questions (Q1-42) aimed at exploring common demographic and lifestyle characteristics deemed relevant to addressing the research questions and hypotheses. Each question was followed by a finite number of responses from which to choose, and the subjects were asked to circle the answer that best approximated their situation or opinion.

The Valued Occupational Roles Inventory has two sections which are separated by other sections of the total questionnaire: 1)current valued occupational roles and 2) expected valued occupational roles five to ten years in the future. Its development was based on the Role Checklist (Oakley et al., 1986) and suggestions made by Watson \& Ager (1991) and 
Branholm \& Fugl-Meyer(1992). Modifications and additions were made to the instrument in an attempt to make the role categories more specific and relevant to homosexual males. The questionnaire lists 24 individual occupational roles (as opposed to 10 used in the Role Checklist) with definitions and examples of each. Subjects were asked to answer four questions for each role. The questions covered 1) frequency of participation in the role, 2) level of value placed on the role, 3) degree of autonomy of participation in. the role, and 4) the degree of enjoyment derived from participation in the role.

Answer options were developed to provide a continuum of answers sensitive to change. The answer options for role frequency were "never", "rarely (3-4 times per year)", "occasionally (once per month or so)", "frequently (3-4 times per month)", "very often (2-4 times per week)", and "daily (or just about)". The answer options for role valuation were "not at all important to me", "somewhat important to me", "moderately important to me", "quite important to me", and "extremely important to me". The answer options for autonomy in 'role participation were "want to participate" , "mixture of wanting to and having to participate", and "have to participate". The answer options for enjoyment in role participation were "dislike participating", "don't mind participating or neutral" and "enjoy 
participating". The full scale of answer options was provided for each role in a grid format.

The Life Satisfaction Inventory also had two sections: current life satisfaction and expected life satisfaction five to ten years in the future. The subjects were asked to rank each item on a 7-point likert scale ranging from "very dissatisfying" to "very satisfying". The scale used for this study was a revised version of the scale used by Branholm \& Fugl-Meyer (1992) which is both a global and a domain specific scale. The authors of the original scale reported that they had demonstrated "reasonable construct validity and internal consistency of the checklist" (Branholm \& Fugl-Meyer, 1992, p. 163). Two revisions were made to this scale: 1) a category of "neutral or mixed feelings" was added making it a 7-point scale rather than a 6-point one, and 2) domains were added which were deemed necessary to match identified roles in The Valued Occupational Roles Inventory and to include areas considered important to homosexual males. The domains added to the scale were "psychological health", "physical health", "spiritual life", and "level of community involvement". In addition, the original domain of "family life" was broken down into "caregiver relationships", "family of origin relationships", and "family of choice relationships". 
The Attitudes About HIV-infection Survey is a series of 15 questions with limited responses. The first eight questions were only to be answered by participants who believed they are HIV-positive and the last seven questions were to be answered only by participants who believed they are HIV-negative. The purpose of this section was to determine any differences in attitudes between the two groups regarding how personal HIVinfection is perceived to impact an individual's life.

A copy of the entire questionnaire is included in the Appendix.

\section{Procedure}

Subjects were addressed by the investigator individually and in groups at the places listed previously. Accessing these groups required initially securing permission from administrators or group leaders in order to address the group. In most cases, the investigator was granted permission and given 30 minutes to an hour of the groups' regular meeting times. Members of these groups (i.e. potential volunteers) were verbally provided with basic information about the purpose and content of the study and then asked for their participation. Those who wished to fill out the questionnaire stayed on and were provided with written information regarding the study and the questionnaire. A standard procedure was followed in the 
administration of the questionnaire. Individual questions or concerns were addressed by the investigator on a one-to-one basis throughout the group session. The questionnaires were collected and coded with a number as they were entered into the database. No personal identification information was requested on the questionnaire to protect the confidentiality and anonymity of the subjects. For those who wished to be contacted for study results or future follow up research, the option of filling out a separate identification sheet was provided. These sheets were kept in a separate confidential file.

\section{Statistical Analysis}

Standard descriptive statistics (mean, frequency, variance, and crosstabs) were used to analyze the demographic information obtained from the sample. Three groupings were used in analyzing the data: 1) all subjects (both infected and non-infected), 2) HIV-infected gay men $(\mathrm{HIV}+)$ and 3) non-infected gay men (HIV-). Chi-square tests were used to compare the HIV+ and HIV-groups with respect to demographic variables that provided ordinal data.

Q1: What are the valued occupational roles of gay men? 
Information derived from The Valued Occupational Role Inventory was used in answering this question. Frequencies, means and variances were calculated for each of the 24 roles in all four categories of frequency, valuation, autonomy, and enjoyment. This information was reported by groupings (all, HIV+, HIV-) and by time (current and expected).

Q2: What factors influence the occupational roles of gay men?

Spearman's rank correlation coefficients $\left(r_{s}\right)$ between ordinal demographic information items and The Valued Occupational Roles Inventory items which distinguishes between role frequency, valuation, autonomy and enjoyment were calculated in order to identify possible relationships.

Q3: Do the occupational role configurations of HIV+ gay men differ from those of HIV- gay men?

Means and variances of all items in The Valued Occupational Role Inventory were compared between HIV+ and HIV- gay men using $t$ tests and $F$ tests. All 24 occupational roles were compared between groups as to frequency, valuation, autonomy and enjoyment. In addition, roles were ranked in descending order of valuation and these ranked lists were compared between groups. 
Q4: What are the occupational role shifts expected by gay men 5 to 10 years from now?

Two methods were used to calculate shifts in occupational roles: 1) pair-wise comparisons within each group's mean current score and mean expected score were carried out, and 2) a new variable of expected role shift was calculated for each subject by subtracting the expected score from the current score (current minus expected). This variable was then described using means and variances. In addition, a ranked list of roles with descending degrees of expected shift was compiled.

Q5: Do the expected occupational role shifts of HIV+ gay men differ from those of HIV- gay men?

This variable of expected role shift was further analyzed using $t$ tests and $F$ tests to determine differences in means and variances between HIV+ and HIV- groups. Each group's expected role shifts were also ranked and listed separately in descending order for comparison.

Q6: What are the factors that influence life satisfaction among gay men? 
Information derived from The Life Satisfaction Inventory was used in conjunction with demographic information and The Valued Occupational Role Inventory to answer this question. Spearman's correlation coefficients $\left(r_{s}\right)$ were calculated between life satisfaction scores and responses to The Valued Occupational Role Inventory (current and expected) as well as between life satisfaction scores and ordinal demographic variables in order to identify possible relationships between them. In these analyses, three methods were used to calculate life satisfaction scores: 1) the reported global life satisfaction scores were based on subjects' answers to the single global life satisfaction question, 2) the fourteen individual life satisfaction domain scores and 3) the calculated global life satisfaction score which was the mean of all fourteen life satisfaction domain scores for each subject.

Q6/ Sub-Q A: What is the relationship of role frequency, role valuation, autonomy of role participation and enjoyment of role participation to overall life satisfaction in gay men?

Spearman's rank correlation coefficients $\left(r_{s}\right)$ were calculated between life satisfaction scores (both reported global and calculated global) and The Valued Occupational Role Inventory to answer this question. 
Q6/ Sub-Q $B$ and Sub-Q C: What is the actual and perceived impact of $H T V$ infection on the life of a gay man? Is there a difference between actual and perceived impact of $H I V$ on life among $H I V-$ infected and non-infected gay men?

The effects of HIV infection on life satisfaction were studied in particular using information derived from the Attitudes About HIV-infection Survey. Means and variances were calculated for each item. Of the eight questions addressed to the HIV+ group and the seven addressed for the HIV-group in this section, six questions from each set were parallel in nature posing the item differently for each group. These questions sought to understand each group's perception of how HIV impacts a person's life; the HIV+ group was asked how HIV had impacted their personal, and the HIV- group was asked how they would expect HIV to impact their personal life. Answers to these parallel questions were then analyzed as a whole. To compare between groups, $t$ tests and $F$ tests were carried out in analyzing means and variances of the ordinal data questions and chi-square $\left(\chi^{2}\right)$ calculations were carried out in analyzing the categorical data. 
Q6/ Sub-Q D \& Sub-Q E: What shift in life satisfaction do gay men expect 5 to 10 years from now? Do the expected shifts in life satisfaction differ between HIV+ and HIV- gay men?

Answer to sub-questions $D$ and $E$ were sought using similar methods used with determining expected role shifts: 1) pair-wise comparisons within each group's mean current score and mean expected score were carried out, and 2) a new variable of expected satisfaction shift was calculated for each subject by subtracting the expected score from the current score (current minus expected). This variable was then described using means and variances, and further analyzed with $t$ tests and $F$ tests to determine differences between groups.

$H 1$ and H2: 1) A diagnosis of $H I V$ infection negatively impacts life satisfaction among gay men and 2) gay men who have been given a diagnosis of HIV infection have higher variance in life satisfaction scores than uninfected gay men.

$T$ tests and $F$ tests were used to compare means and variances on all life satisfaction indexes (current, expected, and expected satisfaction shift) between both groups in order to test both of these hypotheses.

In all statistical analyses, a predetermined significance of $p<0.05$ was used. 


\section{Limitations of the study}

Due to the nature of the research design and the nature of the population being investigated, several limitation to the study are noted:

1. No cause-effect relationships can be determined. The study sought to explore factors that influence the occupational behavior and life satisfaction of gay men.

2. Sampling difficulties inherent to research among the homosexual community results in an inability to obtain a representative sample of homosexual males (Gonsiorek, 1982).

A study that uses volunteers therefore, can result in skewing of the data that is reflective of qualities shared by this group (i.e. volunteerism, help-seeking behaviors, socialseeking behaviors, South Florida residency) as opposed to those who refused or never frequent these meetings and places. The intent of the study is to describe general trends in this population, but the results cannot be generalized to all homosexual men.

3. To allow for statistical analysis, questions were designed with limited response options. Hence, the questionnaire may not capture all the information relevant to gay men's life satisfaction and occupational behavior since it may not 
provide the precise answer options or necessary questions that reflect their true opinions and concerns. The preliminary pilot testing of the questionnaire was conducted in an effort to minimize this limitation.

4. In research designs which use self-reporting, participants may potentially respond to items in a socially desirable or idealistic way. This tendency can cloud the accuracy of the information and opinions reported. Making the questionnaire anonymous was done in the hope of encouraging full honesty.

5. The use of items which require responses on a Likert scale gives no guarantee that respondents sense the magnitude of each response in the same way. Effort was made to make the range of the scales used as wide as possible in order to capture more meaningful data. The analysis is limited to those methods appropriate to ordinal data.

6. No reliability or validity studies were made on the instrument in its present form. It was, however, subjected to a preliminary pilot test with the participation of ten gay men from varying socioeconomic positions in an effort to improve the face validity and reliability of the instrument. No formal studies, however, were conducted. 
CHAPTER 4: RESULTS

Characteristics of Respondents

Of the 80 subjects who volunteered to fill out the questionnaire, 39 reported to be infected by HIV (HIV+) and 41 reported being uninfected by HIV (HIV-). They had a mean age of 36.0 years $(S D=8.4)$. All reported being either "exclusively homosexual" (93\%) or "bisexual (mostly homosexual)" (7\%). As a group, $94 \%$ of the sample had some level of college education or greater. Gross annual household income was distributed fairly evenly across the spectrum with $23 \%$ earning less than $\$ 20 \mathrm{~K}, 45 \%$ earning between $\$ 20 \mathrm{~K}$ and $\$ 50 \mathrm{~K}$, and $32 \%$ earning over $\$ 50 \mathrm{~K}$. The sample was predominantly white-Americans (81\%) with some African-Americans and Hispanic-Americans reporting as well (19\%). A majority of subjects came from traditional JudeoChristian heritage (61\%) with a significant portion reporting other non-Judeo-Christian belief systems (16\%) such as Science of Mind and Scientology or no spiritual affiliation (23\%).

Chi-square $\left(\chi^{2}\right)$ tests and $t$ tests were used to determine any differences in demographics between HIV+ and HIV- groups. of the 42 variables investigated by the questionnaire, differences between groups surfaced in only nine areas.

1. The HIV+ group was, on average, older than the HIVgroup, $t=3.13, p=0.002$, by 5.6 years with the HIV+ group 
mean age being 38.7 years $(S D=7.8)$ as compared to the HIVgroup mean age being 33.10 years $(S D=8.4)$.

2. Employment status differed, $\chi^{2}(2, N=80)=15.16, p<$ 0.001 , in that only $44 \%$ of the HIV+ group worked in full time jobs as compared to $80 \%$ of the HIV- group. This was also reflected in the fact that a much larger portion of the HIV+ group was unemployed or disabled (46\%) than the HIV- group (8\%).

3. The HIV+ group had identified with a homosexual orientation longer than the HIV- group, $\chi^{2}(3, N=80)=15.31, p$ $=0.002$. A greater portion of the HIV+ group had identified as homosexual for greater than 10 years (85\%) when compared to the HIV- group (53\%). This may be explained by the higher mean age of the HIV+ group.

4. Moderate differences in use of mood altering drugs was noted, $\chi^{2}(3, N=78)=8.50, p=0.037$. In general, the HIV+ group reported more frequent use of mood altering drugs than the HIV- group. Specifically, 54\% of the HIV+ group reported some use of mood altering drugs compared to $26 \%$ of the HIV- group.

5. Only marginal differences in use of alcohol to the point of intoxication were noted, $\chi^{2}(3, N=80)=7.49, p=0.058$. The HIV+ group showed more variance with $44 \%$ reporting never becoming intoxicated, $44 \%$ reporting moderate frequency of intoxication and $12 \%$ reporting frequent intoxication (once a 
week or more). In comparison, the $36 \%$ of HIV-group reported never becoming intoxicated, $63 \%$ reported moderate frequency of intoxication, and $0 \%$ reported frequent intoxication (once a week or more).

6. General health status differences were expected and found, $\chi^{2}(3, N=80)=13.85, p=0.003$. The greatest difference between the groups was in the category of no illness symptoms with 56\% of the HIV- group reporting no symptoms as compared to only $20 \%$ of the HIV+ group. Minor symptoms of illness were experienced by $36 \%$ of the HIV- group and by $63 \%$ of the HIV+ group. Only $17 \%$ of the HIV+ group and $8 \%$ of the HIV- group reported significant symptoms of illness.

7. It was expected and discovered, then, that some differences in experiencing chronic health conditions were also present, $\chi^{2}(1, N=80)=9.27, p=0.002$. While the majority of each group reported no chronic physical or mental conditions which affected their daily activities, $32 \%$ of the HIV+ group reported the presence of a chronic condition other than their HIV status compared to $5 \frac{\circ}{\circ}$ if the HIV- group.

8. Differences were noted between the groups in subjects' self-assessment of their knowledge of the human immunodeficiency virus $(\mathrm{HIV}), \chi^{2}(3, N=80)=10.96, p=0.012$. In general, the HIV+ group reported that their level of knowledge was higher 
than that of HIV-group. However, greater variance was noted among the HIV+ group, $F(1,80)=1.96, p=0.039$, in that $15 \%$ of this group reported their level of knowledge to be inadequate compared to $3 \frac{\%}{5}$ of the HIV- group. This can be explained by the fact that those infected by HIV might feel that they need to know more than average about HIV than those who are not infected. The differences noted were in subjects' perceptions of their knowledge, not in objective levels of knowledge.

9. Finally, differences in levels of openness with families of origin regarding their sexual orientation were noted between the groups, $\chi^{2}(3, N=80)=13.63, p=0.001$. Those who were infected with HIV reported being more open with only 5\% reporting not being open compared to $39 \%$ of HIV-group reporting the same.

Relationships between demographic variables Demographic items that provided ordinal data from the general information section of the questionnaire were tested using Spearman's rank correlation to identify any relationships. Nominal data items that were not tested included employment status, religion, race, and male and female significant other status. Special attention was given to those variables that showed a relation to item 39 ("general attitude toward life") 
for its similarity to the global life satisfaction item. This question provided answers ranging from "life is great" to "life is terrible". Significant correlation was defined as $p<0.05$.

One strong positive relationship was found between greater satisfaction with number of friendships and greater satisfaction with depth of friendships $\left(r_{s}=0.80, p<0.001\right)$

Other expected relationships were only moderately strong: greater openness (low scores) on openness about orientation with family of origin correlated with greater acceptance (high scores) on level of acceptance of orientation within family of origin $\left(r_{s}=-0.70, p<0.001\right)$; fewer chronic health conditions with better general health $\left(r_{s}=0.60, p<\right.$ $0.001)$; greater age with greater length of homosexual orientation $\left(r_{s}=0.59, p<0.001\right)$ more comfortable feelings about personal sex behavior with more comfortable feelings about personal sex orientation $\left(r_{s}=0.54, p<0.001\right)$; and more optimistic attitude toward people with greater satisfaction with number of friendships $\left(r_{s}=0.54, p<0.001\right)$. In addition, five items (attitude towards life, attitude towards people, self-esteem, coping strength and perceived level of daily stress) all showed moderate strength relationships between one another. These are summarized in Table 1. 
Table 1

Inter-relations between general attitude, coping and stress items

\begin{tabular}{lccccc}
\hline & Life & People & Self & Coping & Stress \\
& $r_{s}$ & $r_{s}$ & $r_{s}$ & $r_{s}$ & $r_{s}$ \\
Life & -- & $0.47 \star \star \star$ & $0.49 \star \star \star$ & $0.58 \star \star \star$ & $-0.40 \star \star \star$ \\
People & & -- & $0.49 \star \star \star$ & $0.51 \star \star \star$ & $-0.26 \star$ \\
Self & & -- & $0.42^{\star \star \star}$ & $-0.30 \star$ \\
Coping & & & -- & $-0.25 \star$ \\
Stress & & & & -- \\
\hline
\end{tabular}

Note. $r_{s}=$ Spearman's rank correlation coefficient. "Life" = general attitude toward life (lower = greater optimism). "People" = general attitude toward people (lower = greater optimism). "Self" = general attitude toward self (lower = greater self-esteem). "Coping" = strength of general coping style (lower = stronger coping style). "Stress" = perceived level of daily stress (lower = higher stress). $\star p<0.05, \star \star p<0.01, \star \star \star p<0.001$.

A few of the lower strength relationships were also of particular interest to this study. More optimistic attitude toward people correlated with greater general support from family of origin $\left(r_{s}=0.44, p<0.001\right)$ and with greater satisfaction with depth of friendships $\left(r_{s}=\right.$ $0.44, p<0.001)$. Greater length of homosexual orientation correlated with greater openness (low scores) on openness about orientation with family of origin $\left(r_{s}=-0.43, p<\right.$ $0.001)$ and with a positive HIV status $(1=$ negative, $2=$ 
positive $)\left(r_{s}=-0.42, p<0.001\right)$. Of special interest to this study, greater self-esteem (low scores) on attitude toward self was found to correlate with having a confidant $(1=$ no confidant, 2 = have a confidant $)\left(r_{s}=-0.40, p<\right.$ 0.001). Lastly, greater optimism (lower scores) on general attitude toward life showed correlation with lower stress levels (higher scores) on daily stress level $\left(r_{s}=-0.40, p\right.$ $<0.001)$. The implications of these relationships is discussed in Chapter 5.

Research Questions

Q1: What are the valued occupational roles of gay men?

Tables 2-5 summarize the findings by ranking the 24

occupational roles by descending frequency (Table 2), descending value (Table 3), descending autonomy of participation (Table 4) and descending enjoyment of participation (Table 5) for all 80 subjects as a single group.

Mean role frequency ranged from 5.80 (nearly daily) to 2.25 (rarely) with self care manager, personal activity manager and worker in home leading the list. All role frequencies combined yielded a mean of 4.09 . 
Table 2

Ranked Current Role Frequency by All Respondents $(n=80$ )

Current Roles

All current roles combined

1. Self care manager

2. Personal activity manager

3. Worker in home

4. Relaxation Participant

5. Physical health manager

6. Low Energy activity participant

7. Friend

8. Personal finance manager

9. Choice family member

10. Worker out of home

11. Individual activity participant

12. Psychological health manager

13. Informal Group activity participant

14. Sexual activity participant

15. Outdoor activity participant

16. Family of Origin member

17. Spiritual activity participant

18. High Energy activity participant

19. Pet owner

20. Primary Partner

21. Formal Group activity participant

22. Volunteer

23. Caregiver

24. Student

$M \quad S D$

4.09

0.60

5.80

0.69

5.22

1.08

5.05

1.37

4.95

1.32

4.91

1.23

4.81

1.07

4.67

1.21

4.66

1.28

4.62

1.33

4.47

2.06

4.42

1.36

4.30

1.44

4.03

0.92

4.00

1.29

3.95

1.21

3.87

1.43

3.65

1.59

3.57

1.48

3.55

2. 31

3.42

2.16

3.11

1.30

2.85

1.50

2.82

1.70

2.25

1.48

Note. Answer codes: $6=$ "daily", $5=$ "very often", $4=$ "frequently", $3=$ "occasionally", $2=$ "rarely", $1=$ "never". 
Table 3

Ranked Current Role Valuation by All Respondents $(n=80)$ Current Roles

$M \quad S D$

\begin{tabular}{|c|c|c|}
\hline All current roles combined & 3.88 & 0.56 \\
\hline 1. Self care manager & 4.54 & 0.87 \\
\hline 2. Friend & 4.41 & 0.80 \\
\hline 3. Primary Partner & 4.28 & 1.06 \\
\hline 4. Choice family member & 4.21 & 0.94 \\
\hline 5. Personal activity manager & 4.21 & 0.86 \\
\hline 6. Physical health manager & 4.21 & 0.94 \\
\hline 7. Relaxation Participant & 4.12 & 1.13 \\
\hline 8. Individual activity participant & 4.10 & 1.13 \\
\hline 9. Personal finance manager & 4.05 & 1.06 \\
\hline 10. Informal Group activity participant & 4.03 & 0.87 \\
\hline 11. Sexual activity participant & 4.00 & 1.01 \\
\hline 12. Psychological health manager & 3.91 & 1.10 \\
\hline 13. Worker out of home & 3.91 & 1.27 \\
\hline 14. Low Energy activity participant & 3.82 & 0.96 \\
\hline 15. Outdoor activity participant & 3.79 & 1.06 \\
\hline 16. Family of Origin member & 3.78 & 1.09 \\
\hline 17. Worker in home & 3.69 & 1.23 \\
\hline 18. Spiritual activity participant & 3.64 & 1.59 \\
\hline 19. Caregiver & 3.62 & 1.33 \\
\hline 20. High Energy activity participant & 3.51 & 1.25 \\
\hline 21. Volunteer & 3.48 & 1.19 \\
\hline 22. Pet owner & 3.42 & 1.56 \\
\hline 23. Formal Group activity participant & 3.21 & 1.28 \\
\hline 24. Student & 2.95 & 1.35 \\
\hline
\end{tabular}

Note. Answer codes: 5 = "extremely important", 4 = "quite important", 3 = "moderately important", 2 = "somewhat important", 1 = "not at all important". 
Table 4

Ranked Current Role Autonomy by All Respondents $(n=80)$

Current Roles $M \quad S D$

\begin{tabular}{|c|c|c|}
\hline All current roles combined & 2.55 & 0.29 \\
\hline 1. Friend & 2.87 & 0.38 \\
\hline 2. Individual activity participant & 2.87 & 0.34 \\
\hline 3. Choice family member & 2.84 & 0.47 \\
\hline 4. Primary Partner & 2.82 & 0.43 \\
\hline 5. Informal Group activity participant & 2.80 & 0.46 \\
\hline 6. Sexual activity participant & 2.80 & 0.43 \\
\hline 7. Low Energy activity participant & 2.78 & 0.48 \\
\hline 8. Relaxation Participant & 2.77 & 0.48 \\
\hline 9. outdoor activity participant & 2.72 & 0.45 \\
\hline 10. Spiritual activity participant & 2.67 & 0.61 \\
\hline 11. Formal Group activity participant & 2.62 & 0.58 \\
\hline 12. High Energy activity participant & 2.62 & 0.60 \\
\hline 13. Volunteer & 2.59 & 0.62 \\
\hline 14. Pet owner & 2.57 & 0.68 \\
\hline 15. Psychological health manager & 2.52 & 0.69 \\
\hline 16. Family of Origin member & 2.44 & 0.67 \\
\hline 17. Caregiver & 2.41 & 0.69 \\
\hline 18. Self care manager & 2.35 & 0.74 \\
\hline 19. Personal activity manager & 2.31 & 0.74 \\
\hline 20. Student & 2.30 & 0.79 \\
\hline 21. Physical health manager & 2.29 & 0.68 \\
\hline 22. Worker out of home & 2.23 & 0.68 \\
\hline 23. Worker in home & 2.04 & 0.72 \\
\hline 24. Personal finance manager & 1.96 & 0.84 \\
\hline
\end{tabular}

Note. Answer codes: 3 = "want to participate", 2 = "mix of wanting to and having to participate", 1 = "have to participate". 
Table 5

Ranked Current Role Enjoyment by All Respondents $(n=80)$

\begin{tabular}{|c|c|c|c|}
\hline & Current Roles & $M$ & $S D$ \\
\hline All & current roles combined & 2.64 & 0.24 \\
\hline 1. & Informal Group activity participant & 2.93 & 0.25 \\
\hline 2. & Friend & 2.91 & 0.33 \\
\hline 3. & Low Energy activity participant & 2.88 & 0.33 \\
\hline 4. & Individual activity participant & 2.87 & 0.34 \\
\hline 5. & Primary Partner & 2.85 & 0.40 \\
\hline 6. & Relaxation Participant & 2.85 & 0.39 \\
\hline 7. & Sexual activity participant & 2.83 & 0.41 \\
\hline 8. & Choice family member & 2.81 & 0.46 \\
\hline 9. & outdoor activity participant & 2.80 & 0.44 \\
\hline 10. & Formal Group activity participant & 2.75 & 0.50 \\
\hline 11. & Volunteer & 2.74 & 0.48 \\
\hline 12. & Spiritual activity participant & 2.72 & 0.64 \\
\hline 13. & High Energy activity participant & 2.71 & 0.54 \\
\hline 14. & Pet owner & 2.70 & 0.59 \\
\hline 15. & Worker out of home & 2.60 & 0.56 \\
\hline 16. & Psychological health manager & 2.58 & 0.53 \\
\hline 17. & Family of Origin member & 2.56 & 0.60 \\
\hline 18. & Student & 2.55 & 0.68 \\
\hline 19. & Self care manager & 2.52 & 0.56 \\
\hline 20. & Personal activity manager & 2.47 & 0.60 \\
\hline 21. & Physical health manager & 2.46 & 0.65 \\
\hline 22. & Caregiver & 2.45 & 0.57 \\
\hline 23. & Worker in home & 2.21 & 0.70 \\
\hline 24. & Personal finance manager & 1.96 & 0.78 \\
\hline
\end{tabular}

Note. Answer codes: 3 = "enjoy participating", $2=$ "neutral or don't mind participating", 1 = "dislike participating". 
Mean role value ranged from 4.54 (between quite important and extremely important) to 2.95 (moderately important) with self-care manager, friend, and primary partner leading the list. The mean value for all roles combined was 3.88. All roles for the most part were at least moderately important to the sample group.

The mean level of autonomy in role participation ranged from 2.87 (on a scale from 1 to 3 ) to 1.96 meaning that all roles except personal finance manager are performed with a minimum score of 2 ( $\mathrm{mix}$ of wanting to and having to). The roles in which the sample felt most autonomous were friend, individual activity participant, choice family member and primary partner.

The mean level of enjoyment in role participation ranged from 2.93 to 1.96 (on a scale from 1 to $3,1=$ "enjoy", $2=$ "neutral or mixed" and 3 = "dislike") with informal group activity participant, friend, low energy activity participant, individual activity participant, primary partner, relaxation participant, sexual activity participant and choice family member leading the list of roles that are enjoyed with means over 2.80. The only role whose mean was lower than 2.0 (neutral or mixed) was personal finance manager. 
Q2: What factors influence the occupational roles of gay men?

Table 6 lists the demographic variables that showed significant correlation (Spearman's rank) with current roles greater than $r_{s}=0.22, p<0.05$. In general, greater frequency, greater value, greater autonomy and greater enjoyment of occupational role participation were highly correlated with more optimistic attitude toward life, more optimistic attitude toward people, greater knowledge of HIV, greater self-esteem, and more frequent levels of political activism.

Greater frequency (high scores) on overall role frequency in the entire sample was most highly correlated with greater optimism (lower scores) on general attitude toward life $\left(r_{s}=-\right.$ $0.53, p<0.001$ ), greater optimism (lower scores) on general attitude toward people $\left(r_{s}=-0.43, p<0.001\right)$ and greater perceived knowledge (lower scores) on knowledge of HIV $\left(r_{s}=-\right.$ $0.43, p<0.001)$. 
Table 6

Correlation of Demographic Variables With Current Roles $(n=80)$

Demographic Variable

$\begin{array}{cccc}\text { Freq } & \text { Value } & \text { Auto } & \text { Enjoy } \\ r_{s} & r_{s} & r_{s} & r_{s}\end{array}$

Age

Social climate:

$0.26^{\star}$

Residence

(low $=$ hostile)

Social climate:general

(low = hostile)

Social political views

(low = conservative)

Political activism

$0.39 \star \star \star$

$0.24 *$

0.28 *

(low $=$ never)

Feelings: sex behavior

(low = comfortable)

Family support:general

$0.22^{\star}$

(low = non-supportive)

Number of friends

(low = very satisfied)

Confidant

$0.40 \star \star \star \quad 0.23^{\star}$

(1 = no, 2 = yes $)$

Physical health status

0.24 *

$0.25^{\star}$

$-0.24 *$

(low = excellent)

Daily stress levels

$-0.23^{\star} \quad-0.27$ *

(low = very high)

Table continues on next page

Note. $r_{s}=$ Spearman's rank correlation coefficient.

$\star p<0.05,{ }^{\star \star} p<0.01,{ }^{\star \star \star} p<0.001$. 
Table 6 (continued)

Correlation of Demographic Variables With Current Roles $(n=80)$

Demographic Variable Current Role

$\begin{array}{cccc}\text { Freq } & \text { Value } & \text { Auto } & \text { Enjoy } \\ r_{s} & r_{s} & r_{s} & r_{s}\end{array}$

Knowledge of HIV

$\begin{array}{llll}-0.43^{\star \star \star} & -0.26^{\star} & -0.22^{\star} & -0.34^{\star \star}\end{array}$

(low = greater)

Attitude toward life

$-0.53^{\star \star \star} \quad-0.49 \star \star \star \quad-0.35^{\star \star} \quad-0.52^{\star \star \star}$

(low $=$ more optimism)

Attitude toward people

$-0.43^{\star \star}$

$-0.30 \star \star$

$-0.32 \star \star$

$-0.50 \star \star \star$

(low $=$ more optimism)

Self esteem

$-0.40 \star \star \star \quad-0.24 *$

$-0.38^{\star \star}$

(low = high esteem)

Coping style

$-0.41^{\star \star \star}-0.35 \star \star$

(low = stronger)

Note. $r_{s}=$ Spearman's rank correlation coefficient.

$\star p<0.05, \star \star p<0.01, \star \star \star p<0.001$.

Greater value (higher scores) on overall role valuation in the entire sample was correlated with greater optimism (lower scores) on general attitude toward life $\left(r_{s}=-0.49, p<0.001\right)$, with greater optimism (lower scores) on general attitude toward people $\left(r_{s}=-0.30, p<0.01\right)$ and with greater perceived knowledge (lower scores) on knowledge of HIV $\left(r_{s}=-0.26, p<\right.$ $0.05)$.

In consideration of overall role autonomy in the entire sample, greater autonomy (higher scores) was correlated with 
stronger coping (lower scores) on coping style ( $r_{s}=-0.41, p<$ 0.001 ), greater optimism (lower scores) on general attitude toward life $\left(r_{s}=-0.35, p<0.01\right)$ and greater optimism (lower scores) on general attitude toward people $\left(r_{s}=-0.32, p<\right.$ $0.01)$.

Greater overall enjoyment (higher scores) in the entire sample showed strongest correlation with greater optimism (lower scores) on general attitude toward life $\left(r_{s}=-0.52, p<0.001\right)$, greater optimism (lower scores) on general attitude toward people $\left(r_{s}=-0.50, p<0.001\right)$ and greater self-esteem (lower scores) on self-esteem $\left(r_{s}=-0.38, p<0.01\right)$.

Q3: Do the valued occupational role configurations of HIV+ gay men differ from those of HIV- gay men?

Table 7 compares the top ranked valued occupational roles of HIV+ gay men and HIV- gay men. For both groups, the roles of self-care manager and friend are ranked first and second. However, for the HIV+ group physical health manager (ranked third) and personal activity manager (ranked fourth) are ranked significantly higher than their HIV- counterparts who rank them as eighth and tenth respectively. Of note as well is that personal finance manager and psychological health manager are ranked higher in the HIV+ group than the HIV- group. 
Table 7

Comparison of Top 11 Current Roles by Value and HIV Status

Ranked Roles: HIV+ group $(n=39)$

1. Self care manager

$M$

d

2. Friend

4.71

0

. Friend

4.53

0

3. Physical health manager

4.46

$+7$

4. Personal activity manager

4.39

$+4$

5. Choice family member

4.33

0

6. Primary Partner

4.29

$-3$

7. Individual activity participant

$4.17-1$

8. Personal finance manager

4.15

$+3$

9. Relaxation Participant

4.10

$-5$

10. Informal Group activity participant

4.08

$-1$

11. Psychological health manager

4.05

$+3$

Ranked Roles: HIV- group $(n=41)$

1. Self care manager

$$
\text { M }
$$

d

2. Friend

4.37

0

3. Primary Partner

4.29

0

4. Relaxation Participant

4.22

$+3$

5. Choice family member

4.11

$+5$

6. Individual activity participant

4.08

0

7. Sexual activity participant

4.08

$+1$

8. Personal activity manager

4.03

$+5$

9. Informal Group activity participant

3.97

$-4$

10. Physical health manager

3.97

$+1$

11. Personal finance manager

3.95

$-7$

Note. Answer codes: 5 = "extremely important", 4 = "quite important", 3 = "moderately important", 2 = "somewhat important", 1 = "not at all important". $M=$ mean score answer. $d=$ difference in ranking from other group. 
Further differences between groups were studied using $t$ tests and $F$ tests. When comparing the variables of role frequency, valuation, autonomy, and enjoyment across all combined current roles between groups, no significant differences were found between means. The only variable with variance that tested significantly different between groups was that of role enjoyment, $F(1,63)=2.59, p=0.005$, showing that HIV+ group had more varied responses to role enjoyment items than did the HIV- group.

When tested as current individual roles, more differences were noted. With respect to role frequency, HIV+ group members participated more frequently than the HIV- group in the roles of physical health manager, $t(53)=3.58, p=0.001$, personal activity manager, $t(54)=3.04, p=0.004$, and pet owner, $t(75)$ $=2.42, p=0.018$. HIV + group members participated less frequently than HIV- group members in the roles of worker outside of the home, $t(68)=-3.68, p<0.001$, and high energy activity participant, $t(74)=-2.31, p=0.024$

With respect to role valuation, HIV+ group members valued more highly the roles of physical health manager, $t(60)=2.51$, $p=0.015$, personal activity manager, $t(65)=2.13, p=0.037$, and pet owner, $t(71)=2.36, p=0.021$, the same roles noted to be different in role frequency. 
With respect to perceived autonomy in role participation, the HIV+ group reported feeling more autonomous than the HIVgroup with respect to the roles of personal activity manager, $t(75)=2.47, p=0.016$, and family of choice member, $t(46)=$ $2.02, p=0.049$.

The only difference in role enjoyment between groups showed up in the role of high energy activity participant in that the HIV+ group members enjoyed this role less than the HIV- group members, $t(56)=-3.30, p=0.002$.

Q4: What are the shifts in valued occupational roles expected by gay men 5 to 10 years in the future?

Both groups of gay men regardless of HIV status showed significant differences between expected and current scores not only in role valuation but also in occupational role frequency, autonomy, and enjoyment. These differences in scores were termed expected shifts and were tested for differences with paired t-tests. Both groups generally expected to participate more frequently in roles (HIV+ group: $t(38)=-4.45, p<0.001$; HIV-group : $t(37)=-6.44, p<0.001)$, expected to value their roles more (HIV+ group: $t(38)=2.22, p=0.032$; HIV- group : $t(37)=4.41, p<0.001)$, expected to participate in their roles with greater autonomy (HIV+ group: $t(36)=3.27, p=0.002$; HIV- 
group: $t(37)=4.38, p<0.001)$, and expected to enjoy their roles more (HIV+ group: $t(36)=-2.70, p=0.010$; HIV- group : $t(36)=3.64, p=0.001$. Table 8 is a ranked listing of all respondents' significant expected shifts in individual role valuation, beginning with those roles expected to shift in value the most and proceeding down to those expected to shift in value the least. 
Table 8

Significant Expected Role Shifts by Valuation of All Respondents Occupational Role $\operatorname{Exp}$ Curr Shift t-value p-value $M \quad M \quad$ d

\begin{tabular}{|c|c|c|c|c|c|c|c|}
\hline 1 & $\begin{array}{l}\text { Formal Group } \\
\text { participant }\end{array}$ & 72 & 3.62 & 3.21 & 0.41 & 2.77 & 0.007 \\
\hline 2 & $\begin{array}{l}\text { Primary partner } \\
\text { participant }\end{array}$ & 67 & 4.63 & 4.28 & 0.35 & 2.90 & 0.005 \\
\hline 3 & $\begin{array}{l}\text { Psych. health } \\
\text { manager }\end{array}$ & 75 & 4.24 & 3.91 & 0.33 & 3.19 & 0.002 \\
\hline 4 & $\begin{array}{l}\text { Low Energy } \\
\text { participant }\end{array}$ & 72 & 4.11 & 3.82 & 0.29 & 2.92 & 0.005 \\
\hline 5 & $\begin{array}{l}\text { Indiv. activity } \\
\text { participant }\end{array}$ & 72 & 4.37 & 4.10 & 0.27 & 2.74 & 0.008 \\
\hline 6 & $\begin{array}{l}\text { Relaxation } \\
\text { participant }\end{array}$ & 72 & 4.38 & 4.12 & 0.26 & 2.11 & 0.038 \\
\hline 7 & $\begin{array}{l}\text { Spiritual act. } \\
\text { participant }\end{array}$ & 71 & 3.83 & 3.61 & 0.22 & 2.56 & 0.013 \\
\hline 8 & $\begin{array}{l}\text { Physical health } \\
\text { manager }\end{array}$ & 75 & 4.42 & 4.21 & 0.21 & 2.33 & 0.023 \\
\hline 9 & $\begin{array}{l}\text { Personal act. } \\
\text { manager }\end{array}$ & 74 & 4.41 & 4.21 & 0.20 & 2.36 & 0.021 \\
\hline
\end{tabular}

Note. $n=$ number of subjects answering both items. $M=$ mean valuation score $(5=$ "extremely important", $4=$ "quite important", 3 = "moderately important", 2 = "somewhat important", 1 = "not at all important"). $d=$ mean difference of individuals' expected minus current scores. 
Q5: Do the expected valued occupational role shifts of HIV+ gay men differ from those of HIV- gay men?

Table 9 lists the top significant $(p<0.10)$

occupational roles expected to shift in relative value by each group. When ranked, several differences between the groups are apparent. One role in the top ranking of the HIV+ group was more than 20 positions above where it ranked in the HIV-group: student. The HIV+ group expected the value of this role to increase in the future, $t(26)=1.99$, $p=0.057$, more so than did the HIV- group. In contrast, the role which ranked high in the HIV - group and was 14 positions above where it ranked in the HIV+ group was family of choice member, $t(36)=2.07, p=0.046$.

Table 9 also lists the means (current and expected) of each group's responses to those roles expected to shift most in the future. The difference (d) between expected and current mean scores along with the paired $t$ test value and $p$ value are also listed. The role that shifted the greatest for the HIV+ group in terms of $p$ values was that of primary partner, $t(32)=2.27, p=$ 0.030, while that of the HIV- group was the role of spiritual participant, $t(36)=2.71, p=0.010$. 
Table 9

Camparison of Top Ranked Expected Valued Role Shifts by HIV Group

Occupational Role

\begin{tabular}{|c|c|c|c|c|c|c|c|}
\hline Role & & $d$ & $M$ & $M$ & $d$ & val & \\
\hline & & $\mathrm{HI}$ & $+g r$ & & & & \\
\hline $\begin{array}{l}\text { 1. Primary } \\
\text { Partner }\end{array}$ & 32 & +6 & 4.70 & 4.30 & 0.39 & 2.27 & 0.030 \\
\hline 2. Student & 26 & +21 & 3.11 & 2.74 & 0.37 & 1.99 & 0.057 \\
\hline $\begin{array}{l}\text { 3. Psych health } \\
\text { manager }\end{array}$ & 37 & +1 & 4.39 & 4.08 & 0.32 & 1.97 & 0.057 \\
\hline $\begin{array}{l}\text { 4. Low Energy } \\
\text { act. part. }\end{array}$ & 37 & +3 & 5.11 & 4.79 & 0.27 & 1.78 & 0.083 \\
\hline $\begin{array}{l}\text { 5. Individual } \\
\text { act. part. }\end{array}$ & 36 & -1 & 4.35 & 4.14 & 0.22 & 1.75 & 0.088 \\
\hline
\end{tabular}

$$
\text { HIV - group }
$$

\begin{tabular}{|c|c|c|c|c|c|c|c|}
\hline $\begin{array}{l}\text { 1. Formal Group } \\
\text { participant }\end{array}$ & 36 & -1 & 3.70 & 3.27 & 0.43 & 2.46 & 0.019 \\
\hline $\begin{array}{l}\text { 2. Spiritual } \\
\text { participant }\end{array}$ & 36 & +9 & 3.78 & 3.43 & 0.35 & 2.71 & 0.010 \\
\hline
\end{tabular}

3. Choice family $36+14 \quad 4.46 \quad 4.11 \quad 0.35 \quad 2.07 \quad 0.046$ member

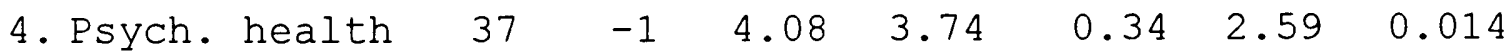
manager

5. Individual

$\begin{array}{lllllll}35+1 & 4.39 & 4.06 & 0.33 & 2.09 & 0.044\end{array}$ act. part.

6. Low Energy act. part.

$0.312 .45 \quad 0.020$

Note. $n=$ sample size that responded to both items. "Rank $d$ ' $=$ difference in ranking between $+/-$ groups. $M=$ mean valuation score $(5=$ "extremely important", 4 = "quite important", 3 = "moderately important", 2 = "somenthat important", 1 = "not at all important"). "Shift $d$ " = the expected shift of mean role valuation in the future (expected minus current mean soore). 
$T$ tests were also used to determine differences between the groups expected shifts in a different way. The difference between expected and current value for each role was calculated for each subject and then the group's mean difference score was calculated for each role. When compared, the groups did not differ in their mean expected shifts in any of the roles with respect to valuation.

The groups did, however, differ in other role variables: HIV+ group members $(M=1.27)$ expected to increase the frequency of their participation in the worker outside of the home role more, $t(60)=2.84, p=0.006$, than did the HIV- group $(M=$ $0.03)$. In autonomy, the groups differed, $t(67)=2.39, p=$ 0.020 , in that the HIV+ group members $(M=-0.11)$ expected less autonomy in the family of choice role while the HIV- group members $(M=0.14)$ expected to be more autonomous in the family of choice role in the future. They also differed, $t(65)=2.16$, $p=0.034$, with respect to expected autonomy in the worker in home role in that the HIV- group $(M=0.46)$ expected greater increased autonomy in the role than did the HIV+ group $(M=$ 0.09). In the area of role enjoyment, the groups differed in mean expected shifts in role enjoyment in the roles of personal finance manager, $t(66)=2.13, p=0.037$, in that the HIV+ group members $(M=0.09)$ expected to increase enjoyment of it 
but less than that expected by the HIV- group $(M=0.56)$. They also differed in expected enjoyment of the informal group activity participant, $t(50)=2.57, p=0.013$, and high energy activity participant, $t(43)=2.32, p=0.025$. In both of these cases, the HIV+ group expected to enjoy the role more while the HIV- group expected to enjoy it less.

Q6: What are the factors that influence life satisfaction among gay men?

Table 10 lists the Spearman's correlation coefficients $\left(r_{s}\right)$ when current life satisfaction was correlated to demographic variables. Both reported global life satisfaction scores and computed global life satisfaction scores (i.e. the mean of the 14 individual domains of life satisfaction scores) were used to identify relationships. 
Correlation of Demographic Items with Life Satisfaction $(n=80)$

Demographic Variable
Current Satisfaction

Reported Computed

$r_{s}$

$r_{s}$

Perceived adequacy of income $-0.23^{\star}$

(lower $=$ more adequate)

Social climate: general

$0.28^{*}$

(lower = hostile, higher $=$ supportive)

Erequency of political activism

$0.24^{\star}$

(lower $=$ never)

Feelings about personal sex behavior

(lower $=$ comfortable)

Family support: general

$0.31^{\star \star}$

(lower $=$ not supportive)

Number of friends

$-0.56^{\star \star \star} \quad-0.48 \star \star \star$

(lower = satisfactory)

Depth of friendships

$-0.53^{\star \star \star} \quad-0.51^{\star \star \star}$

(lower = satisfactory)

Confidant

$0.24^{\star}$

$(1=$ no, 2 = yes $)$

Physical health levels

$-0.26^{\star}$

(lower $=$ excellent)

Daily stress levels

$0.30 \star \star$

$0.40 \star \star \star$

(lower = very high)

Stressful life event levels

$-0.38 * \star$

$-0.42 \star \star \star$

(lower = minimal)

Table continues next page

Note. $r_{s}=$ Spearman's rank correlation coefficient. $\star p<0.05, \star \star p<$ $0.01, \star \star \star p<0.001$. 
Table 10 (continued)

Correlation of Demographic Items with Life Satisfaction $(n=80)$

Demographic Variable

Current Satisfaction

Reported Computed

$r_{s} \quad r_{s}$

Chronic physical condition

( 1 = no, 2 = yes $)$

Knowledge of HIV

(lower $=$ high)

$-0.35 \star \star \quad-0.28 *$

Attitude toward life

(lower $=$ more optimistic)

$-0.68 \star \star \star \quad-0.70 \star \star \star$

Attitude toward people

$-0.56 * \star \star \quad-0.48 * \star \star$

(lower $=$ more optimistic)

Self esteem

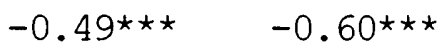

(lower $=$ high)

Coping style

$-0.52^{\star \star \star}-0.42^{\star \star \star}$

(lower $=$ stronger)

Note. $r_{s}=$ Spearman's rank correlation coefficient. $* p<0.05, \star \star p<$ $0.01, \star \star \star p<0.001$.

Seventeen of the forty-two demographic variables had some degree of relationship (i.e. $r_{s}>0.22, p<0.05$ ) to life satisfaction (see Table 10). Eleven demographic variables showed relationships with reported global life satisfaction scores and fifteen of the same demographic variables showed relationship with computed life satisfaction scores. The strongest relationships between the demographic variables and life satisfaction scores were as follows: greater satisfaction 
(higher scores) on life satisfaction was correlated with greater optimism (lower scores) on general attitude toward life $\left(r_{s}=-\right.$ $0.68, p<0.001$ reported, $r_{s}=-0.70, p<0.001$ computed), with greater optimism (lower scores) on general attitude toward people $\left(r_{s}=-0.56, p<0.001\right.$ reported, $r_{s}=-0.48, p<0.001$ computed), greater self-esteem (lower scores) on self-esteem ( $r_{s}$ $=-0.49, p<0.001$ reported, $r_{s}=-0.60, p<0.001$ computed), stronger coping (lower scores) on coping style strength $\left(r_{s}=-\right.$ $0.52, p<0.001$ reported, $r_{s}=-0.42, p<0.001$ computed), greater satisfaction (lower scores) on number of friendships ( $r_{s}$ $=-0.56, p<0.001$ reported, $r_{s}=-0.48, p<0.001$ computed), and greater satisfaction (lower scores) on depth of friendships ( $r_{s}$ $=-0.53, p<0.001$ reported, $r_{s}=-0.51, p<0.001$ computed) . Refer to Table 10 for other significant relationships.

Sub-question $A$ : What is the relationship of role frequency, role valuation, autonomy of role participation and enjoyment of role participation to overall life satisfaction in gay men?

Greater life satisfaction was correlated to overall greater frequency of role participation $\left(r_{s}=0.44, p<0.001\right)$, greater valuation of roles $\left(r_{s}=0.31, p<0.01\right)$, greater autonomy of 
role participation $\left(r_{s}=0.37, p<0.01\right)$ and greater enjoyment of role participation $\left(r_{s}=0.46, p<0.001\right)$.

Table 11 lists the coefficients $\left(r_{s}\right)$ when current life satisfaction scores (reported and computed) were correlated to all the occupational role variables. Greater life satisfaction correlated most strongly with greater frequency of role participation as outdoor activity participant $\left(r_{s}=0.44, p<\right.$ $0.001)$, as high energy activity participant $\left(r_{s}=0.44, p<\right.$ $0.001)$, as friend $\left(r_{s}=0.37, p<0.001\right)$, as informal group activity participant $\left(r_{s}=0.35, p<0.01\right)$, and as individual activity participant $\left(r_{s}=0.33, p<0.01\right)$.

Greater life satisfaction also correlated most strongly with greater valuation of the roles of high energy activity participant $\left(r_{s}=0.33, p<0.01\right)$ and caregiver $\left(r_{s}=0.30, p<\right.$ $0.01)$.

Greater perceived autonomy of participation in the roles of spiritual activity participant $\left(r_{s}=0.53, p<0.001\right)$, high energy activity participant $\left(r_{s}=0.46, p<0.001\right)$, and physical health manager $\left(r_{s}=0.32, p<0.01\right)$ were those most strongly correlated to greater life satisfaction. 
Table 11

Correlation of Satisfaction with Roles of All Respondents Global Life Satisfaction

$\begin{array}{cccc}\text { Freq } & \text { Value } & \text { Auto } & \text { Enjoy } \\ r_{s} & r_{s} & r_{s} & r_{s}\end{array}$

\begin{tabular}{|c|c|c|c|c|}
\hline All roles combined & $0.44^{\star \star \star}$ & $0.31 \star \star$ & $0.37 \star \star$ & $0.46^{\star \star \star}$ \\
\hline Self care manager & - & - & - & $0.33 \star \star$ \\
\hline Physical health manager & - & - & $0.32 \star \star$ & $0.38^{\star \star}$ \\
\hline Psychological health mgr & - & - & - & - \\
\hline Personal activity manager & - & - & - & $0.35^{\star \star}$ \\
\hline Personal finance manager & - & - & - & $0.27 \star$ \\
\hline Family of Origin member & - & - & - & - \\
\hline Caregiver & $0.23^{\star}$ & $0.30 \star \star$ & - & - \\
\hline Choice family member & - & $0.28 *$ & $0.25^{\star}$ & $0.24 *$ \\
\hline Primary Partner & $0.29 *$ & - & $0.32^{\star}$ & - \\
\hline Friend & $0.41 * \star \star$ & - & $0.23^{\star}$ & - \\
\hline Pet owner & - & - & - & - \\
\hline Worker out of home & - & $0.24^{\star}$ & - & $0.32 \star$ \\
\hline Worker in home & - & $0.23^{\star}$ & - & - \\
\hline Student & - & - & - & - \\
\hline
\end{tabular}

Table continues on next page

Note. $\quad r_{s}=$ Spearman's rank correlation coefficient. Coefficients in bold italics indicate use of the computed life satisfaction score; otherwise reported life satisfaction scores were used. $\star p<0.05, \star \star p<0.01, * \star \star p<0.001$. 
Table 11 (continued)

Correlation of Satisfaction with Roles of All Respondents Global Life Satisfaction

$\begin{array}{cccc}\text { Freq } & \text { Value } & \text { Auto } & \text { Enjoy } \\ r_{s} & r_{s} & r_{s} & r_{s}\end{array}$

Volunteer

Relaxation Participant

Outdoor activity part.

Individual activity part.

Informal Grp act. part.

Formal Grp activity part.

High Energy act. part.

Low Energy activity part.

Sexual activity part.

Spiritual activity part.
$0.35 \star *$

$0.30 *$

$-$

$0.28^{\star}$

$0.44 \star \star \star$

$0.33 \star \star$

$0.36 * *$

$0.24^{\star}$

$0.44 \star \star \star$

$0.33^{*}$

$0.46^{\star \star}$

$0.47 \star \star$

$0.28 *$

$-$

$0.25^{\star}$

$0.29 \star$

$0.30 *$

\section{$0.27 \star$}


manager $\left(r_{s}=0.38, p<0.01\right)$, personal activity manager $\left(r_{s}=\right.$ $0.35, p<0.01)$, and self care manager $\left(r_{s}=0.33, p<0.01\right)$. Sub-question $B$ : What is the impact of HIV infection on the life of gay men?

This question as well as sub-question $\mathrm{C}$ was investigated using information gathered from The Attitudes About HIVInfection Survey. Six questions were asked but posed differently to each group in order to understand their perceptions of how HIV impacts a person's life. The HIV+ group was asked how HIV had impacted their personal life and the HIVgroup was asked how they would expect HIV to impact their personal life. Answers to these parallel questions were analyzed with the following results.

As a whole, the subjects ranked the negative impact of HIV on life in general quite high $(M=7.98)$ on a scale of $1-10$ with 10 being the highest level of negative impact. The negative impact of HIV on roles, activities and lifestyle $(M=6.36)$ and on sex life $(M=6.57)$ were both moderately negative using the same scale. In consideration of getting ill in the future, subjects reported that life satisfaction would be somewhat lower $(M=4.48)$ with 4 being "mixed (some lower; some higher)" and 5 being "lower than now". When considering the personal need for 
formal help adjusting to HIV, 59\% of the subjects reported "yes" to the need and $41 \%$ reported no need.

Sub-question $C$ : Is there a difference between actual and perceived impact of HIV on life among HIV-infected and non-infected gay men?

The HIV+ group, in general, tended to perceive greater negative impact of HIV on their lives than did the HIV- group in terms of the latter group's expectations of its impact, but not all areas investigated were significantly different. Considering life in general, both groups rated the negative impact of HIV very high ( $M=8.41$ for HIV+, $M=7.58$ for HIV-) based on a ranking of 1-10. Impact of HIV on life in general between groups was not different but the variances between the groups were different, $F(1,61)=2.74, p=0.003$, with the HIVgroup being more variable in their responses. When asked to consider how life with HIV infection might affect their overall life satisfaction, no significant differences between the groups was noted.

The perceived negative impact of HIV on roles, activities and lifestyle was moderate for both groups $(M=6.92$ for HIV+, $M$ $=5.83$ for $\mathrm{HIV}^{-}$) based on a ranking of 1-10 but no significant differences were found between their perceptions. The impact of 
potential frequent illness on life satisfaction, however, did differ between the groups, $t(45)=-2.45, p=0.018$, with the HIV+ group expecting lower levels of life satisfaction $(M=$ 4.54) than the HIV-group $(M=5.82)$. On the same item, the groups also differed in variance, $F(1,45)=8.89, p<0.001$, the HIV- group $(M=3.05)$ showing much greater variability than the HIV+ group $(M=1.02)$.

In consideration of a personal need for formal help adjusting to HIV, the groups differed, $\chi^{2}(1, N=71)=8.73, p=$ 0.003 , in that a much greater percentage of the HIV+ group reported needing formal help (67\%) compared to a much smaller number of subjects in the HIV- group (33\%) projecting the need for formal help adjusting.

Finally, the most significant difference between the groups was in their perceptions of the impact of HIV on their sex life, $t(74)=3.40, p=0.001$. The HIV+ group $(M=7.79)$ reported much greater actual negative impact of HIV to their sex lives than the impact the HIV- group $(M=5.59)$ projected it would have on their sex lives.

Sub-question $D$ : What shift in life satisfaction do gay men expect 5 to 10 years in the future? 
The entire sample expected to increase in overall mean level of life satisfaction in considering both the reported global life satisfaction scores, $t(73)=3.08, p=0.003$, and the computed global life satisfaction scores, $t(74)=7.81, p<$ 0.001). When scores were analyzed by life satisfaction domains, most domains were expected to increase in levels of life satisfaction ( $t$ tests showing significance ranging from $p<$ 0.001 to $p=0.036)$ except for self-care which showed no significant difference. Of these domains the most significant increases were noted in the areas of finances $(M=1.14)$, sexual life $(M=1.96)$ and romantic life $(M=2.61)$.

All subjects also expected to increase in life satisfaction level when each subject's current score was subtracted from his expected score to determine mean expected shifts. The reported global scores showed an increase in satisfaction $(M=0.43)$ slightly less than the increase in computed global scores $(M=$ 0.81 ) based on the seven unit scale where 7 represented "very satisfied" and 1 represented "very dissatisfied".

Sub-question E: Do the expected shifts in life satisfaction differ between HIV+ and HIV- gay men?

The HIV+ and HIV- groups differed in their expected shifts of life satisfaction both in consideration of the reported 
scores, $t(69)=2.28, p=0.026$, and the computed scores, $t(73)$ $=2.88, p=0.005$. In both cases the HIV- group expected a greater increase in life satisfaction $(M=0.75$, reported/ $M=$ 1.09, computed) than did the HIV+ group ( $M=0.13$, reported $M=$ 0.53, computed). The domains that were noted to be contributing most to this difference were physical health, leisure life, vocation, caregiver relationships, family of choice and friendships.

Hypotheses

H1: A diagnosis of HIV infection negatively impacts life satisfaction among gay men.

In consideration of mean current global life satisfaction scores, HIV+ group members were not found to be different when compared to HIV- individuals. Thus, one element of the hypothesis was not validated by the data. However, other elements of life satisfaction were found to be impacted by HIVinfection.

In consideration of expectations of future life satisfaction, the scores of the HIV+ group $(M=5.61$, reported/ $M=5.55$, computed) were found to be lower than those of the HIV- group ( $M=6.68$, reported/ $M=6.35$, computed $)$ with both the reported global scores, $t(55)=4.05, p<0.001$, and the 
computed global scores, $t(62)=3.76, p<0.001$. In consideration of expected shifts in life satisfaction, it was also noted that the HIV+ group $(M=0.13$, reported/ $M=0.53$, computed) expected less increase in life satisfaction than did the HIV- group ( $M=0.75$, reported/ $M=1.09$, computed) in both reported global scores, $t(69)=2.28, p=0.026$, and computed global scores, $t(70)=2.89, p=0.005$.

H2: Gay men who have been given a diagnosis of HIV infection have higher variance in life satisfaction scores than uninfected gay men.

This hypothesis was found to be true in consideration of both current life satisfaction scores, $F(1,68)=2.41, p=$ 0.008 , reported $F(1,69)=2.28, p=0.013$, computed, and expected life satisfaction scores, $F(1,55)=3.73, p<0.001$, reported/ $F(1,62)=2.56, p=0.005$, computed. However, there were no differences in variances between the groups in expected shift in life satisfaction scores. 


\section{CHAPTER 5: DISCUSSION}

Research Questions and Hypotheses

The primary purpose of this study was to describe and better understand the occupational behavior of gay men with special attention given to the impact of HIV-infection on this population.

General relationships among demographic data

In analyzing the demographic and general information, relationships were uncovered which were considered note-worthy for their implications for treatment. A discussion of these follows. Those areas deemed most accessible to traditional treatment strategies head up the list.

Knowledge of HIV

Obtaining an adequate knowledge about HIV is a seemingly simple matter of an individual taking the time and making the effort to investigate and educate himself from established resources. This very specific realm of knowledge apparently influences the life experiences of gay men in a significant way regardless of their HIV status. The degree of confidence that a gay man has in his own personal understanding of HIV and its transmission has the power to influence his outlook on life, his perception of people, and his feelings about personal sex behavior. In a related finding, the degree of confidence that 
both HIV+ and HIV- gay men had about their perceived HIV status was also associated with their feelings about personal sex behavior; greater confidence was related to a higher degree of comfort with their sex behaviors. This area with its associated bearing on life satisfaction is readily addressable by professionals. Gay men need to feel confident about their HIV status and they need to feel that they have adequate knowledge about HIV for their personal sense of well-being. Social climate

Environment plays a significant role in human occupation (Kielhofner, 1995). Two related aspects of gay men's environment surfaced which bear on their life satisfaction. Both items involved perceptions of social climate: the perceived social climate toward homosexuals 1 ) in their general social settings and 2) in their areas of residence. These perceptions of social climate were themselves influenced by the degree of openness and acceptance that their families of origin demonstrate toward their homosexuality. These findings affirm the notion that human development occurs best within positive and nurturing environments. Those who experienced social climates that were "gay friendly" or that had a marked gay presence showed a more positive influence in their outlook on life, in self-esteem, and in feelings about personal sex 
behaviors. They also had greater success with making social and sexual contacts. In contrast, gay men who experienced these supportive environments less frequently, perceived higher levels of daily stress. Again, these findings affirm the significance and benefits of experiencing supportive social environments. Various life activities

A few note-worthy life activities showed both positive and negative influences in subjects' lives. On the negative side, HIV-infected individuals showed more frequent use of mood altering drugs. Drug usage was also associated with alcohol indulgence. This could mean that infected individuals may have a tendency to be less restrained in using mood-altering substances or that those who are less restrained in their use of drugs and alcohol may be more likely to become infected. If the former is true, it may be due to a mal-adaptive reaction to being infected or to a rekindling of personal pleasure seeking. On the positive side, political activism was associated with greater integration with the heterosexual community, greater openness about sexual orientation, and higher levels of knowledge about HIV. An in-depth discussion of the role of activities in the experience of life satisfaction follows later in the discussion of Question 6 . 
General outlook on life

General outlook on life was investigated carefully for its strong relationship to life satisfaction $\left(r_{s}=-0.70\right)$; these two items appear to be strongly related but not identical. Lesser associations with an optimistic outlook on life included having general support from family of origin, having satisfactory social and sexual relations, and having adequate knowledge of HIV. Surprisingly, finances, HIV-status, health and age did not correlate with this general outlook on life as was expected. Items that had the most direct relationship to this general outlook on life were daily stress, perception of people, selfesteem, and conflict management style. These five items demonstrated close inter-related associations and were, thus, studied as a dynamic group (see Table 1). A discussion of these follows.

Stress colors the life experience of gay men. This stress was particularly note-worthy for its widespread influence in areas of living: conflict management styles, use of alcohol, personal outlook on life, personal perception of people, and self-esteem. Increased daily stress negatively impacted all of these areas. Two aspects that seemed to offset daily stress, however, were having positive general and residential social climates. This supports the notion that stress can be mediated 
by external factors as well as by internal ones. Stress management techniques are, thus, affirmed as an important aspect of on-going well-being for this population.

A person's perception of people in general is a function of a dynamic development process; it both shapes and is shaped by most areas of human life. Its strongest association among gay men was with their current and past experience with people, in particular the experience of having a confidant, a supportive family of origin, a variety of friendships, and healthy selfesteem. Managing conflict is a natural aspect of social dynamics, so personal coping style, understandably, was also found to be a key influence on this perception of people. Becoming HIV-infected appears to have an influence on encouraging greater levels of openness between gay men and their family of origin. Clearly, a gay man's general perception of people impacts the state of his social support network which in turn impacts the state of his well-being. This makes it an area of concern to professionals seeking to help gay men discover or recover their sense of well-being. At times, therapeutic efforts to influence a person's perception of people in a positive way may become important, but the challenge can be expected to be a lengthy, difficult, and frustrating one. 
Self-esteem is established in the literature as a key factor in human occupation and a sense of well-being (Kielhofner, 1995). This study identified several factors that possibly shape the self-esteem of gay men which includes their conflict management style, their personal outlook on life, their perception of people in general, the level of support received from their family of origin, the depth of their friendships and having a confidant. This last relationship between self-esteem and having a confidant is particularly note-worthy. In human development, perceptions of oneself begin with feedback received from family members (i.e. people of trust). Later on in adulthood, this pattern continues so that the presence of at least one trusted relationship has been demonstrated in the literature to be related to life satisfaction in old age. In gay development, this internal state of self-esteem is also shaped by the common conflict gay men experience with traditional society. In the group studied, an associated negative behavior indicative of impaired self-esteem was the use of mood altering drugs while a positive associated behavior of healthy esteem was choosing to reside in a gay-friendly neighborhood.

Research has indicated that style of conflict management is an important factor influencing the state of gay men's well- 
being with particular effects on their affect and their perceptions of social support (Wolf, et. al., 1991). The questionnaire item used to determine the style of conflict management (i.e. coping) was based on the work of Wolf and colleagues. They identified active-behavioral styles to be the most effective style in increasing mood state and obtaining social support, followed next in effectiveness by activecognitive styles and lastly by avoidance styles (Wolf et. al., 1991). Gay men who integrated more with heterosexual people (i.e. who spent more time with them outside of work) had a stronger conflict management style (i.e. coping). This integration with heterosexuals could possibly be an indicator of healthy adjustment and coping; it is also associated with selfacceptance, and sex behavior integration.

In summary, those factors which were most associated with the perceived well-being of gay men were their outlook on life, their perception of people, their self-esteem, their conflict management style, their satisfaction with friendships, the level of daily stress they perceived, their having a confidant and the level of general support they receive from their families of origin. With respect to the last item, it is of note that the well-being of these gay men was not associated with their families' openness and acceptance of their homosexuality. 
Rather, it was the general supportive behavior of their families in all other aspects of living that related to their well-being.

\section{$\underline{\text { Research Questions }}$}

Question 1

The first formal item of inquiry sought to describe the valued occupational roles of gay men regardless of HIV status. All but one of the roles ("student") were on the average moderately important to these gay men. Responses tended to be high across the board. Future studies should consider using forced ranking of roles instead of the Likert-scale of responses used in this study; forced ranking of roles may better identify top valued roles. The purpose of identifying these roles (Table 3) was to be able to plan treatment interventions that reflect patient values.

The most valued role was self-care manager, that is, the ability to care for one's self. Independence in $A D L$ and IADL is highly valued by people in general. This, however, may be particularly true of gay men. Gay men place a high value on their personal freedom and autonomy which may perhaps be due to the more tenuous nature of their support systems. This reality may, therefore, sensitize them to the importance of being able to care for themselves. 
The role of friend ranked second, slightly above primary partner (third), family of choice member (fourth), and significantly above family of origin member (sixteenth). This reflects the greater role of relationships other than "familyof-origin" members to the well-being of gay men. Many people tend to move away from their families of origin during adulthood, but the response pattern of these gay men indicates a larger discrepancy than the general population. This is likely indicative of the lower frequency of emotional support that gay men in general receive from their families of origin.

Two other roles also shared fourth ranking with family of choice member: physical health manager and personal activity manager. The value of these along with several other top ranked roles (i.e. individual activity participant-ranked eighth and personal finance manager-ranked ninth) seem to indicate a high value for personal autonomy among gay men. The valuation of social relations (e.g. friends, partners, informal group members) does not appear to be lessened, but the relative importance of personal independence appears to be a significant trend in the findings.

Responses to the role valuation items previously mentioned were fairly closely clustered around the group mean. This was not the case, however, for other roles. Those which had highest 
rates of variance in role valuation were spiritual activity participant, pet owner, student, and caregiver. All of these roles were valued in the bottom third of the list. The high variance noted, however, may be indicative that the respondents did not closely agree on the value of these roles. Value of these particular roles, then, appears to be more subjective. Question 2

The second question sought to identify factors that influence the overall occupational role behavior of gay men regardless of HIV status. Refer to Table 6 for a listing of all the significant correlations between role items and demographic items. In general, the factors that showed the most influence across all participants were personal knowledge of HIV, outlook on life, perception of people, self-esteem, and conflict management style.

The overall frequency of participation in occupational roles is better understood when termed "general activity level". This level is most influenced by a gay man's outlook on life, affirming established ideas that depressed people experience reduced levels of activity. Social forces also come to play in a person's activity level. In gay men specifically, having a confidant, an optimistic perception of people and high selfesteem is associated with increased activity levels. Greater 
knowledge about HIV and political activism showed significant association with increased activity levels as well. This may be explained by personality types (e.g. the Type A personality) in that certain personality types are attracted to more active life-patterns, ones which may include political activity and self-study. It also may be that more active people are associated with greater intentional living behaviors which includes activities such as these. Intentional living refers to a highly conscious and deliberate act of zealously engaging in activities chosen for their link to one's passions or greatest values.

The overall value of occupational roles is better understood when it is termed "personal passion for doing". Passion is an exuberance of desire, esteem, or valuation. This passion for doing (i.e. greater overall role valuation) is associated highly with gay men who have an optimistic outlook on life and people. On the flip side, this passion for doing is dampened in gay men who reported incongruous sexual behavior. Valuing personal human occupation is a function of finding them meaningful. Those with greater "passion for doing" have likely tapped into sources that unlock this meaningfulness. Given the association of this "passion for doing" variable with an optimistic outlook on life and people, it is likely that a 
person's philosophy regarding the nature of life and people plays a large role in shaping this ability to create meaningfulness and to sustain passion for occupation. The difficulty that this presents to the gay male community is that this fundamental philosophy is addressed and fostered in arenas of life from which they are most often isolated: society's traditional family and religious communities. Meaningfulness is initially addressed in human development by nuclear family, yet many gay men are estranged from or at odds with these families of origin. As adults, meaningfulness is most readily addressed by religious communities, but many (if not most) established Judeo-Christian faiths, exclude homosexuals from their blessing and from their spiritual paths for experiencing meaning in existence. Addressing this common dilemma and finding alternate sources of philosophy-shaping support is fundamental to fostering the well-being of gay men.

The spill-over from this poverty of meaning-making support is noted in gay men's sense of global autonomy (i.e. feeling in charge of their life activities) and their global enjoyment of life activities. Both of these items reflect affective states that are shaped by the ability to experience meaning in human actions. They are both correlated to gay men's outlook on life, to their perception of people, and to their coping style (i.e. 
their conflict management style). Active-behavioral coping (considered in the literature to be most effective) may lessen the negative impact of conflicts on their sense of personal autonomy and life enjoyment. In this way, coping may be understood to be a human process by which a person handles internal and external incongruities while minimizing the loss to the sense of autonomy or life-enjoyment. In essence, effective coping mechanisms are able to move an individual's perspective from the present conflict (one which may have him feeling powerless, angry or sad) back to the greater context of life where he may remember that he is autonomous (for the most part) and that life is good (for the most part).

Finally, greater confidence in gay men's personal knowledge of HIV was related to greater levels of activity, of passion for doing, of personal sense of control, and of life-enjoyment. Ominous global threats (such as that which HIV poses to the U.S. gay male community) are an invisible source of daily stress. Research has shown that individuals who have some perception of control over the effects of imposing threats demonstrated reduced levels of physiological and emotional stress (Bandura, 1982; Geer, Davison \& Gatchel, 1970). Feelings of helplessness in the face of such threats may turn into a life-numbing fear unless the individual has some real way to offset the threat. 
Greater knowledge about HIV is just such a way of gaining some control over that threat. Knowledge is, therefore, a tool of personal defense against HIV and the fear associated with it. Greater understanding of HIV is, then, understandably associated with greater enjoyment of life (from experiencing less fear), greater sense of personal control (from having some form of self-defense), greater passion for doing (from offsetting the numbing brought about by fear), and higher activity levels (from having a greater passion for life.)

Question 3

The third question sought to determine whether the valued occupational role configurations of HIV+ gay men differed from those of HIV- gay men. Refer to Table 7 for the listing of each group's top ten valued roles. By comparing these two lists, differences in the two group's valued role configurations were noted. Several roles were similarly ranked including the top two roles in each group: self-care manager and friend. However, differences did surface which may be attributable to value shifts induced by an existential crisis associated with personal HIV infection. These differences between groups may also be a matter of different group membership composition (i.e. differing personal preferences or personality styles). The 
following is a review and discussion of these differences in valued roles.

The role of physical health manager showed a seven-place ranking difference between the groups with the HIV+ group elevating it to third most important. As the management of HIV infection has progressed, the role of comprehensive wellness (including exercise, nutrition, stress management, and sleep) is being seen as an essential adjunct to the traditional pharmacological therapies. The two approaches harmonize and unify in maintaining the strength of the human immune system. Though this holds true for all persons whether or not they are infected with HIV, the HIV+ group of gay men gave it higher relative importance in their lives. Wellness-focused treatment has the potential to tap into this established value among HIVinfected gay men to help them maximize its benefits.

The role of personal activity manager was more highly valued by the HIV-infected group, being ranked fourth overall by them compared to the eighth place ranking by the HIV- group. With the onset of mortality awareness, individuals consider time to be more precious and, therefore, worthy of more careful planning. Occupational therapists are the key professionals poised to assist individuals in exploring, developing and 
organizing their life activities in a way that is regularly congruous with their most valued aspirations.

The roles that were significantly lower in relative value among the HIV+ group when compared to the HIV- group were relaxation participant and sexual activity participant. Several things may account for this difference in value for the relaxation role. Demographic data indicated that the HIV+ individuals worked considerably less time outside the home than the HIV- individuals. This may indicate more frequent loss of the worker role among the infected group. The loss of socially recognized and rewarded productivity may be a factor contributing to the relatively lower value for relaxation. The more unstructured and stress-free time a person has, the less relative value he may place on relaxation. In the extreme case, boredom could set in. Yet another reason for this may be that with an increased awareness of personal mortality, HIV-infected individuals may feel an increased desire to fulfill personal dreams and/or to fully engage in the life-experience. For some, this may be expressed by wanting to leave a legacy or contributing something unique to their community. Typical human development patterns show shifts of life-focus between early and later adulthood: younger adults tend to focus on careers and achievement while older adults (in light of mortality) move to a 
focus on legacy, that is, leaving a contribution to their world which reflects their individual uniqueness (Papalia \& Olds, 1992). Managing boredom, pursuing aspirations, and quests for legacy are areas therapists may need to explore in treatment with infected gay men, ones which are most appropriately addressed by an occupational therapist.

The relatively lower rank that the HIV+ group gave to sexual activity participant also has several possible explanations. Depression, medications, and HIV itself are known to lower human libido. They may also have internalized the idea of there being a more limited number of sexual partners available to them. Furthermore, infected men may fear further compromising their personal health (e.g. re-infection by another strain) or fear the idea of infecting others with HIV. This fear may also play a role in the noted shift in value for sex. The re-evaluation of the importance of sex in light of mortality may, however, be the best explanation for this noted shift. In lieu of participating in more meaningful roles, HIV-infected gay men may downgrade the role of sex participant. Therapists who note this in their clients may need to pursue further information in order to determine whether the change is based on fear (a mal-adaptive response) or one based on a conscious shift in values. 
Question 4

The fourth question posed sought to describe and explain future shifts in valued occupational roles expected by gay men, regardless of their HIV status. This question was considered important in that wellness-centered treatment should be assisting people in preparing for future changes. A person's expectations of their future may possibly be inaccurate. Never the less, dealing with these internalized images of the future may still be a necessary concern to address. All subjects in this study tended to view the future optimistically in that they projected higher levels of general activity, passion for doing, sense of control, and life-enjoyment in their futures. The reporting of a future shift in valued roles is relative to what is already established as a current valued role. In order to understand these shifts, then, one must know an individual's current valued roles. The current valued roles of gay men were discussed previously in Question 1. Refer to Table 3 for a list of these. Also refer to Table 8 for the ten top ranked roles with most expected shift in value.

The role of formal group activity participant is surprisingly first on the list of greatest future shifts in value expected; it had ranked $23^{\text {rd }}$ in the list of current valued roles. One possible explanation for why gay men may see 
themselves valuing this role more in the future has to do with human development. Younger adults, especially younger gay men, tend to highly value personal independence and consequently do not often join "constraining" formal groups which have rules, schedules, group agendas, etc. Aging in the gay community may elevate the value of formal groups as these may be seen as a means to making a contribution to their world and to staying socially connected to like-minded people. This expected shift may be related to the similar shift expected in the role of spiritual activity participant.

Family roles were among the top ten roles expected to become more valued in the future including those of primary partner and family of choice member. This projection of increased value for family also reflects the notions of natural human development and aging; as mortality awareness heightens individuals tend to shift away from more ego-centric values to more philanthropic ones.

Three of the personal life management roles were also among the top ten roles expected to shift in value: psychological health manager, physical health manager, and personal activity manager. Focusing on life management is, in general, about giving more intentional effort to the direction of one's life. 
These shifts reflect, once again, natural human patterns of development.

Finally, roles that may reflect a more introspective sense to them were among those expected to have greater value in the future: psychological health manager (already mentioned), low energy activity participant, individual activity participant (i.e. expressly doing something to be alone and with your own thoughts), relaxation participant and spiritual activity participant (previously mentioned). On the one hand, aging tends to move people from a "self" perspective to an "other" perspective, but on the other hand, aging also tends to move people from an "outer world" focus to an "inner world" focus. This inner world of self is experienced differently by people; it can be a place of deep serenity or one of deep loneliness. This value shift toward introspection in gay men's futures also reflects natural patterns of development and may indicate an openness on their part to reviewing and revising their patterns of occupation for their future well-being. Finding ways to be comfortable in one's own thoughts can be facilitated by therapists sensitive to this developing need. Question 5

The fifth question posed sought to determine the presence of differences between HIV status groups, this time in reference 
to these future value shifts expected in occupational roles. Shifts in role valuation was relatively similar between groups with the exception of student (it increased significantly in value for the HIV+ group but lowered in value for the HIVgroup) and pet owner (it decreased in value for the HIV+ group and increased significantly for the HIV- group).

The value of student role in the future still remained near the bottom of the list, yet it had increased relative to their current value or it. One possible explanation may be that mortality awareness sparks some desire to explore and know the world better and to actualize oneself by gaining knowledge in personal areas of interest.

The response to the role of pet owner was more varied than other roles; subjects tended to either enjoy the role highly or not at all. The difference noted between groups regarding this role could be a simple matter of differing areas of interest between them. Other possible explanations for this may be that animals are known to pose hygienic problems to people with compromised immune systems. Images of being unable to care for their pet properly in the future may also come into play. Caring for them without the support of others could, then, become more difficult and risky in the future. For some it could simply become less of a priority. Therapists are able to assist these 
clients by providing guided direction to their pursuit of knowledge and by assisting them to clarify the pros and cons of pet ownership. Adaptive pet ownership ideas may also help those who really enjoy their pets to stay close to them without compromising their own health. Question 6

The sixth area of inquiry sought to identify factors that are associated with life satisfaction among gay men with the hope of exploring possible ways to influence that sense of wellbeing. The strongest relationships among the demographic items were very similar to those items related to overall role frequency (i.e. general activity level) and overall role valuation (i.e. passion for doing). Those items associated with life-satisfaction were outlook on life, perspective on people, self-esteem and conflict management (i.e. coping) style. The way that these items relate to life satisfaction is, predictably, dynamic; each influences the state of the other(s) and viceversa. Refer to Table 1 for the inter-correlations between these items. Exploring clinically effective ways to interrupt maladaptive patterns related to these factors is essential. Finding ways to foster an optimistic outlook and the regular use of an active-behavioral coping style is another challenge worth exploring. 
In addition to these, gay men's satisfaction with

friendships and stress levels proved to be related to their life satisfaction. Given these, effective clinicians will wish to analyze, devise and implement creative ways to facilitate the development of particular social skills (that may improve gay men's friendships) and stress management skills (that may decrease the effects of stress). These things, however, should be done in light of the real-life environment of gay men and not in the traditional heterosexual environment of the majority culture. This may mean a therapist getting first hand experience with traditional gay social settings or communicating very candidly with clients about the uniqueness of their own social experience. Therapists can then help clients open up to unexplored gay social settings, using group role play to work on real social skills, or even embarking on real-life excursions together that explore the nuances and demands of gay men's social environments.

Included in this line of inquiry was the pursuit of understanding the relationship of role frequency, role valuation, autonomy of role participation and enjoyment of role participation to overall life satisfaction in gay men. All of these showed mild to moderate relationship to life satisfaction. The positive correlation with role frequency suggests that a 
person's general activity level may influence his sense of wellbeing. The other three items, in effect, explored motivation, that is the forces driving the role activity (i.e. the valuation of it, autonomy of it, and enjoyment of it). The relationship of life-satisfaction to these suggests that these aspects of human motivation shape and/or are shaped by a gay man's personal sense of life satisfaction. These findings affirm what occupational therapists have assumed and known through experience all along: that a person can influence the state of his own well-being by engaging in activities that reflect his unique passions, that strengthen his sense of self and autonomy and that breathe pleasure into his life through the act of doing them.

When HIV enters the life of a gay man, many things change. One aspect of this study explored the perceived level of impact associated with personal HIV-infection awareness in gay men. Results suggest that those who have experienced HIV-infection view the impact of HIV on their current lives much greater than did the uninfected subjects. If this is true, those who wish to help them must appreciate and address the personal turmoil that HIV initiates in an individual's life experience. The findings suggest that prior to any bouts with illnesses or symptoms, personal HIV-infection awareness itself causes significant 
disruption in the personal roles and activities of gay men. The majority of infected subjects reported needing formal help adjusting to this turmoil. The experience of becoming aware of personal HIV-infection itself had a highly negative impact on the lives of subjects. It may even be considered "traumatic" for some.

In pursuit of further understanding the relationship of HIV to the life experience of gay men, the following hypotheses were presented for testing.

\section{Tested Hypotheses}

Hypothesis 1

The first one hypothesized that a diagnosis of HIV infection negatively impacts life satisfaction among gay men prior to any significant physical ailments brought on by the virus. The life satisfaction concept was based on current global scores, expected global scores, and expected shifts scores.

Though the HIV+ group's mean current global score did not statistically test lower than the HIV- one, it was in the expected direction. Since the HIV+ group members were predominantly asymptomatic, only subtle differences were expected between their current life-satisfaction scores. A factor that possibly accounts for the lack of significance is 
that most of this group had been infected for greater than two years (the mean length of infection was 80 months). Some nature of adjustment to a personal HIV-infected status had likely taken place in most of the infected subjects. Although efforts were made in the data collecting process to secure recently diagnosed individuals, only five were obtained for the study. Recently diagnosed HIV-infected individuals as a group would likely test significantly lower on current global satisfaction due to the bluntness of that initial personal trauma with which HIV is associated.

Though the HIV+ group still reported optimistic images of future global life satisfaction, the group's mean score was lower when compared to the control group. Positive future outlook is an arguably adaptive psychological mechanism in light of a prognosis of failing health. Apparently, this mechanism still influences infected gay men's image of future satisfaction, but the effects of this optimism were dampened by the awareness of HIV's possible progression in their bodies. When expected shifts in satisfaction were calculated (which for both groups resulted in positive directions), the mean shift of the HIV- group was less dramatically positive than that of the HIV- group. In other words, awareness of personal HIV infection seemed to offset the typical optimistic view of the 
future by some degree. Knowing what has been established in the literature about the effects of depression and lowered affect on human occupation, this finding should motivate occupational therapists to investigate this future image in their HIVinfected gay male clientele.

Hypothesis 2

The second hypothesis posed was that these gay men who have been given a diagnosis of HIV infection would have higher variance in reporting life satisfaction than do their uninfected counterparts. A higher variance in responses to life satisfaction would indicate that within the HIV-infected group there is a wider spectrum of satisfaction with life (i.e. some may have much higher than average satisfaction with life while some may have much lower than average satisfaction).

It was speculated that HIV-infected individuals either acknowledge and respond to the existential crisis imposed by HIV-infection or they avoid it with resulting lowered life satisfaction. From this vantage point, HIV can be considered a metaphorical knife dividing its hosts into those who rise in their experience of life (i.e. those who have the necessary skills and support to face the challenge) from those who drop in their experience of life (i.e. those who do not have the necessary skills or support). With HIV-infected subjects, life 
satisfaction items did show higher variance in responses than did the control group. The only exception to this was the expected satisfaction shift scores. Although the HIV+ group's shift scores had greater variance than the HIV- group, it did not test significant. A potential situation, then, does exist among HIV-infected gay men which places them at a higher risk for mal-adaptive life trajectories.

\section{Implications}

The larger questions being asked in this study are 1) whether or not there is evidence of a need for directed occupational therapy services among gay males infected with HIV and 2) whether there are any factors that influence the occupational role behavior and life satisfaction of gay men that prove useful in assessing and effectively addressing the needs of this population. Both of these questions are answered by this study in an affirmative way. More specific implications are provided in the discussions of the questions and hypotheses.

\section{Recommendations}

From this study, several practical ideas for action arise. These recommendations follow: 


\section{Education and behavior of professionals}

1. That occupational therapy professionals learn to approach clients without a presumption of a given sexual orientation, understanding the important role that sexual orientation may have in shaping the values and activities of daily living of their clients. In order to do this, they need to stay alert during interactions which they have with their clients, listening for subtle cues that may be offered and framing questions in ways that do not presume a given sexual orientation. The need to know this information must be superseded by the client's right to privacy. It must also be made clear that the issue is only relevant in so far as it impacts their activities of daily living.

2. That occupational therapy professionals develop and maintain settings of practice that expect professional attitudes and behaviors from all staff members toward people of all types (including homosexuals). In so doing, they will help create atmospheres that are safe and respectful of all people and that encourage clients to speak freely about all relevant issues of life.

\section{Strategic planning}

1. That occupational therapists work with and encourage their healthcare systems to develop early intervention programs 
for HIV-infected individuals targeting those at risk for occupational disturbances (i.e. those with tenuous social support, little knowledge of HIV, poor coping skills, and depression) .

\section{Use of information gathering tools}

1. That occupational therapists develop and use a domains of life satisfaction index screening tool (such as that used in this study) to be able to quickly identify those clients most at risk for decreased well-being.

2. That occupational therapists develop and regularly use an assessment of occupational roles such as the instrument used in this study that makes use of more specifically defined micro-roles and life management roles in order to clearly understand gay client priorities.

3. That occupational therapists research, develop and use a social support screening instrument that is inclusive of gay relationships or that makes use of descriptive categories of relationships as opposed to labeled ones.

4. That occupational therapists clearly define the skills necessary in all life management roles (i.e. selfcare manager, personal finance manager, physical health manager, psychological health manager, personal activity 
manager) and develop a life management assessment tool that helps identify areas of deficit in these important roles. Treatment implications

1. That occupational therapy professionals make use of established resources or develop new ones that prove effective in assisting HIV-infected individual clients to learn more information about HIV, to understand effective coping methods, to practice stress management techniques, to value and explore creative philosophy-shaping support, and to effectively learn and practice the important life skills involved in personal activity management, physical health management and psychological health management.

2. That occupational therapy professionals explore further the unique set of social skills required of gay men that will enable them to successfully build comprehensive social support networks.

\section{Future areas of inquiry}

1. That a study similar in nature to this one be conducted with a target population of newly diagnosed HIVinfected individuals in order to better understand that initial phase of adjustment to living with HIV. 
2. That researchers investigate further the particular relationship of coping style strength to life satisfaction in gay men.

3. That occupational therapy researchers explore the significance of the role of personal activity manager with other similar populations such as the chronically ill.

Summary

This study sought to describe and better understand the role behavior of gay men. In particular, the study was designed to describe and understand the impact of an HIV diagnosis on their roles and life satisfaction. The process resulted in a description of the valued occupational roles of gay men along with a general understanding of potential shifts in those roles that may occur as a result of becoming infected with HIV. This study concludes that a diagnosis of HIV infection did impact this particular population of gay men both by altering their value for particular occupational roles and by darkening the images that they hold of their futures. The study also identified key factors which may contribute to the life satisfaction and role behavior of gay men, namely that greater life satisfaction was associated with higher general activity levels, greater passion for doing, greater sense of autonomy and greater enjoyment of occupational roles. Other key factors for 
greater life satisfaction included greater confidence in personal HIV knowledge, a more optimistic outlook on life and people, the use of stronger coping styles, greater self-esteem, more satisfying friendships, and perceiving lower stress. These findings affirm occupational therapy's philosophy which has historically acknowledged that a person can influence the state of his own well-being by engaging in activities that reflect his own unique passions, that strengthen his sense of self and his sense of autonomy and that breathe pleasure into his life through performing them. 


$$
163
$$




\section{REFERENCES}

American Occupational Therapy Association (1984). A Professional Legacy: The Eleanor Clarke Slagle Lectures in Occupational Therapy, 1955-1984. Rockville, MD: AOTA Products.

AOTA Commission on Practice (1992, April). Revision: Standards of practice for occupational therapy. In H. Hopkins and H. Smith (Eds.), Willard and Spackman's occupational therapy. Philadelphia: J.B.Lippincott Company.

Bandura, A. (1982). Self-efficacy mechanism in human agency. American Psychologist, 37, 122-147.

Barris, R. (1982). Environmental interactions: An extension of the model of human occupation. The American Journal of Occupational Therapy, 36, 637-644.

Barry, A. (1987). The rise of a gay and lesbian movement. Boston: Twayne.

Baum, A., McKinnon, Q. \& Silva, C. (1987). Chronic stress and the immune system. Paper presented at the Society of Behavioral Medicine, Washington, D.C.

Biddle, B.J., \& Thomas, E. J. (Eds.) (1966). Role theory: Concepts and research. New York: Wiley.

Black, M. M. (1976). The occupational career. The American Journal of Occupational Therapy, 30(4), 225-228. 
Blaney, N. \& Antoni, M. (1990). Psychoneuroimmunology and HIV infection. In C. Eisdorfer \& C. Millon (Eds.), The Biopsychosocial Aspects of HIV Infection. New York: Springer.

Blaney, N., Goodkin, K., Morgan, R., Feaster, D., Millon, C., Szapocznik, J., \& Eisdorfer, C. (1991). A stressmoderator model of distress in early HIV-1 infection: Concurrent analysis of life events, hardiness and social support. Journal of Psychosomatic Research, 35, $297-305$.

Branholm, I., \& Fugl-Meyer, A. (1992). Occupational role preferences and life satisfaction. The Occupational Therapy Journal of Research, 12(3), 159-171. Britton, P. Zarski, J., \& Hobfol, S. (1993). Psychological distress and the role of significant others in a population of gay/bisexual men in the era of HIV. AIDS Care, 5, 4354 .

Broadhead, W., Kaplan, B., James, S., Wagner, E., Schoenberg, V., Grimson, R., Heyden, S., Tibblin, G. \& Goblback, S. (1983). The epidemiologic evidence for a relationship between social support and health. American Journal of Epidemiology, 117, 521-537. 
Browning, F. (1993). The culture of desire: Paradox and perversity in gay lives today. New York: Crown Publishers, Inc.

Cabaj, R.P. (1988). New thinking on sexuality and homosexuality. Psychiatric Annals, 18(1), 11.

Cain, R. (1991). Stigma management and gay identity development. Social Work, 36, 67-73.

Carmack, B. (1992). Balancing engagement/detachment in AIDSrelated multiple losses. Image Journal of Nursing Scholarship, 24, 9-14.

Catania, J., Turner, H., Choi, K., Coates, T. (1992). Coping with death anxiety: help-seeking and social support among gay men with various HIV diagnoses. AIDS, 6, 999-1005. Ceballos-Capitaine, A., Szapocznic, J., Blaney, N., Morgan, R., Millon, C., \& Eisdorfer, C. (1990). Ethnicity, emotional distress, stress-related disruption, and coping among HIV seropositive gay males. Special Issue: Hispanics and AIDS. Hispanic Journal of Behavioral Sciences, 12(2), 135-152.

Centers for Disease Control (1996, June 30). Centers for Disease Control Quarterly HIV/AIDS Surveillance Report, 8 (13). Clark, F. \& Jackson, J. (1990). The application of occupational science negative heuristic in the 
treatment of persons with HIV infection. Occupational Therapy in Health Care, 6, 69-91.

Cohen, S. Mermelstein, R. Kanarack, T., et al, (1984).

Measuring the functional components of social support.

In S. Sarason (Ed.), Social support: Theory, research and applications. The Hague, Netherlands: Martines Nijhoff.

Cory, D. W. (1951). The homosexual in America. New York:

Greenberg .

Denton, R. (1987). AIDS: Guidelines for occupational

therapy intervention. The American Journal of Occupational Therapy, 41, 427-432.

Derogatis, L. \& Spencer, P. (1982). Brief Symptom

Inventory: Administration, scoring and procedures.

Baltimore, MD: The John Hopkins University.

Dilallo, K. \& Krumholtz, J. (1994). The unofficial gay manual:

Living the lifestyle or at least appearing to. New York:

The Main Street Book.

Dillard, M., Andonian, L., Flores, O., Lai, L., MacRae, A., \& Shakir, M. (1992). Culturally competent occupational therapy in a diversely populated mental health setting. The American Journal of Occupational Therapy, 46, 721-726. 
Dunn \& Giacone (April 14, 1995). Timeline of Occupational Therapy interventions. OT Forum.

Elliott, M. S., \& Barris, R. (1987). Occupational role performance and life satisfaction in elderly persons. The Occupational Therapy Journal of Research, 7(4), 215-224.

Finn, G. L. (1972). The 1971 Eleanor Clark Slagle lecture: The occupational therapist in prevention programs. The American Journal of Occupational Therapy, 26(2).

Fitzgerald, M.H. (1992). Multicultural clinical interactions. Journal of Rehabilitation, 58, 38-42.

Florey, L. L., \& Michelman, S. M. (1982). Occupational role history: A screening tool for psychiatric occupational therapy. The American Journal of Occupational Therapy, $36(5), 301-308$.

Galantino, M.L. (Ed.)(1992). Clinical Assessment and Treatment of HIV: Rehabilitation of a Chronic Illness. Thorofare, NJ: SLACK Inc.

Gavanski, I., \& Hoffman, C. (1987). Awareness of influences on one's own judgment: The roles of covariation detection and attention to the judgment process. Journal of Personality and Social Psychology, 52(3), 453-463. 
Geer, J., Davison, G., \& Gatchel, R. (1970). Reduction of stress in humans through nonveridical perceived control of aversive stimulation. Journal of Personality and Social Psychology, 16, 731-738.

Glaser, R., Rice, J., Sheridan, J., Fertel, R., Stout, J., Speicher, C., Pinsky, D., Kotur, M., Post, A., Beck, M. \& Kiecolt-Glaser, J. (1987). Stress related immune suppression: Health implications. Brain, Behavior and Immunity.

Gonsiorek, J. C., \& Shernoff, M. (1991). AIDS prevention and public policy: The experience of gay males. In J. C. Gonsiorek \& J.D. Weinrich (Eds.), Homosexuality: Research implications for public policy. Newbury Park, CA: Sage Publications.

Gonsiorek, J.C., \& Weinrich, J.D. (Eds.)(1991). Homosexuality: Research implications for public policy. Newbury Park, CA: Sage.

Grady, A.P. (1995). Building inclusive community: A challenge for occupational therapy. The American Journal of Occupational Therapy, 49, 300-310. Gregory, M. D. (1983). Occupational behavior and life satisfaction among retirees. The American Journal of Occupational Therapy, 37, 548-553. 
Groups push for specific discussion of HIV risk. (1996, September). AIDS Alert, 105-107.

Hart, G., Fitzpatrick, R., McLean, J., Dawson, J., et al. (1990). Gay men, social support and HIV disease: A study of social integration in the gay community. AIDS Care, 2(2), 163-170.

Heard, C. (1977). Occupational role acquisition: A perspective on the chronically disabled. The American Journal of Occupational Therapy, 31(4), 243-247.

Herdt, G. (Ed.) (1992). Gay culture in America: Essays from the field. Boston: Beacon Press.

Herek, G. M. (1991). Stigma, prejudice, and violence against lesbians and gay men. In J. C. Gonsiorek \& J.D. Weinrich (Eds.), Homosexuality: Research implications for public policy. Newbury Park, CA: Sage Publications.

Herek, G. M., and Berrill, K. T. (1992). Hate crimes:

Confronting violence against lesbians and gay men. Newbury Park, CA: Sage.

Hirsch, D. A., \& Enlow, R. W. (1984). The effects of the acquired immune deficiency syndrome on gay lifestyle and the gay individual. Annals of the New York Academy of Sciences, 437, 273-282. 
Ho, D., Pomerantz, R., \& Kaplan, J. (1987). Pathogenesis of infection with human immunodeficiency virus. The New England Journal of Medicine, 317(5), 278-286. Hollman, F.W. (1990). United States population estimates, by age, sex, race, and hispanic origin: 1980-1988. U.S. Department of Commerce, Bureau of the Census. Huggins, J., Elman, N., Baker, C., Forrester, R., Lyter, D. (1991). Affective and behavioral responses of gay and bisexual men to HIV antibody testing. Social Work, 36(1), $61-66$

Isay, R.A. (1989). Being homosexual: Gay men and their identity. New York: Avon Books.

Kameny, F. E. (1971). Homosexuals as a minority group. In E. Sagarin (Ed.), The other minorities (pp. 50-65). Waltham, MA: Ginn.

Kelley, H. H. (1952). Two functions of reference groups. In G.E. Swanson, T. M. Newcomb, \& E. L. Hartley (Eds.), Readings in social psychology, Rev. Ed. (pp. 410-414). New York: Holt.

Kessler, R. \& Cleary, P. (1980). Social class and psychological stress. American Sociological Review, $24,687-690$. 
Kiecolt-Glaser, J., Garner, W., Speicher, C., Penn, G. \& Glaser, R. (1984). Psychosocial modifiers of immunocompetence in medical students. Psychosomatic Medicine, 46, 7-14.

Kielhofner, G. (Ed.). (1995). A model of human occupation: Theory and application. Baltimore: Williams and Wilkins.

Kielhofner, G., \& Burke, J.P. (1985). Components and determinants of human occupation. In G. Kielhofner (Ed.), The model of human occupation (pp. 12-41). Baltimore: Williams \& Wilkins.

Kleinberg, S. (1980). Alienated affections: Being gay in America. New York: St. Martin's Press.

Krause, N. (1994). Stressors in salient social roles and wellbeing in later life. Journal of Gerontology, 49 (3), 137148 .

Kubler-Ross, E. (1969). On death and dying. New York: Macmillan. Kubler-Ross, E. (1975). Death: The final stage of growth. Englewood Cliffs, NJ: Prentice-Hall. Kurdek, L.A. \& Schmitt, J.P. (1987). Perceived emotional support from family and friends in members of gay, 
lesbian, and heterosexual cohabitating couples. Journal of homosexuality, 14, 57-68.

Kurdek, L.A. (1988). Perceived social support in gays and lesbians in cohabitating relationships. Journal of Personal Social Psychology, 54, 504-509.

Lazarus, R.S. \& Folkman, S. (1984). Stress, appraisal, and coping. New York, NY: Springer.

Levine, R.E. (1987). Culture: A factor influencing the outcomes of occupational therapy. Occupational Therapy in Health Care $4(1), 3-16$

Levy, J. (1989). Human immunodeficieny viruses and the pathogenesis of AIDS. Journal of the American Medical Association, 261(20), 2997-3006.

Levy, S., Herberman, R., Lippman, M., \& d'Angelo, T. (1987). Correlation of stress factors with sustained depression of killer cell activity and predicted prognosis in patients with breast cancer. Journal of Clinical oncology, 5, 348-353.

Locke, S., Kraus, L., Leserman, J., Jurst, M., Heisel, J. \& Williams, R. (1984). Life change stress, psychiatric symptoms, and natural killer cell activity. Psychosomatic Medicine, 46, 441-453. 
Lowery, (1990). Uncovering cultural bias and coping with it. Physical Disabilities Special Interest Section Newsletter, $13(3), 2-3$

Malyon, A. (1982). Psychotherapeutic implications of internalized homophobia in gay men. Journal of Homosexuality, 7, 59-69.

Malyon, A. (1982). Psychotherapeutic implications of internalized homophobia in gay men. Journal of Homosexuality, 7, 59-69.

Mann, J., Tarantola, D.J., \& Weller, T.W. (Eds.) (1992). AIDS in the world. Cambridge, MA: Harvard University Press. Mann, W. C. (1985), Survey methods. The American Journal of Occupational Therapy, 39(10), 640-648.

Marcil, W. M., \& Tigges, K. N. (Eds.) (1992). The person with AIDS: A personal and professional perspective. New Jersey: Slack Incorporated.

Matsutsuyu, F. (1971). Occupational behavior--A perspective on work and play. The American Journal of Occupational Therapy, 26(6), 291-294. 
Mattingly, C.(1994). Occupational therapy as a two-body practice: The body as machine. In C. Mattingly \& M. H. Fleming, Clinical Reasoning: Forms of Inquiry in a Therapeutic Practice. Philadelphia: F.A. Davis Company .

McCormack, G.L. (1987). Culture and communication in the treatment planning for occupational therapy with minority patients. Occupational Therapy in Health Care, 4(1), 1736 .

McLeod, R.G. (1991, August 27). Gay market a potential goldmine. San Francisco Chronicle.

McNair, D., Lorr, M., \& Droppelman, L. (1971). Profile of mood states. San Diego, CA: Educational and Industrial Testing Service.

Merluzzi, T. V., Glass, C. R., \& Genest, M. (1981). Cognitive Assessment. New York, NY: The Guilford Press. Miller, D., Green, J., Farmer, R., Carroll, G. (1985). A 'Pseudo-AIDS' syndrome following from fear of AIDS. British Journal of Psychiatry, 146, 550-551.

Miranda, J., \& Storms, M. (1989). Psychological adjustment of lesbians and gay men. Journal of Counseling \& Development, 68 (Sept/Oct), 41-45. 
Moorehead, L. (1969). The occupational history. The American Journal of Occupational Therapy, 23(4), 329-334.

Morin, S. F., Charles, K. A., Malyon, A. K. (1984). The psychological impact of AIDS on gay men. American Psychologist, 39(11), 1288-1293.

Morrow, G., Ciarello, R., and Derogatis, L. (1978). A new scale for assessing patients' psychosocial adjustment to medical illness. Psychological Medicine, 8, 605.

Mukand. J. (Ed.) (1991). Rehabilitation for patients with HIV disease. New York: McGraw-Hill.

Neistadt, M. E. (1995). Methods of assessing clients' priorities: A survey of adult physical dysfunction settings. The American Journal of Occupational Therapy, $49(5), 428-436$.

Neugarten, B. L., Havighurst, R. J. \& Tobin, S. S. (1961). The measurement of life satisfaction. Journal of Gerontology, $16,134-143$

Oakley, F., Kielhofner, G., Barris, R., Reichler, R. (1986). The Role Checklist: Development and empirical assessment of reliability. The Occupational Therapy Journal of Research, $6(3), 157-170$

Opatz, J.P. (1985). A primer of health promotion. Washington, D.C.: Oryn Publishers. 
Papalia, D.E., \& Wendkos-Olds, S. (1992). Human

Development. New York: McGraw-Hill, Inc. Pattison, E.M. (1977). The experience of dying, In E.M.Pattision (Ed.) , The experience of dying. Englewood Cliffs, NJ: Prentice-Hall. Pennebaker, J., Kiecolt-Glaser, J. \& Glaser, R. (1988). Disclosure of trauma and immune function: Implications for psychotherapy. Journal of Consulting and Clinical Psychology, 56, 239-245.

Pizzi, M. (1993). HIV infection and AIDS. In H. Hopkins \& H. Smith (Eds.), Occupational Therapy (pp. 716-729) . Philadelphia: J.B.Lippincott Company.

Pope-Davis D.B., Prieto L., Whitaker C. and Pope-Davis S. (1993). Exploring multicultural competencies of occupational therapists: Implications for education and training. The American Journal of Occupational Therapy, 47, 838-844.

Reid, D., and Ziegler, M. (1981). The desired control measure and adjustment among the elderly. In $\mathrm{H}$. Lefcourt (Ed.), Research with the Locus of Control Construct, Vol. 1. New York: Academic Press. 
Reilly, M. (1962). Occupational therapy can be one of the great ideas of twentieth century medicine. The American Journal of Occupational Therapy, 16, 1-9.

Reilly, M. (1966). A psychiatric occupational therapy program as a teaching model. The American Journal of Occupational Therapy, 20(2), 61-67.

Reilly, M. (1969). The educational process. The American Journal of Occupational Therapy, 23(4), 299-307. Ritter, K., \& O'Neill, C.(1989). Moving through loss: The spiritual journey of gay men and lesbian women. Journal of Counseling \& Development, 68 (Sept/Oct), $9-15$

Rofes, E. (1987). Gay life: Leisure, love, and living for the contemporary gay male. New York: Dolphin Doubleday. Rosenfield, M. (1993). Wellness and lifestyle renewal: A manual for personal change. Rockville, MD: The American Occupational Therapy Association, Inc.

Ross, M., Tebble, W., and Viliunas, D. (1989). Staging of psychological reactions to HIV infection in asymptomatic homosexual men. Journal of Psychology and Human Sexuality, 2(1), 93-104. 
Sarbin, T.R. (1966). Role enactment. In B.J. Biddle \& E. J. Thomas (Eds.), Role theory: Concepts and research (pp. 195200). New York: Wiley.

Sarason, I., Johnson, J., \& Siegel, J. (1978). Assessing

the impact of life changes: Development of the Life Experience Survey. Journal of Counselling and Clinical Psychology, 46, 932-946.

Sayles-Folks, S. \& People, L. (1990). Cultural sensitivity

training for occupational therapists. Physical

Disabilities Special Interest Section Newsletter, 13(3), 45 .

Schaefer, S, \& Coleman, E. (1992). Shifts in meaning, purpose and values following a diagnosis of human immunodeficiency virus (HIV) infection among gay men. Journal of Psychology and Human Sexuality, 5(1-2), 1329 .

Shannon, P.D. (1972). The relevance of work-play theory to human adaptation: Work-play theory and the occupational therapy process. The American Journal of Occupational Therapy, 26(4), 169-172.

Shaw, M.E. \& Costanzo, P.R. (1970). Theories of social psychology. New York: McGraw-Hill Book Company. 
Singer, B.L., \& Deschamps, D. (Eds.) (1994). Gay and lesbian stats: A pocket guide of facts and figures. New York: The New Press.

Skawski, K.A. (1987). Ethnic/racial considerations in occupational therapy: A survey of attitudes. Occupational Therapy in Health Care, 4(1), 37-48.

Spector, R. E. (1991). Cultural diversity in health and illness, Third Edition. Norwalk, Connecticut: Appleton \& Lange.

Stevens, P. A., and Hall, J. M. (1988). Stigma, health beliefs and experiences with health care in lesbian women. Image: Journal of Nursing Scholarship, 20(20), 171-179.

The Gallup Poll: Public Opinion 1992 (1993). Wilmington, DE: Scholarly Resources, Inc.

Torres, G. (1997). Viral load and progression. PI Perspective, (1997, March), 6.

Vilaubi, A. (1990, December 13). Cultural influences. OT Week, pp. 24-25.

Wallick, M.M. (1992, September). How the topic of homosexuality is taught at U.S. medical schools. Academic Medicine, 67, 23-29. 
Watson, M. A., and Ager, C. L. (1991). The impact of role valuation and performance on life satisfaction in old age. Physical \& Occupational Therapy in Geriatrics, 10(1), 2762.

Wells, S.A. (1995, March 23). Valuing Diversity. OT Week, pp. 24-25.

Weston, K. (1991). Families we choose: Lesbians, gays, kinship. New York: Columbia University Press.

Wolf, T., Balson, P., Morse, E.,Simon, P., Gaumer, R., Dralle, P., \& Williams, M. (1991). Relationship of coping style to affective state and perceived social support in asymptomatic and symptomatic HIV-infected persons: Implications for clinical management. Journal of Clinical Psychiatry, 52, 171-173. 
APPENDIX

183 


\section{Purpose}

\section{Information regarding this study}

This survey is a study being conducted for the purpose of uncovering the roles and activities in life that are most valued by gay men so that health care professionals can be better prepared to address their unique needs in the health care setting.

\section{What to expect}

Should you choose to participate, you will be asked to fill out some general information about yourself (demographics), to identify the pre-defined roles which are a part of your life (using a checklist) along with some relevant questions about the your life roles, and finally, to answer some questions regarding how you perceive your life. The entire event should require no more than 30 minutes of your time.

\section{Benefits}

Though there are no direct or immediate benefits to you for your participation, the knowledge generated from this study will help health care workers perform their duties more sensitively and will also aid in designing an instrument to help health care workers better address their patient's needs.

\section{Is there any risk?}

It is not expected that you will experience any discomfort or face any known risk by participating in this study. The study is categorized as involving "no more than minimal risk" in that the probability and magnitude of harm or discomfort anticipated in the study are not greater in and of themselves than those ordinarily encountered in daily life or during the performance of routine psychological examinations or tests.

\section{Whom to contact for further information}

Should you have any pertinent questions about the research, about your rights as a participant, or should you need to reach someone regarding any concerns of yours, you may contact Dr. Gail Ann Hills in the College of Health at Florida International University at 305-348-3104.

\section{Confidentiality}

All volunteers will participate anonymously; no identifying information will be requested. The option will be made available, however, to include your name and address should you wish to participate in any follow up study. This information will be kept separate and will not be linked to any information you provide on the survey itself. A summary of the results of this study will be made available in the primary centers where the questionnaire was distributed.

\section{Voluntary participation}

Your participation is completely voluntary. No penalty or loss of benefits to which you might otherwise be entitled is involved for refusal to participate. In addition, you may discontinue your participation in the study at any time without any penalty or loss of benefits to which you might otherwise be entitled. 


\section{Can I be a part of this study?}

Please answer the following questions by circling $\mathbf{Y}$ for yes and $\mathbf{N}$ for no. These answers are not part of the study itself, but they simply serve to help determine if you meet the criteria that I am studying:

\begin{tabular}{|llll|}
\hline I. & Are you a male? & Yes & No \\
\hline II. Are you between the ages of 18 \& 55? & Y & N \\
\hline $\begin{array}{l}\text { III. Do you currently identify yourself as a person who is either } \\
\text { homosexual or bi-sexual? }\end{array}$ & Y & $\mathbf{N}$ \\
\hline $\begin{array}{l}\text { IV. Are you willing to answer simple questions about your HIV } \\
\text { status? }\end{array}$ & $\mathbf{Y}$ & $\mathbf{N}$ \\
\hline $\begin{array}{l}\text { V. Do you consider your general health status to be relatively } \\
\text { good whether or not you are HIV-positive or HIV-negative? }\end{array}$ & $\mathbf{Y}$ & $\mathbf{N}$ \\
\hline
\end{tabular}

- If you answered "YES" to all of the above questions, please CONTINUE ON with the questionnaire. Thank you for your participation.

- If you answered "NO" to any of the above questions, you do not need to continue. Thank you for your willingness to help.

- If you are uncertain about any of these questions, please feel free to ask the facilitator for clarification. 


\section{Getting Started}

First of all, thank-you for your willingness to participate in this research.

The entire process should take you no more than 30 minutes.

The Purpose:

The purpose of this study is to uncover the roles and activities in life that are most valued by gay men so that health professionals can be better prepared to address their unique needs within health care settings.

The Format:

The entire questionnaire is composed of three sections:

A. General Information

B. The Valued Roles \& Life Satisfaction Inventory

C. The Attitudes About HIV-Infection Survey

\section{An Explanation of terms:}

\section{Roles}

This term will be used frequently. It refers to the various labels by which we can categorize the activities which make up our lives. Think of the different roles in your life as the different "hats" that you wear during your day. You might also think of them as the different "jobs" in your life. Some examples might include being a "pet owner", "friend", "student", or "employee". Specific roles will be defined in the questionnaire.

\section{Family of Origin vs. Family of Choice}

These terms are important to distinguish. Family of origin refers to all the people who are related to you by blood or adoption. This is the traditional way society usually defines it. Family of choice refers to people that you consider to be "family" because of their being significant members of your emotional support system. These people may or may not be related to you by blood/adoption. Therefore, some people in your life may be part of both types of family. A worksheet will be provided to help you clarify these groups of people.

If at any time you are confused by a question or term, feel free to ask the facilitator for clarification.

You mav now begin. 


\section{General Information}

These questions are designed to find out details about the individuals in this study that may contribute to differences in their responses. They are not meant to pry unnecessarily into your personal life. And remember, you are answering all these questions anonymously.

Directions: Please provide the following information by circling the ONE response that BEST describes you, even if it is not entirely accurate. PLEASE ANSWER ALL QUESTIONS AND MARK ONLY ONE RESPONSE FOR EACH.

\begin{tabular}{|c|c|c|}
\hline 1 & What is your age? & ___ years \\
\hline 2 & $\begin{array}{l}\text { What is the highest education level you have } \\
\text { achieved? }\end{array}$ & $\begin{array}{l}1 \square \text { some high school } \\
2 \square \text { finished high school or GED } \\
3 \square \text { some college } \\
4 \square \text { college degree (Associate of Arts) } \\
5 \square \text { college degree (Bachelor) } \\
6 \square \text { some graduate work } \\
7 \square \text { maters degree } \\
8 \square \text { doctoral degree }\end{array}$ \\
\hline 3 & $\begin{array}{l}\text { What was the approximate total gross income of } \\
\text { your household last year? }\end{array}$ & $\begin{array}{l}1 \square \text { under } \$ 12,000 \\
2 \square \$ 12,000 \text { to } \$ 19,999 \\
3 \square \$ 20,000 \text { to } \$ 29,999 \\
4 \square \$ 30,000 \text { to } \$ 39,999 \\
5 \square \$ 40,000 \text { to } \$ 49,999 \\
6 \square \$ 50,000 \text { to } \$ 69,999 \\
7 \square \$ 70,000 \text { to } \$ 99,9990 \\
8 \square \$ 100,000 \text { or greater }\end{array}$ \\
\hline 4 & $\begin{array}{l}\text { How would you describe your current level of } \\
\text { income? }\end{array}$ & $\begin{array}{l}1 \square \text { much more than adequate } \\
2 \square \text { more than adequate } \\
3 \square \text { adequate } \\
4 \square \text { less than adequate } \\
5 \square \text { much less than adequate }\end{array}$ \\
\hline 5 & $\begin{array}{l}\text { Which ONE of the following phrases BEST } \\
\text { describes the nature of your current employment? }\end{array}$ & $\begin{array}{l}1 \square \text { employed full time } \\
2 \square \text { employed part time } \\
3 \square \text { student (may include part-time work) } \\
4 \square \text { not employed, on disability } \\
5 \square \text { not employed, seeking work } \\
6 \square \text { not employed, not seeking work or retired }\end{array}$ \\
\hline 6 & $\begin{array}{l}\text { Which of the following best approximates your } \\
\text { religious/ spiritual identity, if any? }\end{array}$ & $\begin{array}{l}\text { 1D Eastern philosophy (e.g. Buddhism) } \\
2 \square \text { Judaism } \\
3 \square \text { Muslim } \\
4 \square \text { Protestantism } \\
5 \square \text { Roman Catholicism } \\
6 \square \text { Other (specify): } \\
7 \square \text { No religious affiliation }\end{array}$ \\
\hline
\end{tabular}




\begin{tabular}{|c|c|c|}
\hline 7 & $\begin{array}{l}\text { With which ONE of the following groups do you } \\
\text { BEST identity? }\end{array}$ & $\begin{array}{l}\text { 1口 African American } \\
2 \square \text { White (Caucasian)-American } \\
3 \square \text { Hispanic-American } \\
4 \square \text { Asian-American } \\
5 \square \text { Native-American } \\
6 \square \text { Other (American) specify: } \\
7 \square \text { Other (Non-American) specify: }\end{array}$ \\
\hline 8 & $\begin{array}{l}\text { IN THE PAST YEAR, with which ONE of the } \\
\text { following sexual orientations have you MOST } \\
\text { identified? }\end{array}$ & $\begin{array}{l}1 \square \text { Bisexual (more heterosexual) } \\
2 \square \text { Bisexual (equally homosexual and } \\
\text { heterosexual) } \\
3 \square \text { Bisexual (more homosexual) } \\
4 \square \text { Homosexual exclusively }\end{array}$ \\
\hline 9 & $\begin{array}{l}\text { How long have you identified yourself with the } \\
\text { sexual orientation mentioned above? }\end{array}$ & $\begin{array}{l}1 \square \text { undecided about orientation } \\
2 \square \text { less than a year } \\
3 \square 1-2 \text { years } \\
4 \square 3-4 \text { years } \\
5 \square 5-10 \text { years } \\
6 \square \text { over } 10 \text { years } \\
7 \square \text { all my life }\end{array}$ \\
\hline 10 & $\begin{array}{l}\text { Which of the following BEST describes your current } \\
\text { area of residence compared to other parts of your } \\
\text { county? }\end{array}$ & $\begin{array}{l}1 \square \text { little or no gay concentration } \\
2 \square \text { moderate gay concentration } \\
3 \square \text { high gay concentration (e.g. South Beach, } \\
\text { Victoria Park, etc.) }\end{array}$ \\
\hline 11 & $\begin{array}{l}\text { Which of the following BEST describes the general } \\
\text { social climate toward homosexuals in the places } \\
\text { where you spend most of your time (such as work, } \\
\text { home, social groups)? }\end{array}$ & $\begin{array}{l}1 \square \text { very hostile } \\
2 \square \text { somewhat hostile } \\
3 \square \text { indifferent } \\
4 \square \text { mixed attitudes (hostile and supportive) } \\
5 \square \text { somewhat supportive } \\
6 \square \text { very supportive }\end{array}$ \\
\hline 12 & $\begin{array}{l}\text { Which of the following BEST describes your current } \\
\text { economic political views? }\end{array}$ & $\begin{array}{l}1 \square \text { conservative } \\
2 \square \text { moderate } \\
3 \square \text { liberal }\end{array}$ \\
\hline 13 & $\begin{array}{l}\text { Which of the following BEST describes your current } \\
\text { social political views? }\end{array}$ & $\begin{array}{l}1 \square \text { conservative } \\
2 \square \text { moderate } \\
3 \square \text { liberal }\end{array}$ \\
\hline
\end{tabular}




\begin{tabular}{|c|c|c|}
\hline \multicolumn{3}{|c|}{$\begin{array}{l}\text { In the following items, identify the ONE selection from each that BEST describes your actual behavior } \\
\text { in that category IN THE PAST YEAR: }\end{array}$} \\
\hline 14 & $\begin{array}{l}\text { Participation in any type of social/political } \\
\text { activism (such as ACT-UP rally, letter } \\
\text { writing campaign, Pride Parade): }\end{array}$ & $\begin{array}{l}1 \square \text { never participate } \\
2 \square \text { less than once a year } \\
3 \square 1 \text { or } 2 \text { times a year } \\
4 \square 3 \text { to } 6 \text { times a year } \\
5 \square \text { greater than } 6 \text { times per year }\end{array}$ \\
\hline 15 & $\begin{array}{l}\text { Use of mood altering drugs (non- } \\
\text { prescription): }\end{array}$ & $\begin{array}{l}1 \square \text { never } \\
2 \square \text { less than } 2 \text { times this year } \\
3 \square 2 \text { or } 3 \text { times this year } \\
4 \square 4 \text { to } 10 \text { times this year } \\
5 \square \text { once a month or so } \\
6 \square \text { once a week or so }\end{array}$ \\
\hline 16 & $\begin{array}{l}\text { Use of alcohol to the point of moderate } \\
\text { intoxication (you wouldn't pass a police test) }\end{array}$ & $\begin{array}{l}1 \square \text { never intoxicated } \\
2 \square \text { intoxicated less than } 3 \text { times a year } \\
3 \square \text { intoxicated } 3 \text { to } 10 \text { times a year } \\
4 \square \text { intoxicated about once a month } \\
5 \square \text { intoxicated about once a week } \\
6 \square \text { intoxicated } 2 \text { to } 3 \text { times a week } \\
7 \square \text { intoxicated more than } 3 \text { times a week }\end{array}$ \\
\hline 17 & Number of sexual partners in the past year: & $\begin{array}{l}1 \square \text { celibate or none this past year } \\
2 \square \text { monogamous or one in the past year } \\
3 \square 2 \text { to } 3 \text { this year } \\
4 \square 4 \text { to } 12 \text { this year } \\
5 \square 13 \text { to } 20 \text { this year } \\
6 \square \text { greater than } 20 \text { partners this year }\end{array}$ \\
\hline 18 & $\begin{array}{l}\text { OUTSIDE OF WORK, the amount of time } \\
\text { you spend in the company of people who are } \\
\text { heterosexual: }\end{array}$ & $\begin{array}{l}\text { 1口 I spend most of my free time with heterosexual } \\
\text { friends } \\
2 \square \text { I spend some of my free time with heterosexual } \\
\text { friends } \\
3 \square \text { I occasionally spend my free time with } \\
\text { heterosexual friends } \\
4 \square \text { I rarely spend my free time with heterosexual } \\
\text { friends } \\
5 \square \text { I don't have any heterosexual people for friends. }\end{array}$ \\
\hline 19 & $\begin{array}{l}\text { Number of people with whom you have been } \\
\text { romantically or emotionally intimate (greater } \\
\text { than one week in duration): }\end{array}$ & $\begin{array}{l}1 \square \text { none this year } \\
2 \square \text { one steady relationship this year } \\
3 \square 2 \text { to } 4 \text { relationships this year } \\
4 \square 5 \text { to } 10 \text { relationships this year } \\
5 \square \text { greater than } 10 \text { relationships this year }\end{array}$ \\
\hline 20 & $\begin{array}{l}\text { Which ONE of the following BEST } \\
\text { describes your current feelings toward your } \\
\text { sexual orientation? }\end{array}$ & $\begin{array}{l}1 \square \text { very comfortable } \\
2 \square \text { somewhat comfortable } \\
3 \square \text { ambivalent or confused } \\
4 \square \text { uncomfortable } \\
5 \square \text { very uncomfortable }\end{array}$ \\
\hline
\end{tabular}




\begin{tabular}{|c|c|c|}
\hline 21 & $\begin{array}{l}\text { Which ONE of the following BEST describes } \\
\text { your current feelings toward your sexual behavior } \\
\text { (i.e. outside of your feelings about your } \\
\text { orientation, how do you feel about the way you } \\
\text { participate in sexual activity)? }\end{array}$ & $\begin{array}{l}1 \square \text { very comfortable } \\
2 \square \text { somewhat comfortable } \\
3 \square \text { ambivalent or confused } \\
4 \square \text { uncomfortable } \\
5 \square \text { very uncomfortable }\end{array}$ \\
\hline 22 & $\begin{array}{l}\text { Which ONE of the following BEST describes } \\
\text { your current relationship status with a female } \\
\text { "significant other"? } \\
\text { (that is, a female with whom you have been } \\
\text { sexually or romantically involved) }\end{array}$ & $\begin{array}{l}1 \square \text { no significant relationship, and not seeking } \\
\text { one } \\
2 \square \text { single and desiring a relationship } \\
3 \square \text { dating } \\
4 \square \text { married /in partnership under l year duration } \\
5 \square \text { married / in partnership 1 or more years } \\
\text { duration } \\
6 \square \text { recently separated/ divorced (friendly) } \\
7 \square \text { recently separated/divorced (non-friendly) } \\
8 \square \text { wife/ girlfriend recently passed away }\end{array}$ \\
\hline 23 & $\begin{array}{l}\text { Which ONE of the following BEST describes } \\
\text { your current relationship status with a male } \\
\text { "significant other"? } \\
\text { (that is, a male with whom you hove been } \\
\text { sexually or romantically involved) }\end{array}$ & $\begin{array}{l}1 \square \text { no significant relationship, and not seeking } \\
\text { one } \\
2 \square \text { single and desiring a relationship } \\
3 \square \text { dating } \\
4 \square \text { considered married /in partnership under } 1 \\
\text { year duration } \\
5 \square \text { considered married / in partnership over } 1 \\
\text { year duration } \\
6 \square \text { recent breakup (friendly) } \\
7 \square \text { recent breakup (non-friendly) } \\
8 \square \text { spouse/partner recently passed away }\end{array}$ \\
\hline 24 & Do you have children? & $\begin{array}{l}1 \square \text { no } \\
2 \square \text { yes, little or no contact } \\
3 \square \text { yes, regular contact } \\
4 \square \text { yes, have joint or full custody and/or they } \\
\text { live with me } \\
\text { If yes, age(s): }\end{array}$ \\
\hline 25 & $\begin{array}{l}\text { Which ONE of the following BEST describes the } \\
\text { level of communication you have with your } \\
\text { nuclear family of origin members (mother, father, } \\
\text { sisters, brothers, step-family, children) regarding } \\
\text { your sexual orientation? } \\
\text { For the most part... }\end{array}$ & $\begin{array}{l}10 \text { they know my sexual orientation and are } \\
\text { open about it } \\
2 \square \text { they know my sexual orientation but it is } \\
\text { avoided or not discussed } \\
3 \square \text { some know and some do not } \\
4 \square \text { they do not know my sexual orientation or I } \\
\text { don't know if they know }\end{array}$ \\
\hline 26 & $\begin{array}{l}\text { Which ONE of the following BEST describes } \\
\text { how you feel about the current level of emotional } \\
\text { support you receive from your nuclear family of } \\
\text { origin members with respect to being gay or } \\
\text { bisexual? In general... }\end{array}$ & $\begin{array}{l}\text { 1D not applicable or they do not know } \\
2 \square \text { most are not supportive or minimally } \\
\text { supportive } \\
3 \square \text { some are supportive; some aren't } \\
4 \square \text { most are moderately supportive } \\
5 \square \text { most are fully supportive }\end{array}$ \\
\hline
\end{tabular}




\begin{tabular}{|c|c|c|c|}
\hline 27 & $\begin{array}{l}\text { Which ONE of the following BEST describes how } \\
\text { you feel about the current level of emotional support } \\
\text { you receive from your nuclear family of origin } \\
\text { members with respect to all other matters in your } \\
\text { life? In general... }\end{array}$ & \multicolumn{2}{|c|}{$\begin{array}{l}1 \square \text { not applicable/ no family of origin } \\
2 \square \text { most are not supportive or minimally } \\
\text { supportive } \\
3 \square \text { some are supportive; some aren't } \\
4 \square \text { most are moderately supportive } \\
5 \square \text { most are very supportive }\end{array}$} \\
\hline 28 & $\begin{array}{l}\text { Which ONE of the following BEST describes your } \\
\text { current friendships (with respect to the number of } \\
\text { friends you have)? }\end{array}$ & \multicolumn{2}{|c|}{$\begin{array}{l}1 \square \text { very satisfactory } \\
2 \square \text { satisfactory } \\
3 \square \text { not satisfactory } \\
4 \square \text { very dissatisfactory }\end{array}$} \\
\hline 29 & $\begin{array}{l}\text { Which ONE of the following BEST describes your } \\
\text { current friendships (with respect to the level of } \\
\text { depth you have with your friends)? }\end{array}$ & \multicolumn{2}{|c|}{$\begin{array}{l}1 \square \text { very satisfactory } \\
2 \square \text { satisfactory } \\
3 \square \text { not satisfactory } \\
4 \square \text { very dissatisfactory }\end{array}$} \\
\hline 30 & $\begin{array}{l}\text { Do you currently have at least one person in your } \\
\text { life in whom you feel you can trust and confide? }\end{array}$ & \multicolumn{2}{|l|}{$\begin{array}{l}1 \square \text { no } \\
2 \square \text { yes }\end{array}$} \\
\hline 31 & $\begin{array}{l}\text { How would you describe your general physical } \\
\text { health status in the past year (with reference to } \\
\text { actually experienced symptoms from any injury or } \\
\text { illness): }\end{array}$ & \multicolumn{2}{|c|}{$\begin{array}{l}1 \square \text { no symptoms } \\
2 \square \text { some minor short-lived symptoms } \\
3 \square \text { some minor chronic symptoms } \\
4 \square \text { some significant short-lived symptoms } \\
5 \square \text { some significant chronic symptoms } \\
6 \square \text { overall poor physical health (many } \\
\text { significant symptoms) }\end{array}$} \\
\hline 32 & $\begin{array}{l}\text { How would you rate the current level of daily stress } \\
\text { in your life (with respect to schedule, traffic, } \\
\text { demands, type of job, etc.)? }\end{array}$ & \multicolumn{2}{|l|}{$\begin{array}{l}1 \square \text { very high } \\
2 \square \text { high } \\
3 \square \text { moderate } \\
4 \square \text { low } \\
5 \square \text { very low }\end{array}$} \\
\hline 33 & $\begin{array}{l}\text { Other than possible change in your HIV status, has } \\
\text { there been any event(s) that has significantly } \\
\text { changed your current outlook on life within the past } \\
6 \text { months? }\end{array}$ & \multicolumn{2}{|c|}{$\begin{array}{l}1 \square \text { no } \\
2 \square \text { yes for a positive change (example: a new } \\
\text { romance) } \\
3 \square \text { yes for a negative change (example: death } \\
\text { of your brother) }\end{array}$} \\
\hline 34 & $\begin{array}{l}\text { How would you BEST describe the number and } \\
\text { intensity of significant stressful life events in your } \\
\text { life over the past } 6 \text { months? (such as a divorce, } \\
\text { death of a loved one, financial catastrophe) } \\
\text { CHOOSE ONE FROM EACH COLUMN }\end{array}$ & $\begin{array}{l}1 \square \text { many } \\
2 \square \text { several } \\
3 \square \text { one or two } \\
4 \square \text { none }\end{array}$ & $\begin{array}{l}1 \square \text { very intense } \\
2 \square \text { moderate intensity } \\
3 \square \text { low intensity } \\
4 \square \text { not intense }\end{array}$ \\
\hline 35 & $\begin{array}{l}\text { Do you have any chronic conditions (physical or } \\
\text { psychological) that significantly limit your life } \\
\text { activities in any way? }\end{array}$ & \multicolumn{2}{|c|}{$\begin{array}{l}1 \square \text { no } \\
2 \square \text { yes (please briefly explain): }\end{array}$} \\
\hline
\end{tabular}




\begin{tabular}{|c|c|c|}
\hline 36 & $\begin{array}{l}\text { Which of the following BEST describes your } \\
\text { current HIV status? }\end{array}$ & $\begin{array}{l}1 \square \text { HIV-positive } \\
2 \square \text { HIV-negative }\end{array}$ \\
\hline 37 & $\begin{array}{l}\text { Which of the following BEST describes your level } \\
\text { of confidence regarding your answer about your } \\
\text { HIV status? }\end{array}$ & $\begin{array}{l}1 \square \text { very confident (example: because of } \\
\text { recent lab tests, celibacy, etc.) } \\
2 \square \text { confident } \\
3 \square \text { somewhat confident } \\
4 \square \text { not confident at all }\end{array}$ \\
\hline 38 & $\begin{array}{l}\text { How would you describe your current level of } \\
\text { knowledge regarding HIV (the virus that causes } \\
\text { AIDS)? }\end{array}$ & $\begin{array}{l}\text { 1D I could teach a class on it. (high) } \\
2 \square \text { I am very well informed. } \\
3 \square \text { I know enough for my own satisfaction. } \\
4 \square \text { I know some things but feel my level of } \\
\text { knowledge is inadequate } \\
5 \square \text { I know very little. }\end{array}$ \\
\hline
\end{tabular}

\begin{tabular}{|c|c|c|}
\hline 39 & $\begin{array}{l}\text { General attitude toward life: } \\
\text { Taking everything into consideration, life is... }\end{array}$ & $\begin{array}{l}1 \square \text { great } \\
2 \square \text { good } \\
3 \square \text { O.K. } \\
4 \square \text { bad } \\
5 \square \text { terrible }\end{array}$ \\
\hline 40 & $\begin{array}{l}\text { General attitude toward people/ society: } \\
\text { Considering all things, people are... }\end{array}$ & $\begin{array}{l}1 \square \text { enjoyable to be with most of the time } \\
2 \square \text { enjoyable to be with on occasion } \\
3 \square \text { to be tolerated } \\
4 \square \text { to be avoided }\end{array}$ \\
\hline 41 & $\begin{array}{l}\text { General attitude toward myself: } \\
\text { Considering all things, I feel that I... }\end{array}$ & $\begin{array}{l}\text { 1D am very content with who I am. } \\
2 \square \text { am content with who I am } \\
3 \square \text { am "making do" with who I am } \\
4 \square \text { could do much better if I were different } \\
5 \square \text { am a lousy human being. }\end{array}$ \\
\hline 42 & $\begin{array}{l}\text { General coping style: } \\
\text { When life doesn't go my way, I most often... }\end{array}$ & $\begin{array}{l}10 \text { try to do something to make myself feel } \\
\text { better (such as talk with someone or go } \\
\text { for a walk) } \\
2 \square \text { try telling myself that things will be OK } \\
3 \square \text { end up in a bad mood until I forget about } \\
\text { it }\end{array}$ \\
\hline
\end{tabular}

\section{YOU HAVE COMPLETED THE FIRST SECTION.}

PLEASE CHECK BACK TO MAKE SURE YOU HAVE ANSWERED ALL THE QUESTIONS AND THAT YOL' HAIE MARKED ONLY ONE ANSWER FOR EACH.

NOW PROCEED TO THE NEXT SECTION. 
The term "family" can be confusing because of its multiple meanings, especially for gay individuals. To make sure you understand the terms as they are used in this study, the following worksheet is provided. This is only meant to be a practical mental check list, and it will not be part of the study itself. I am interested in how you define your emotional support system.

Below is a list of typical family members. Indicate with a check if the listed person(s) in this category is/are "family of choice" , "family of origin", both, or does not apply. To clarify these categories. note the following definitions:

- Family of Origin: people who are related to you by blood or adoption. This is the traditional use of the term "family".

- Family of Choice: people who you consider "family" because they are a significant part of your emotional support system. They may or may not be related to you by blood/adoption.

NOTE: A person listed CAN BE BOTH family of origin and family of choice OR NEITHER because it may not apply to you.

\begin{tabular}{|l|l|l|l|l|}
\hline \multicolumn{1}{|c|}{ So-and-so is part of my... } & $\begin{array}{c}\text { Does not } \\
\text { apply }\end{array}$ & $\begin{array}{c}\text { Family of } \\
\text { Origin }\end{array}$ & $\begin{array}{c}\text { Family of } \\
\text { Choice }\end{array}$ \\
\hline Mother & & & & \\
\hline Father & & & & \\
\hline Step-parent (s) & & & & \\
\hline Brother (s) & & & & \\
\hline Sister (s) & & & & \\
\hline Step-brothers/sisters & & & & \\
\hline Aunt (s) & & & & \\
\hline Uncle (s) & & & & \\
\hline Grandparent (s) & & & & \\
\hline God-parent (s) & & & & \\
\hline Cousin (s) & & & & \\
\hline $\begin{array}{l}\text { Past female significant } \\
\text { other }\end{array}$ & & & & \\
\hline Past male significant other & & & & \\
\hline Current significant other & & & & \\
\hline Son (s)/ Daughter (s) & & & & \\
\hline Nephew (s)/ Nieces (s) & & & & \\
\hline Friend(s): & & & & \\
\hline
\end{tabular}

Is the distinction clear in your head now? If "yes" then continue on. I know this is not always a cut-and-dry issue, but do the best you can to distinguish these groups before you go on. 


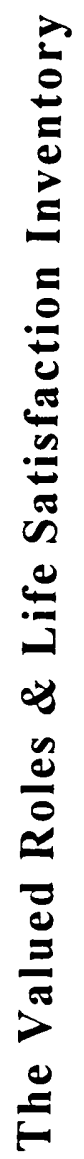




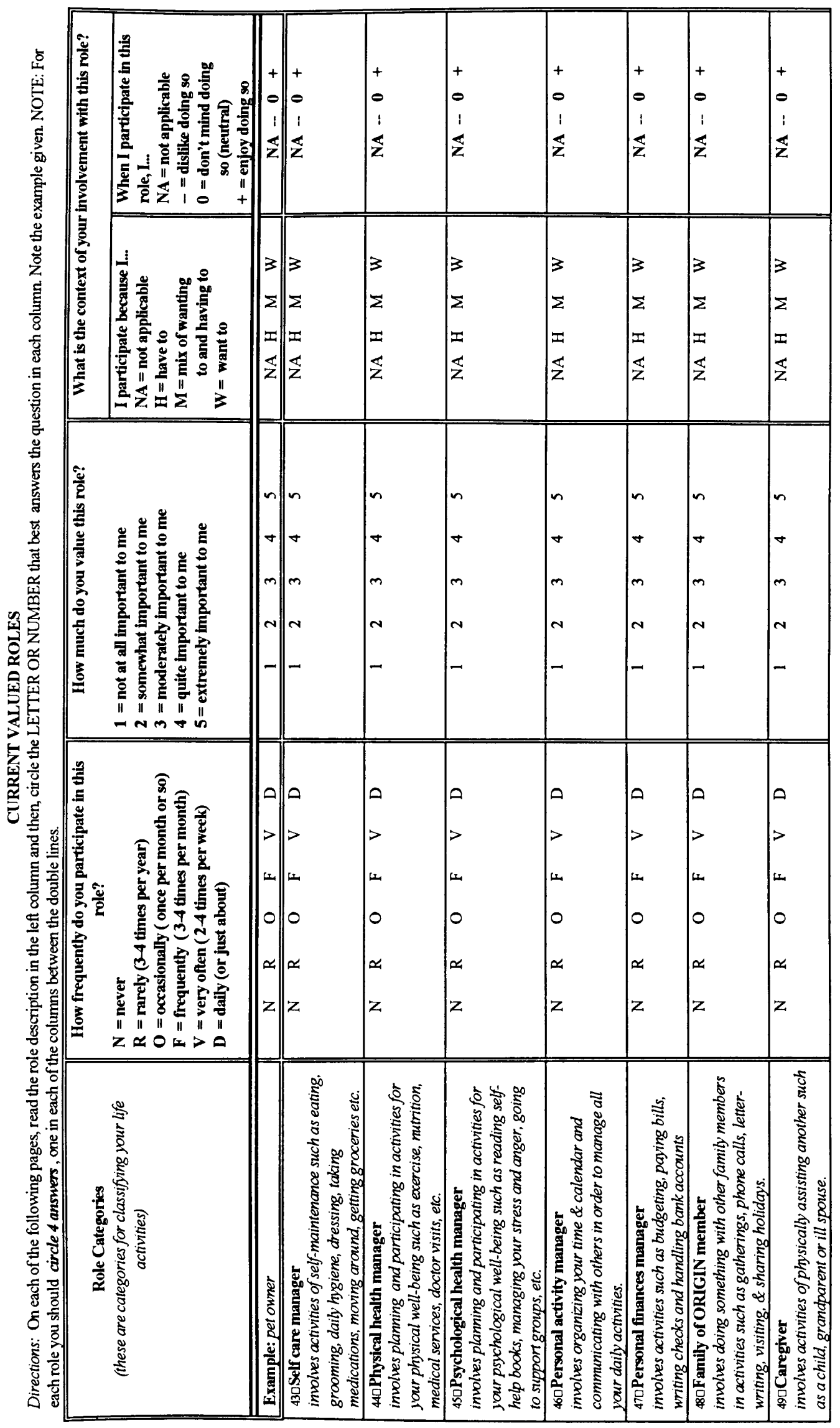




\begin{tabular}{|c|c|c|c|c|c|c|c|c|c|c|}
\hline 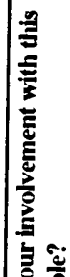 & 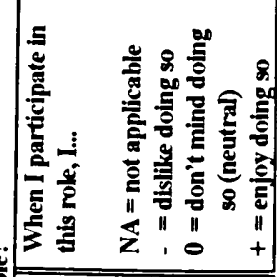 & $\mid \begin{array}{l}+ \\
0 \\
\vdots \\
z\end{array}$ & $\mid \begin{array}{l}+ \\
0 \\
1 \\
z\end{array}$ & $\mid \begin{array}{c}+ \\
0 \\
\vdots \\
\mathbf{z}\end{array}$ & $\mid \begin{array}{l}+ \\
0 \\
1 \\
\overleftarrow{z}\end{array}$ & $\mid \begin{array}{l}+ \\
0 \\
1 \\
z\end{array}$ & $\begin{array}{l}+ \\
0 \\
i \\
z\end{array}$ & $\begin{array}{l}+ \\
0 \\
i \\
z\end{array}$ & $\begin{array}{l}+ \\
0 \\
i \\
z\end{array}$ & $\begin{array}{l}+ \\
0 \\
\vdots \\
z\end{array}$ \\
\hline 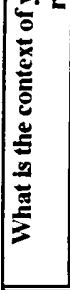 & 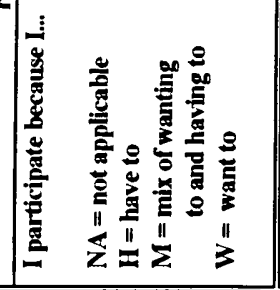 & $\mid \begin{array}{l}z \\
z \\
z\end{array}$ & $\begin{array}{l}3 \\
\Sigma \\
z \\
z\end{array}$ & $\mid \begin{array}{l}z \\
z \\
z \\
z\end{array}$ & $\mid \begin{array}{l}z \\
z \\
z \\
z\end{array}$ & $\mid \begin{array}{l}z \\
\Sigma \\
z \\
z\end{array}$ & $\begin{array}{l}z \\
\Sigma \\
z \\
z\end{array}$ & $\begin{array}{l}3 \\
\Sigma \\
z \\
z\end{array}$ & $\begin{array}{l}z \\
\Sigma \\
z \\
z\end{array}$ & $\begin{array}{l}z \\
z \\
z \\
z\end{array}$ \\
\hline 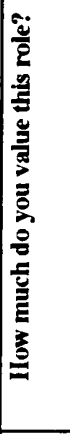 & 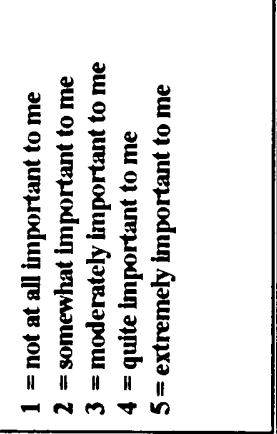 & $\int_{n}^{n}$ & $\int_{n}^{\infty}$ & $\int_{-}^{n}$ & $\int_{-}^{n}$ & $\begin{array}{l}n \\
n \\
n \\
n \\
n\end{array}$ & $\int_{-}^{n}$ & $\int_{n}^{n}$ & $\int_{n}^{n}$ & $\int_{\infty}^{n}$ \\
\hline 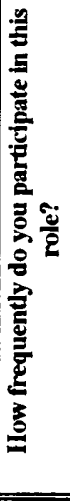 & 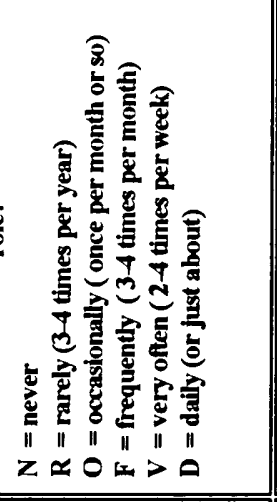 & $\mid \begin{array}{l}0 \\
0 \\
0 \\
2 \\
z\end{array}$ & $\begin{array}{l}0 \\
x \\
0 \\
2 \\
z\end{array}$ & $\begin{array}{l}0 \\
> \\
0 \\
2 \\
z\end{array}$ & $\begin{array}{l}\infty \\
x \\
2 \\
z\end{array}$ & $\begin{array}{l}0 \\
> \\
0 \\
x \\
z\end{array}$ & $\begin{array}{l}0 \\
> \\
0 \\
2 \\
z\end{array}$ & $\mid \begin{array}{l}0 \\
> \\
0 \\
2 \\
z\end{array}$ & $\begin{array}{l}0 \\
> \\
0 \\
z \\
z\end{array}$ & $\begin{array}{l}0 \\
> \\
0 \\
2 \\
z\end{array}$ \\
\hline & 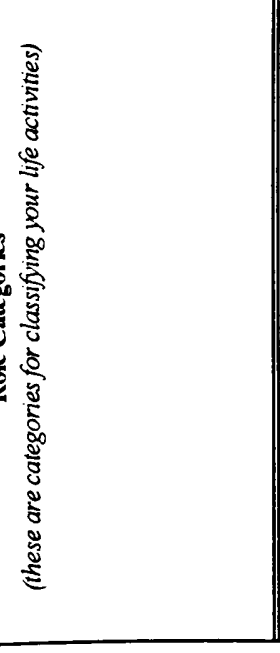 & 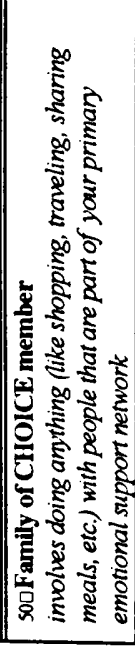 & 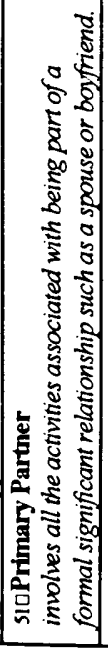 & 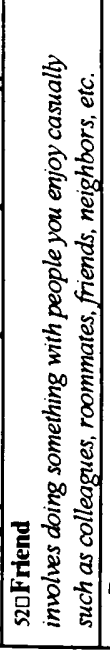 & 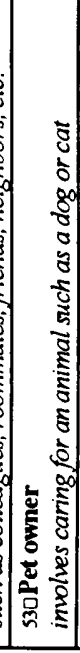 & 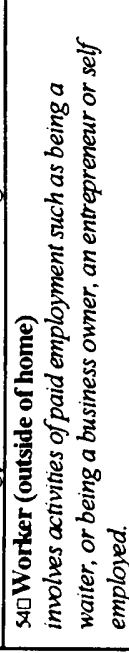 & 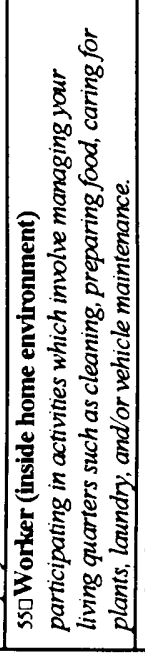 & 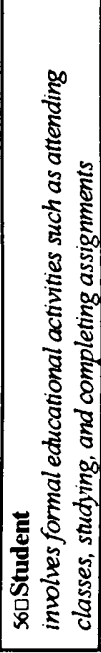 & 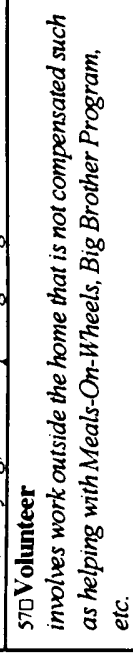 & 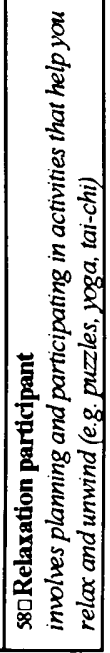 \\
\hline
\end{tabular}




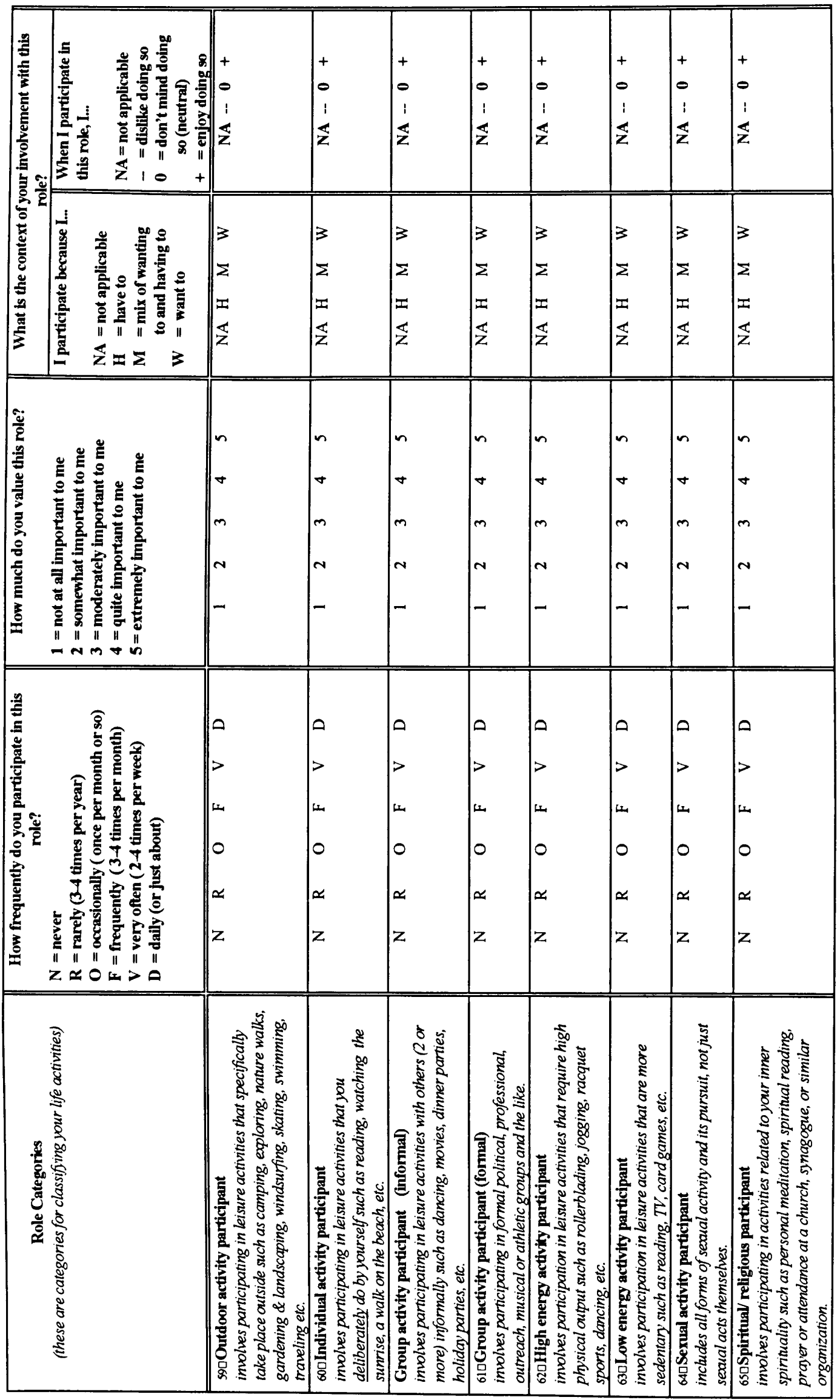




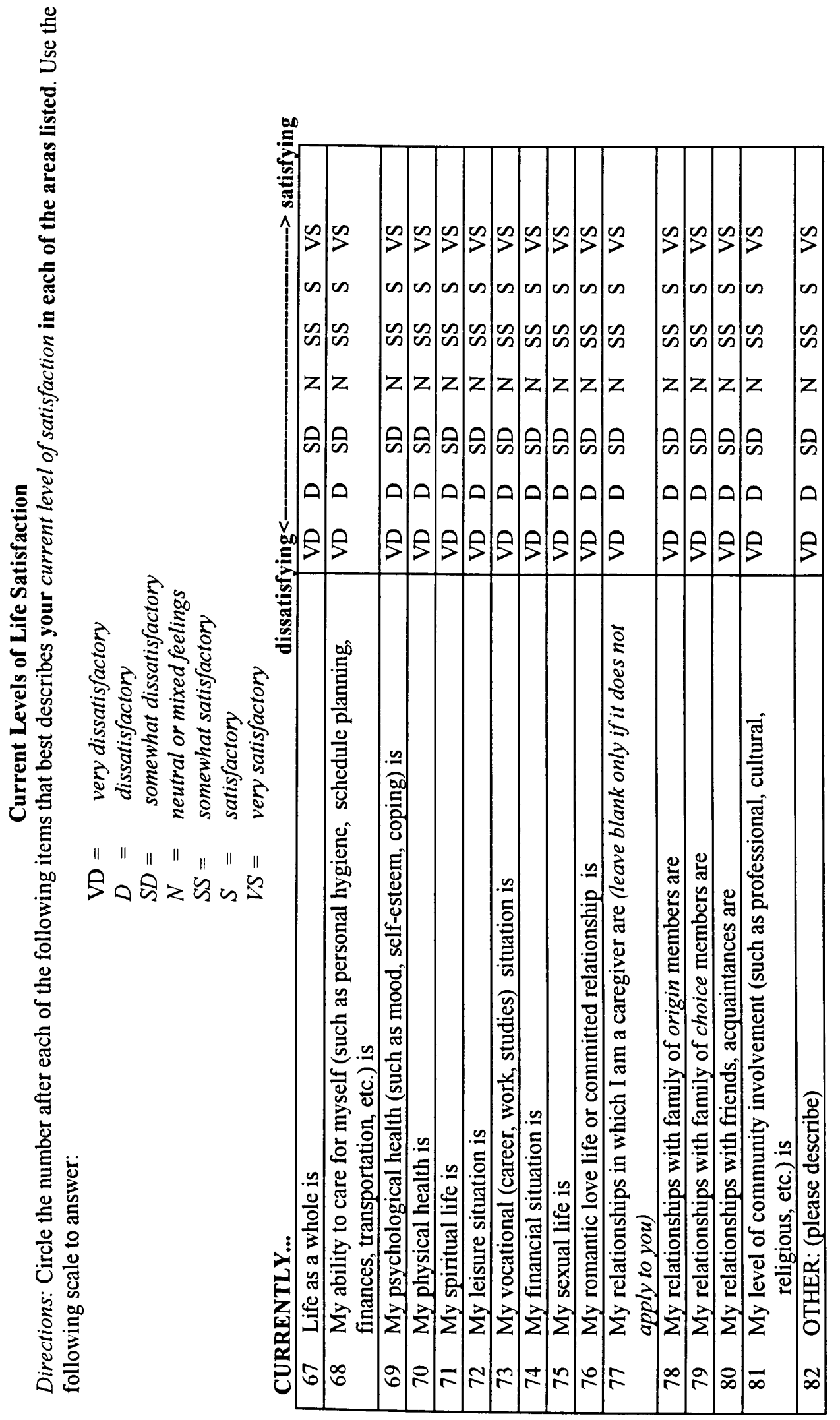




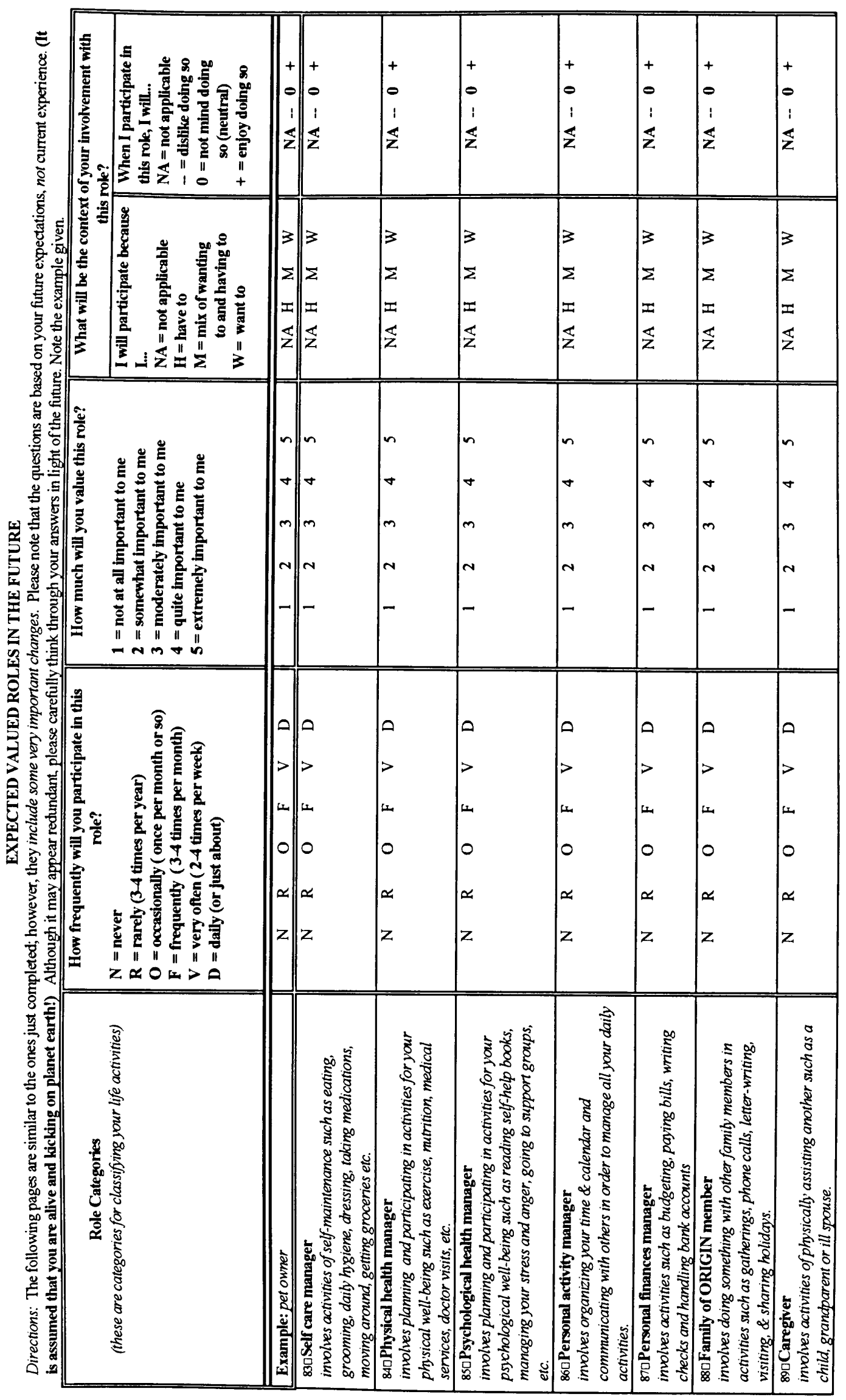




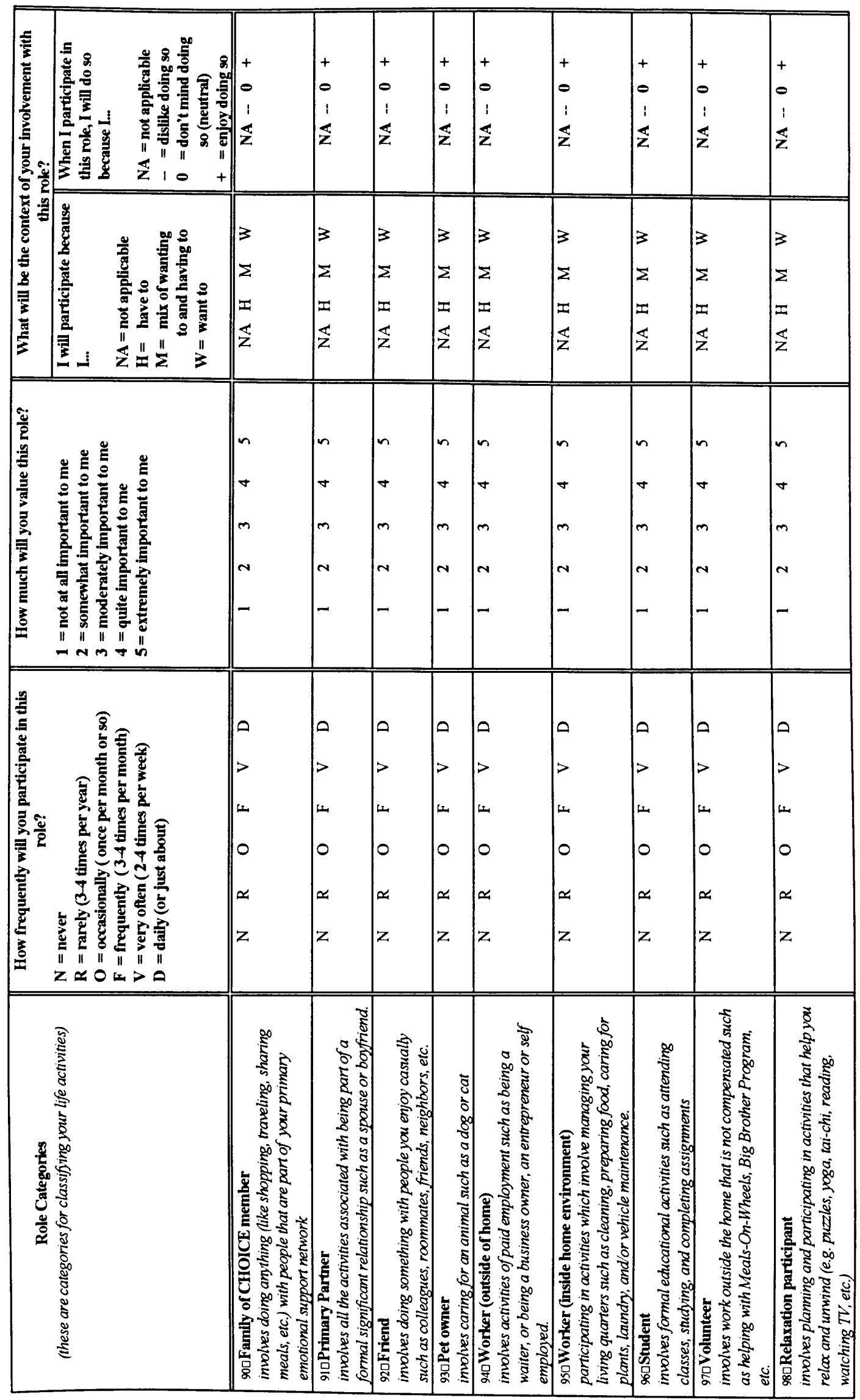




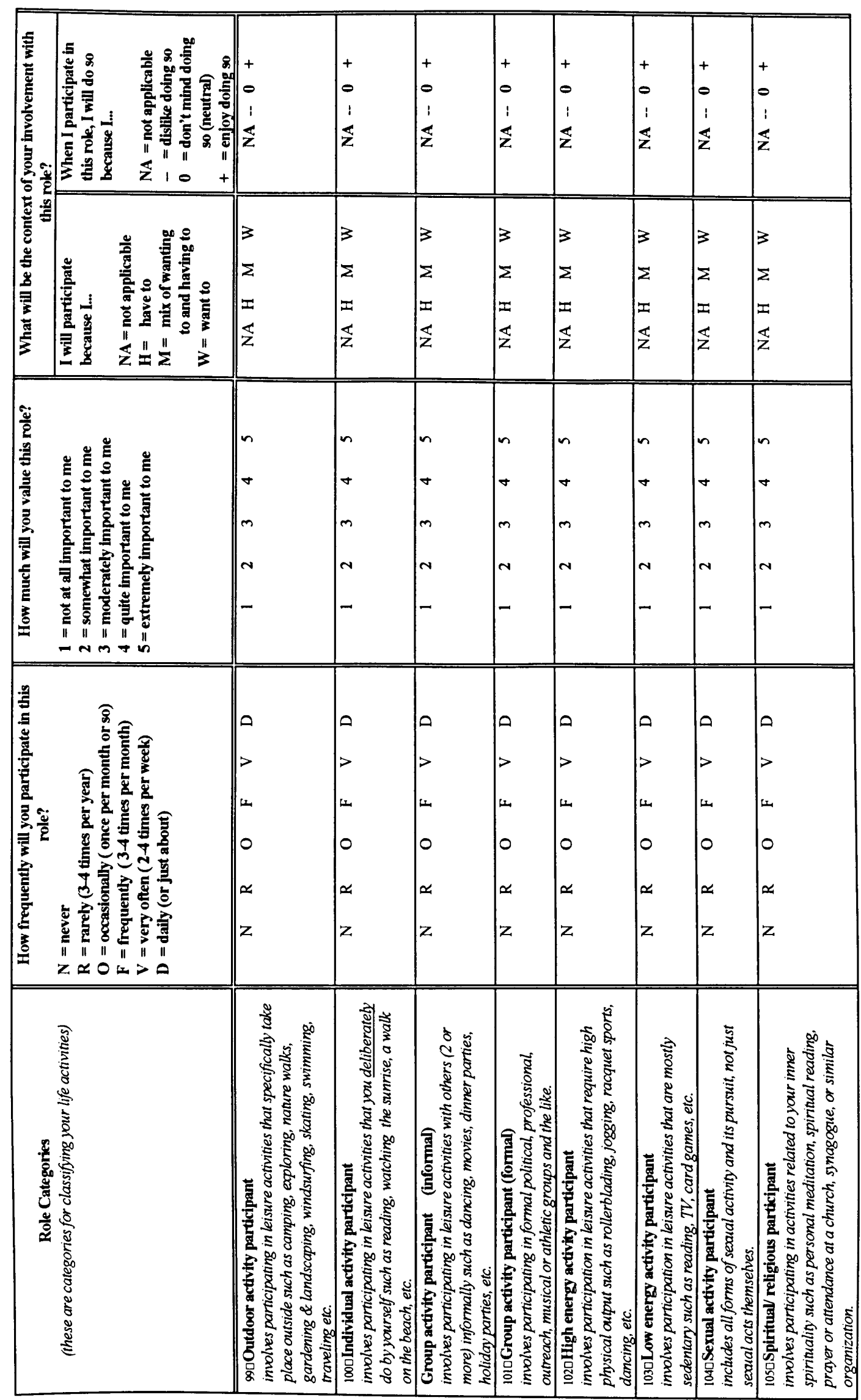




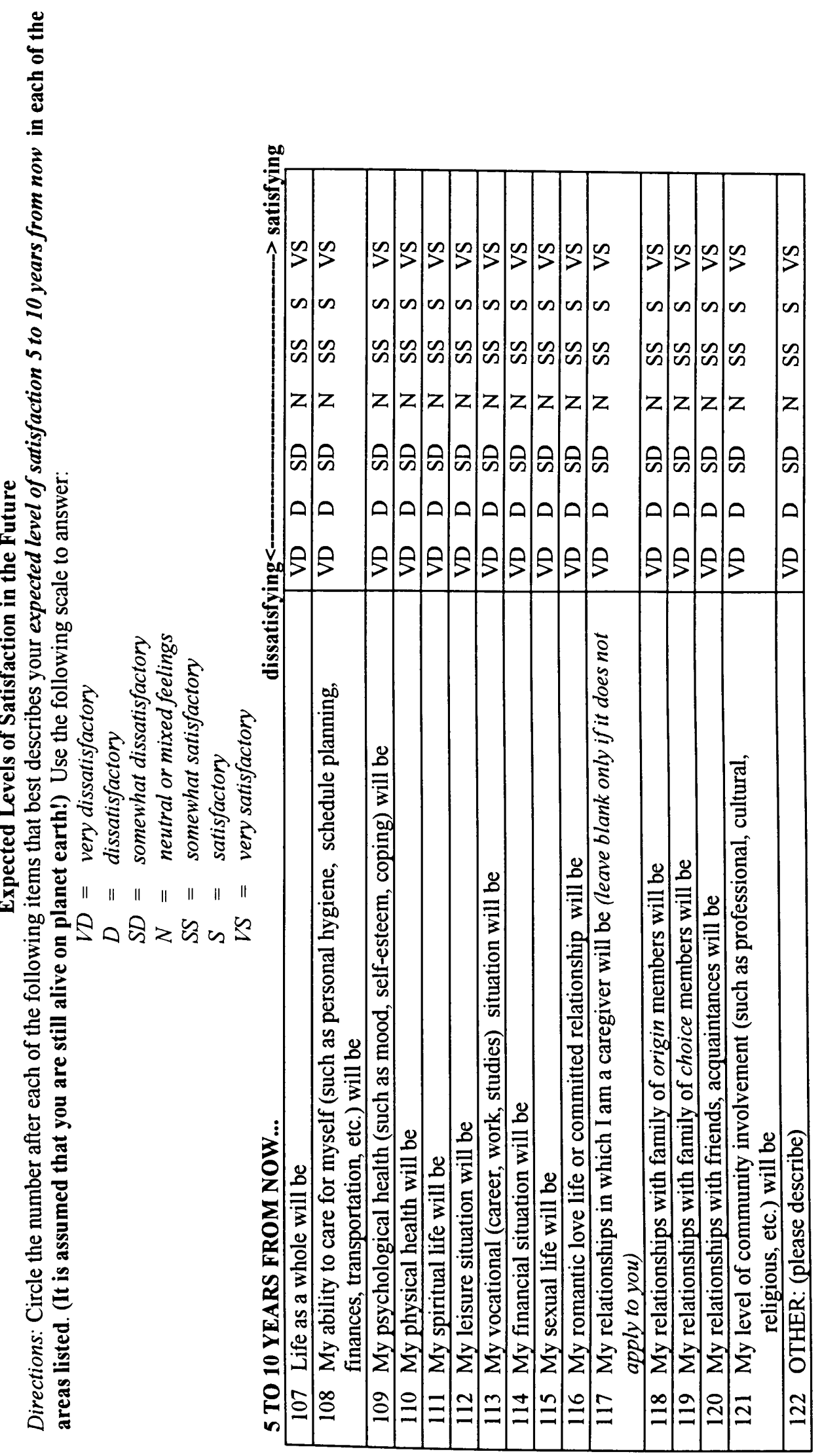


The Attitudes About HIV-Infection Survey 
Directions: Proceed ONLY to the page that best describes your current HIV status and answer the questions on it by circling the ONE answer that best describes you. IT IS IMPORTANT THAT YOU ANSWER ALL QUESTIONS.

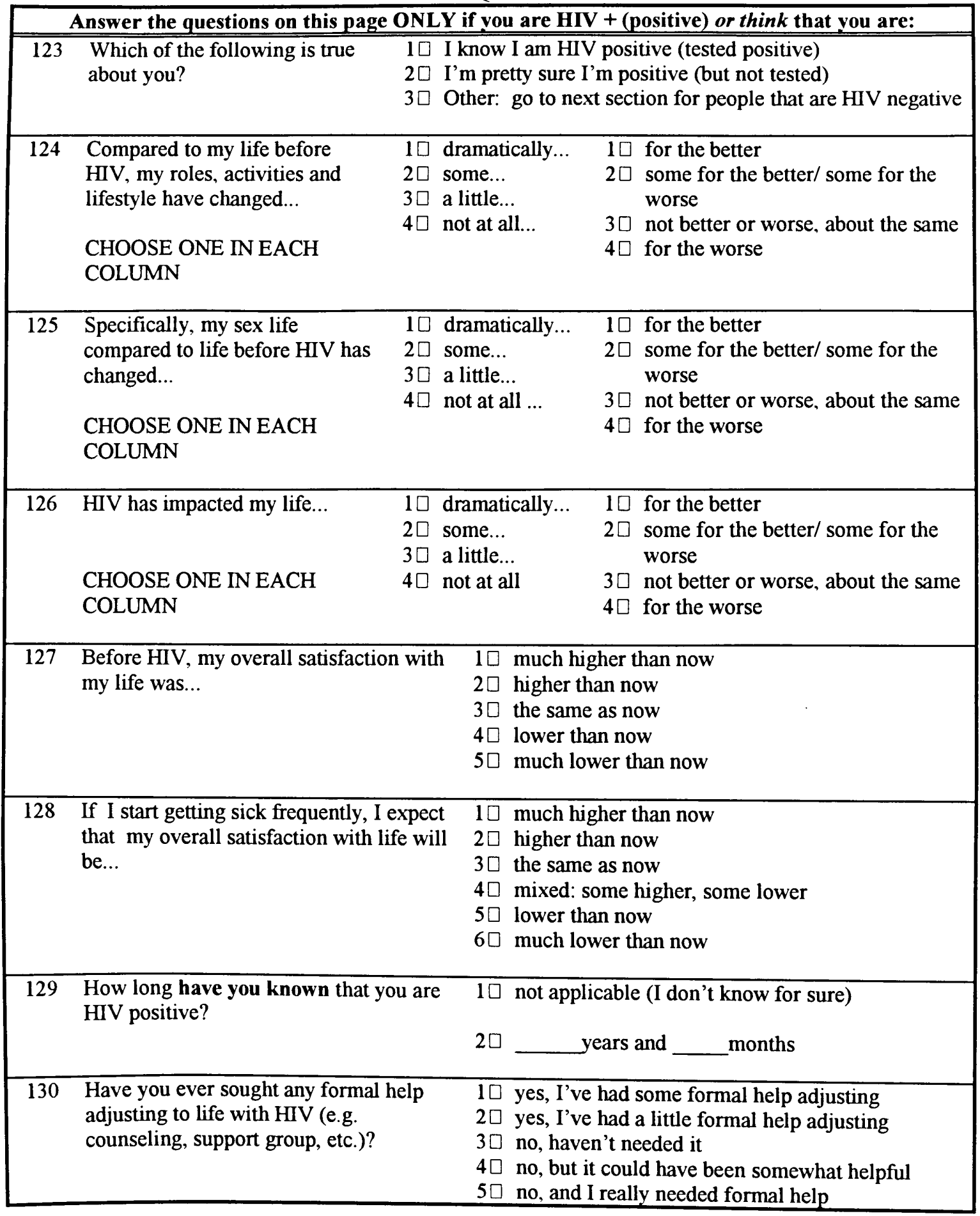


Answer the questions on this page ONLY if you are HIV - (negative) or think that you are:

131 Which of the following is true about you?
1D I know I am HIV negative (for example: tested negative recently, celibate, etc.)

$2 \square$ I'm pretty sure I'm negative (for example: tested negative awhile ago)

$3 \square$ I think I'm negative (but I haven't been tested)

40 Other: go to other section for people that are or think they are HIV positive
132 If I was HIV positive, my roles, activities, and lifestyle would be...

CHOOSE ONE IN EACH COLUMN
10 dramatically..

$2 \square$ somewhat...

$3 \square$ a little...

$4 \square$ no...
$1 \square$ different for the better

$2 \square$ different, some better off some worse off

$3 \square$ different, neither better off or worse off

$4 \square$ different, for the worse
133 Specifically, my sex life compared to life before HIV would be...

CHOOSE ONE IN EACH COLUMN
10 dramatically...

2D some...

$3 \square$ a little...

4D not at all ...
1D different for the better

2ऽ different, some better off some worse off

$3 \square$ different, neither better off or worse off

$4 \square$ different, for the worse
134 In general, HIV infection would impact my life...

CHOOSE ONE IN EACH COLUMN
$1 \square$ dramatically...
2 some...
$3 \square$ a little...
$4 \square$ not at all

$1 \square$ for the better

$2 \square$ some things better; some things worse

$3 \square$ neither better or worse than now

$4 \square$ for the worse
135 If I ever become HIV positive, I expect that my overall satisfaction with life before I ever get sick will be...
10 much higher than now

2D higher than now

30 the same as now

$4 \square$ mixed: some higher, some lower

$5 \square$ lower than now

6D much lower than now
136 If I ever become HIV positive, I expect that my overall satisfaction with life after I start getting sick will be...
$1 \square$ much higher than now

$2 \square$ higher than now

3D the same as now

$4 \square$ mixed: some higher, some lower

5 lower than now

$6 \square$ much lower than now
137 Do you think you would need formal help adjusting if you became HIV positive (e.g. counseling, support groups, etc.)?
$1 \square$ yes, I would need allot of formal helpand I would get it

$2 \square$ yes I would need some formal help and I would go get it

$3 \square$ m, I would not need any help

$4 \square$ yes I would need some helpbut I wouldn't go gat it

$5 \square$ yes I would neod allot of help but I would 't go get it 


\section{Finally... (!!)}

Thanks again for your time and for your honest answers!!

If you wish to be informed about the results of this research, a summary of the results will be sent to each participating facility before April of 1997 . I have also provided the facility with some materials useful for discussion about the issues related to this study, specifically the potential for living well with HIV.

If you consent to being contacted for any follow-up research in the future, please print and sign your name below. Then, detach it from the survey and place it in the appropriate stack.

Mailing address:

(name)

(street address or PO Box)

(apartment number)

(city)

(state)

(zip code)

Telephone (optional)

Signature Date

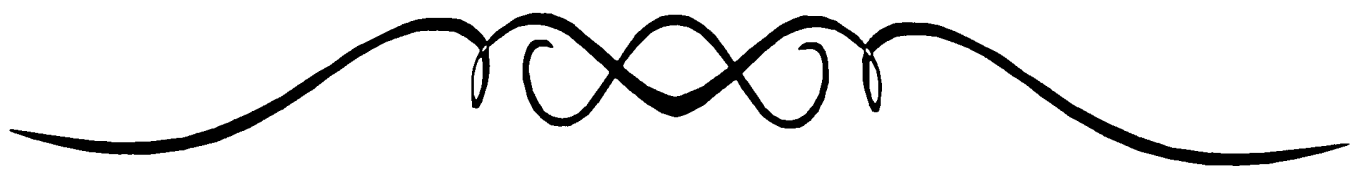

